\title{
Migration Behaviour of Discontinuous Buffers in Capillary Electrophoresis during Protein Enrichment
}

Ting Li, The University of Western Ontario

Supervisor: Dr. Ken Yeung, The University of Western Ontario

A thesis submitted in partial fulfillment of the requirements for the Master of Science degree in Chemistry

(C) Ting Li 2012

Follow this and additional works at: https://ir.lib.uwo.ca/etd

Part of the Analytical Chemistry Commons

\section{Recommended Citation}

$\mathrm{Li}$, Ting, "Migration Behaviour of Discontinuous Buffers in Capillary Electrophoresis during Protein Enrichment" (2012). Electronic Thesis and Dissertation Repository. 720.

https://ir.lib.uwo.ca/etd/720

This Dissertation/Thesis is brought to you for free and open access by Scholarship@Western. It has been accepted for inclusion in Electronic Thesis and Dissertation Repository by an authorized administrator of Scholarship@Western. For more information, please contact wlswadmin@uwo.ca. 


\section{MIGRATION BEHAVIOUR OF DISCONTINUOUS BUFFERS IN CAPILLARY ELECTROPHORESIS DURING PROTEIN ENRICHMENT}

(Spine title: Migration Behaviour of Discontinuous Buffers in CE)

(Thesis format: Monograph)

by

Ting Li

Graduate Program in Chemistry

A thesis submitted in partial fulfillment of the requirements for the degree of Master of Science

The School of Graduate and Postdoctoral Studies

The University of Western Ontario

London, Ontario, Canada

(C) Ting Li 2012 
THE UNIVERSITY OF WESTERN ONTARIO

School of Graduate and Postdoctoral Studies

\section{CERTIFICATE OF EXAMINATION}

Supervisor

Dr. Ken Yeung

Supervisory Committee

Dr.

Dr.

The thesis by

Ting ㄴi

entitled:
Examiners

Dr. Elizabeth Gillies

Dr. Martin Stillman

Dr. Lars Rehmann

Migration Behaviour of Discontinuous Buffers in Capillary Electrophoresis during Protein Enrichment

is accepted in partial fulfillment of the requirements for the degree of Master of Science 


\section{Abstract}

To enrich protein at sub-microliter sample volumes, our group has developed a discontinuous buffer system which consists of an acid and a base inside a capillary. Upon voltage application, the protein moves towards and stacks at the $\mathrm{pH}$ junction. Prior to this work, we only focused on the protein enrichment and have not investigated the migration behaviour of various ions in this system. However, it is important to understand the mechanism of the migration of these ions, because the $\mathrm{pH}$ junction formation and further the protein enrichment are based on it. In this work, the ion migration patterns at the $\mathrm{pH}$ junction have been investigated by both experiments and computer simulation. The discovery of the mobility of the $\mathrm{pH}$ junction controlled by buffer composition allows us to remove unwanted background molecule from the enriched protein sample.

\section{Keywords}

capillary electrophoresis, discontinuous buffers, mass spectrometry, moving reaction boundary, protein enrichment, sample preparation, simulation, sub-microliter volume, urea 


\section{Acknowledgments}

Here is the opportunity for me to thank people who have helped me throughout my research and study.

I would like to thank my supervisor, Dr. Ken Yeung, for his valuable insight and generosity. He was always available for questions, and has provided so much thoughtful advice over past two years. Dr. Yeung's patience and valuable suggestion in my research helped me to be a better graduate student. I am sincerely grateful for his kindness and support during my graduate studies.

I would also like to thank the past and present members of Dr. Yeung's group. Thanks to Christina Booker for her wise advice, patience and sincere support in this laboratory. Thanks to Ming Huang and Thasneen Nazeema for their encouragement and help.

Thanks to the Natural Sciences and Research Council of Canada (NSERC), the University of Western Ontario, and the Department of Chemistry financially supported my research. This financial support made it possible for me to start a new life in Canada, and focus on my research.

My appreciation is also expressed to the staff and faculty of the Department of Chemistry, especially to my committee members and examiners, Dr. Zhifeng Ding, Dr. Elizabeth Gillies, Dr. Martin Stillman, and Dr. Lars Rehmann for their careful reading of the thesis and suggestion.

Finally, I would like to thank my lovely family for their sincere support. My uncle, Yongqin $\mathrm{Xu}$, helped me a lot in the past two years. My parents, Zhiqiang Li and Liqin $\mathrm{Xu}$, encourage and support me in every aspect of my life. Their immeasurable love is the continuous motivation for me to complete my graduate education. 


\section{Dedication}

To my parents for their support and love. 


\section{Table of Contents}

CERTIFICATE OF EXAMINATION ........................................................................ ii

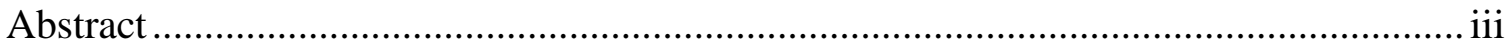

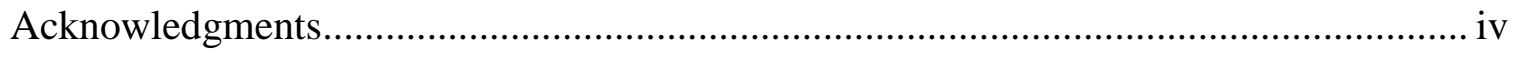

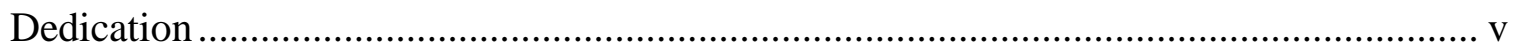

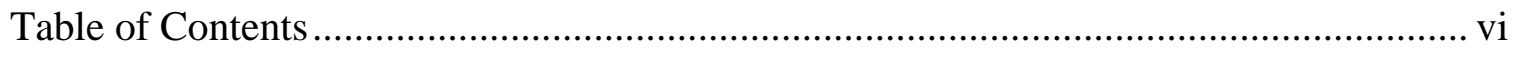

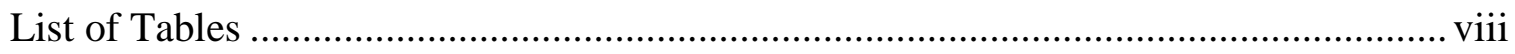

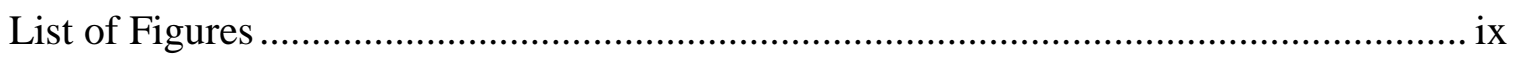

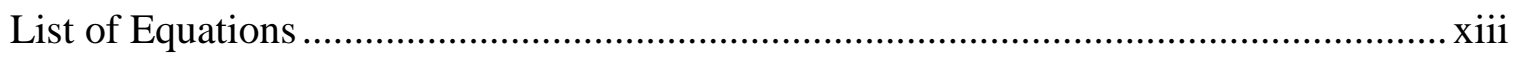

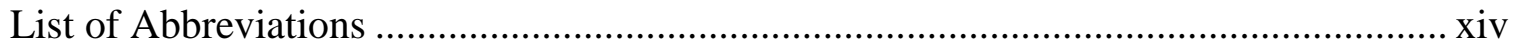

Chapter 1: Introduction to Capillary Electrophoresis and Mass Spectrometry for Sample Preparation and Protein Analysis ............................................................... 1

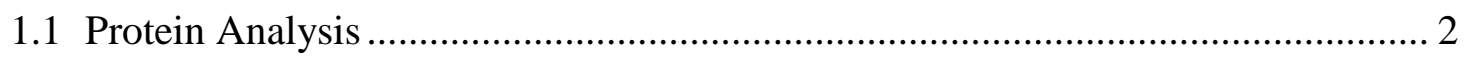

1.1.1 Analysis of Proteins by MS ......................................................... 2

1.1.2 Protein Sample Preparation.......................................................... 5

1.2 Sample Preparation by CE ..................................................................... 9

1.2.1 In-Capillary Sample Enrichment ..................................................... 9

1.2.2 Discontinuous Buffer System for Protein Enrichment …..................... 12

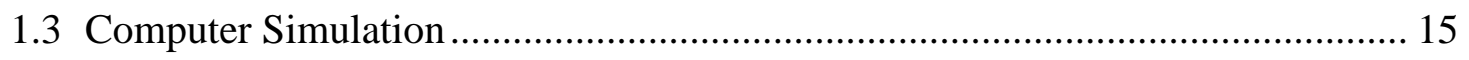

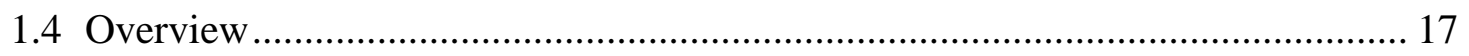

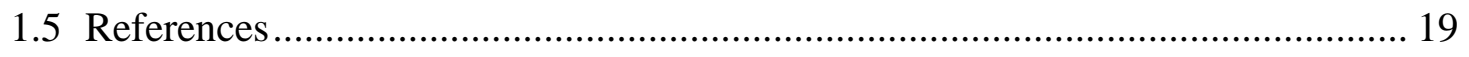

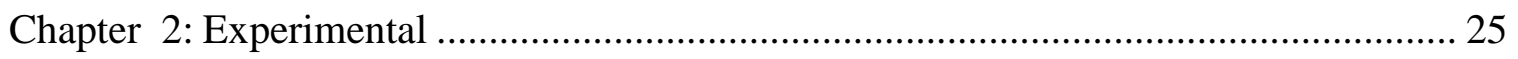

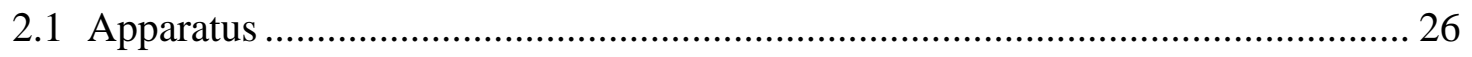

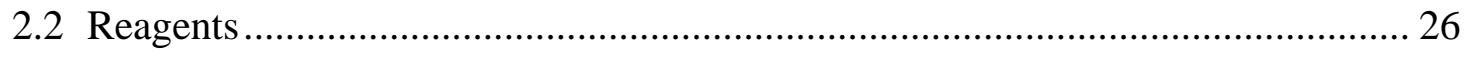

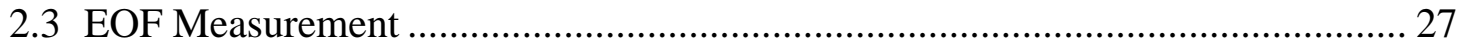




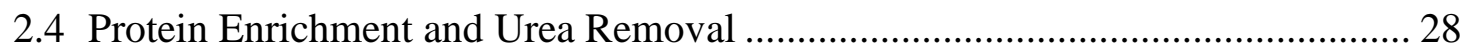

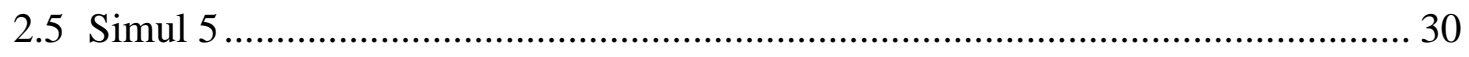

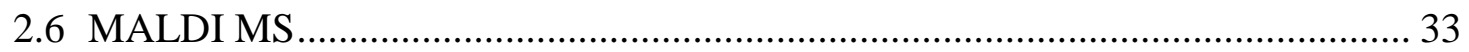

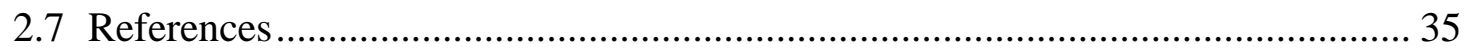

Chapter 3: Migration Behaviour of Discontinuous Buffers in Capillary Electrophoresis during Protein Enrichment ......................................................................... 36

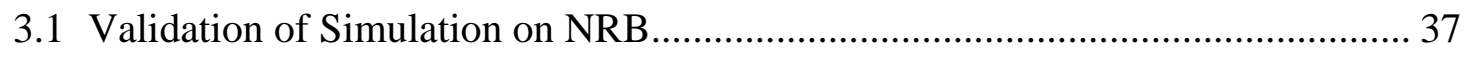

3.2 Ion Migration Behaviour Determined Using UV-Absorbing Ions ........................ 46

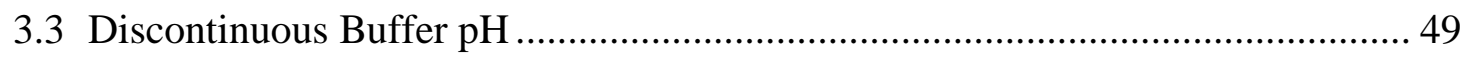

3.4 Discontinuous Buffer Concentration …………….............................................. 59

3.5 Protein Enrichment and Purification from Urea …….......................................... 63

3.5.1 Urea Removal by Discontinuous Buffers System ..................................... 63

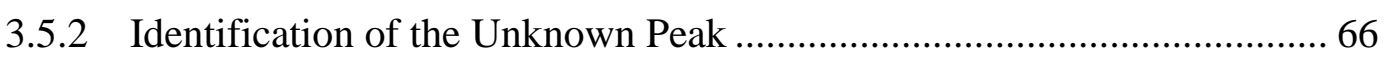

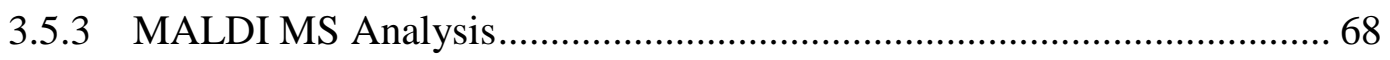

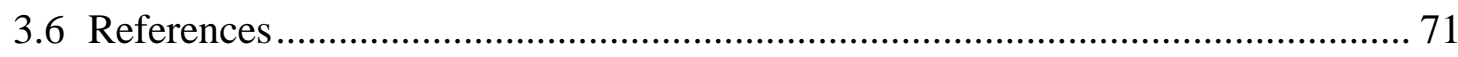

Chapter 4: Conclusions and Future Work ...................................................................... 73

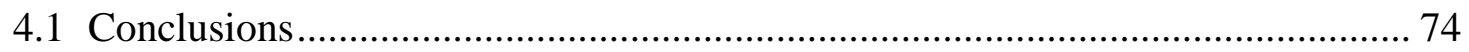

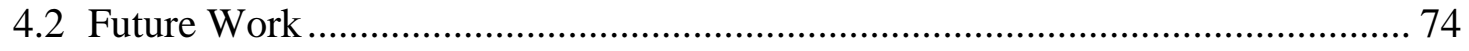

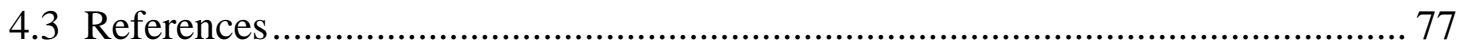

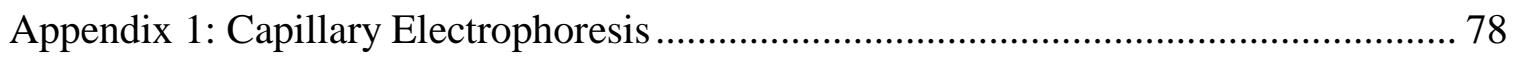

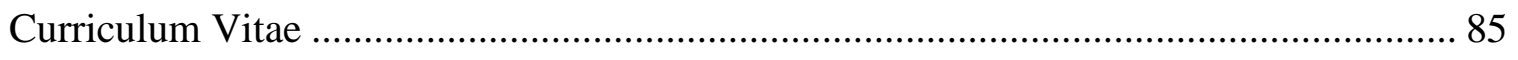




\section{List of Tables}

Table 3.1 Migration times of myoglobin and MO peaks in 20 runs during enrichment with

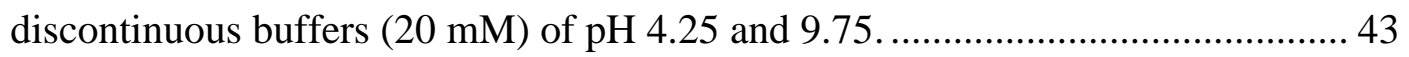

Table $3.2\left[\mathrm{H}^{+}\right] /\left[\mathrm{OH}^{-}\right]$ratios of various discontinuous buffer combinations ...........................53 


\section{List of Figures}

Figure 1.1 Schematic of capillary electrophoresis instrument........................................... 8

Figure 1.2 Schematic representation of protein preconcentration at the $\mathrm{pH}$ junction ......... 13

Figure 2.1 EOF measurements by sequential injection. Shadowed bands and peaks show the position of MO if EOF is zero ...................................................................... 28

Figure 2.2 A screenshot of Simul 5 setup for simulating a discontinuous buffers system.. 32

Figure 2.3 An experimental photo of spotting the sample from the $\mathrm{CE}$ instrument to a MALDI MS target plate 34

Figure 3.1 A schematic illustrating the capillary content at the starting condition for computer simulation. Yellow circles represent the analyte, myoglobin............. 38

Figure 3.2 Simulated conductivity, $\mathrm{pH}$ and ion concentration profiles at: (A) time $=0 \mathrm{sec}$, (B) time $=100 \mathrm{sec}$, and $(\mathrm{C})$ time $=1000 \mathrm{sec}$. Acetate ion conc. $(-)$, conductivity (-), ammonium ion conc. (-), $\mathrm{pH}(-)$, and myoglobin conc. (). Inset displays a magnified view of the myoglobin peak

Figure 3.3 A schematic depicting a cathodic NRB during myoglobin enrichment. 41

Figure 3.4 UV absorbance signals recorded at $200(-)$ and $254 \mathrm{~nm}(---)$ to reveal the presence of myoglobin and MO, respectively, during enrichment with discontinuous buffers $(20 \mathrm{mM})$ of $\mathrm{pH} 4.25$ and 9.75 . Inset displays a magnified view of the myoglobin peak 42

Figure 3.5 (A) UV absorbance signal recorded at $254 \mathrm{~nm}$ to measure EOF in $20 \mathrm{mM} \mathrm{pH}$ 9.75 ammonium acetate buffer; (B) UV absorbance signal recorded at $254 \mathrm{~nm}$ to measure EOF in $20 \mathrm{mM} \mathrm{pH} 4.25$ ammonium acetate buffer.

Figure 3.6 (A) Experimental setup to determine the migration of benzoate ions in discontinuous buffers during voltage application. (B) Experimental setup to 
determine the migration of benzylamine ions in discontinuous buffers during voltage application

Figure 3.7 (A) Simul 5 results predicting the location of benzoate at $600 \mathrm{sec}$. Initial buffer junction at $20 \mathrm{~mm}$; (B) Experimental results obtained after $10 \mathrm{~min}$ of voltage application under the setup illustrated in Figure 3.6 A. (C) Simul 5 results predicted the location of benzylamine at $600 \mathrm{sec}$. Initial buffer junction at 20 $\mathrm{mm}$; (D) Experimental results obtained after $600 \mathrm{sec}$ of voltage application under the setup illustrated in Figure 3.6 B. 48

Figure 3.8 A schematic illustrating the capillary content at the starting condition of the computer simulation 50

Figure 3.9 Simulated conductivity, $\mathrm{pH}$ and ion concentration profiles at: (A) time $=0 \mathrm{sec}$, (B) time $=100 \mathrm{sec}$, and $(\mathrm{C})$ time $=1000 \mathrm{sec}$. Acetate ion conc. $(-)$, conductivity ( - ), ammonium ion conc. ( -$)$, and $\mathrm{pH}(-)$.............................. 51

Figure 3.10 UV absorbance signals recorded at 200 (-) and $254 \mathrm{~nm}(---)$ to reveal the presence of myoglobin and MO, respectively, during enrichment with discontinuous buffers of $\mathrm{pH} 4.75$ and 9.75 52

Figure 3.11 (A) Simulated locations of $\mathrm{pH}$ junctions at $1000 \mathrm{sec}$ with discontinuous buffers of various $\mathrm{pH}$ combinations. (B) Experimental results of the enriched myoglobin peaks obtained with discontinuous buffers of various $\mathrm{pH}$ combinations. The traces were aligned to position the MO peaks at $0 \mathrm{~min}$. The $\mathrm{pH}$ values of acidic/basic buffer were: 5.25/10.25 (-), 4.25/10.25 (一), 5.25/9.75 (一), 4.75/9.75 (-), 4.25/9.75 (一), 4.25/9.25 (-), 4.25/8.75 (一), and MO (---) 55

Figure 3.12 A demonstration of the movement of $\mathrm{H}^{+}$and $\mathrm{OH}^{-}$inside the capillary with discontinuous buffers of $\mathrm{pH} 4.25$ and 9.75 . 57

Figure 3.13 Simulation results of discontinuous buffers under various $\mathrm{pH}$ combinations at $\mathrm{t}=1000 \mathrm{sec}$. The $\mathrm{pH}$ values of acidic/basic buffer were: (A) 4.25/8.75, (B) 4.25/9.25, (C) 4.25/9.75, (D) 4.25/10.25, (E) 4.75/9.75, (F) 5.25/9.75, and (G) 
5.25/10.25. Panels (A-D) correspond to single myoglobin peaks observed in Figure 3.11 B. Panels (E-G) correspond to split myoglobin peaks observed in Figure 3.11 B. Acetate conc. (-), conductivity (-), ammonium conc. (-), and $\mathrm{pH}(-)$. Computer simulation conditions were same as in Figure 3.11 A ....... 58

Figure 3.14 Simulation results of discontinuous buffers under various concentrations (acetate/ammonium, $\mathrm{mM} / \mathrm{mM}$ ) at $\mathrm{t}=1000 \mathrm{sec}$ : (A) 10/10, (B) 10/50, (C) 50/50, and (D) 50/10. Acetate conc. (-), conductivity (-), ammonium conc. (-), and $\mathrm{pH}(-)$. Initial buffer junction at $10 \mathrm{~mm}$, the computer simulation setup same as in Figure 3.1 . 60

Figure 3.15 Experimental results of myoglobin enrichment under various concentrations (acetate/ammonium, $\mathrm{mM} / \mathrm{mM}$ ) at $\mathrm{t}=1000 \mathrm{sec}$ : (A) 10/10, (B) 10/50, (C) 50/50, and (D) 50/10. The $\mathrm{pH}$ of all discontinuous buffers were held at $\mathrm{pH} 4.25$ and $\mathrm{pH}$ 9.75, myoglobin (-), $\mathrm{MO}(---)$ 61

Figure 3.16 The migration time differences between $\mathrm{MO}\left(\mathrm{t}_{\mathrm{MO}}\right)$ and myoglobin $\left(\mathrm{t}_{\mathrm{myo}}\right)$ from triplicates (each bar represents one experiment) obtained at various discontinuous buffer concentrations

Figure 3.17 (A) Schematics illustrating the experimental setup and proposed ion migration behaviours during myoglobin enrichment and simultaneous urea removal. (B) UV absorbance signals at 200 (-) and $254 \mathrm{~nm}(---)$ during the experiment. Insets display the UV absorption spectra of the indicated regions 65

Figure 3.18 Experimental setup to determine the movement of $1 \mathrm{M}$ urea using discontinuous buffers: $20 \mathrm{mM}$ acidic buffer ( $\mathrm{pH} 5.25)$ and $20 \mathrm{mM}$ basic buffer ( $\mathrm{pH} 10.25)$.. 67

Figure 3.19 Experimental results of urea sample in discontinuous buffers at $200 \mathrm{~nm}$ and $214 \mathrm{~nm}$ during $30 \mathrm{kV}$ voltage application, MO (---) marked the initial buffer junction 68

Figure 3.20 MALDI mass spectra of myoglobin: from an untreated $100 \mathrm{ng} \mu \mathrm{L}^{-1}$ sample in $1 \mathrm{M}$ urea (-), and from a $10 \mathrm{ng} \mu \mathrm{L}^{-1}$ sample in $1 \mathrm{M}$ urea after enrichment and urea removal $(-)$. 69 
Figure A.1 (A) Schematic representation of the double layer at the capillary wall. (B) Bulk flow towards the cathode upon the application of voltage ............................. 79 


\section{List of Equations}

Equation 2.1

Equation 2.2

Equation 2.3

Equation A.1

Equation A.2

Equation A.3

$$
\mu_{E O F}=\frac{\mathrm{IL}}{\mathrm{tV}}
$$

$$
\mu_{E O F}=\frac{\left[\left(\mathrm{t}_{\mathrm{C}}-\mathrm{t}_{\mathrm{B}}\right)-\left(\mathrm{t}_{\mathrm{B}}-\mathrm{t}_{\mathrm{A}}\right)\right] v \mathrm{~L}}{\mathrm{t}_{\mathrm{volt}} \mathrm{V}}
$$

$$
v=\frac{\mathrm{I}}{\mathrm{t}_{\mathrm{C}}}
$$

$$
v=\mu_{e} E
$$

$$
\mu_{e}=\frac{q}{6 \pi \eta r}
$$

$$
\mu_{E O F}=\varepsilon \delta / \eta
$$




\section{List of Abbreviations}

$\begin{array}{ll}\text { BGE } & \text { Background electrolyte } \\ \text { BOA } & \text { Benzoic acid } \\ \text { BYA } & \text { Benzylamine } \\ \text { CE } & \text { Capillary electrophoresis } \\ \text { CHCA } & \alpha \text {-cyano-4-hydroxycinnamic acid } \\ \text { CZE } & \text { Capillary zone electrophoresis } \\ \text { DLPC } & \text { 1,2-dilauroyl-sn-glycero-3-phosphocholine } \\ & \\ \text { DTT } & \text { Dithiothreitol } \\ \text { EOF } & \text { Electro-osmotic flow } \\ \text { ESI } & \text { Electrospray ionization }\end{array}$

FTICR Fourier transform ion cyclotron resonance

HPLC High performance liquid chromatography

i.d. Inner diameter

IEF Isoelectric focusing

LE Leading electrolyte

LOC Lab on a chip

LC Liquid chromatography

MALDI Matrix assisted laser desorption ionization 


\begin{tabular}{|c|c|}
\hline $\min$ & Minutes \\
\hline MO & Mesityl oxide \\
\hline MRB & Moving reaction boundary \\
\hline MS & Mass spectrometry \\
\hline Мyо & Myoglobin \\
\hline $\mathrm{m} / \mathrm{z}$ & Mass to charge ratio \\
\hline $\mathrm{NaOH}$ & Sodium hydroxide \\
\hline NRB & Neutralization reaction boundary \\
\hline o.d. & Outer diameter \\
\hline PAGE & Polyacrylamide gel electrophoresis \\
\hline PCR & Polymerase chain reaction \\
\hline $\mathrm{pI}$ & Isoelectric point \\
\hline $\mathrm{pKa}$ & Acid ionization constant \\
\hline Q & Quadrupole \\
\hline $\sec$ & Seconds \\
\hline SDS & Sodium dodecyl sulfate \\
\hline $\mathrm{TE}$ & Terminating electrolyte \\
\hline TFA & Trifluoroacetic acid \\
\hline TOF & Time-of-flight \\
\hline
\end{tabular}


TRIS Tris(hydroxymethyl)aminomethane 
Chapter 1: Introduction to Capillary Electrophoresis and Mass Spectrometry for Sample Preparation and Protein Analysis 


\subsection{Protein Analysis}

Proteins are essential parts of organisms that control the vital functions, such as metabolism. In living cells, the formation of protein follows this procedure: First, the DNA sequence is transcribed into RNA, and then processed into messenger RNA, finally translated into the protein. Each protein has its own amino acid sequence and is involved in different process within cells. Thus, identifying certain proteins is an effective method for early disease detection.

However, there are many challenges in protein identification. First, unlike static genes, proteins are highly dynamic and are expressed at different locations and times. Second, there are 30,000 different protein sequences in human cells, and proteins may be expressed as different forms due to posttranslational modifications, such as phosphorylated proteins. Third, the protein expressed in biological systems can range from 10 to 1,000,000 copies per cell.[1,2] Fourth, the sample background is complex. One of the analytical methods that is able to overcome many of these challenges, mass spectrometry (MS), is demonstrated below.

\subsubsection{Analysis of Proteins by MS}

MS is an analytical technique that measures the mass to charge ratio of charged particles. It has been widely used for determining the mass or the composition of proteins dues to its high selectivity and sensitivity. A typical MS procedure is shown here: First, a sample is loaded onto the instrument and undergoes vaporization; second, charged particles are formed by ionization of the sample; third, according to the mass to 
charge ratio, the charged particles are separated; fourth, these particles reach the detector and the signals are exported as the mass spectra. There are many ionization methods, but the most commonly used methods for protein analysis are electrospary ionization (ESI) and matrix-assisted laser desorption/ionization (MALDI). Compared with other ionization methods, the advantage of these two methods is that they overcome the propensity of proteins to fragment when ionized, therefore called soft ionization techniques. In this section, these two soft ionization techniques are introduced, as well as the reasons for choosing MALDI MS as the protein analytical method have also been explained.

One of the widely used tools for analysis of macromolecules is ESI MS, which was first described by John Bennett Fenn in 1984. Later in 2002, he was awarded with the Nobel Prize in Chemistry for his contribution to ESI technique development.[3] A typical ESI MS analysis process starts with a protein solution flowing through a capillary needle to an electrospray, and then the proteins ionize and fragment to predictable patterns. Eventually the intact ions and fragments pass into the mass analyzer and are detected. ESI MS has the advantage of allowing a continuous flow of liquid sample injected to the mass spectrometer under atmospheric pressure, which is ideal for tandem with chromatographic separation techniques, and so making the separation and analysis of proteins quick and convenient. However, a large distribution of peaks is often observed for one protein due to formation of multiple charges per molecule during ionization. To form the singly charged ions, another soft ionization technique, MALDI, is introduced below. 
MALDI was first introduced in 1988 by Karas and Hillenkamp, and commonly used for protein analysis.[4] It is similar to ESI in regard to relative softness, but causes fewer multiply charged ions. In this soft ionization technique, a matrix (usually an organic acid) is mixed with the protein sample. This mixture is then deposited and dried on a MALDI target plate. The MALDI target plate is placed into a vacuum ion source where the mixture absorbs UV energy from a pulse laser. The matrix ionizes, dissociates, and changes to the gas phase. Then the protein sample is charged by transferring matrix charge. Several mechanisms of the ionization process have been proposed, but the essential part is that the matrix provides both desorption and ionization of the protein sample. Following ionization, various types of mass analyzer affect the path and/or velocity of the ions and thus these ions are separated according to their mass to charge ratio. In comparison with ESI, MALDI MS is considered to be more sensitive as it offers higher tolerance to contamination, and is more suitable for analysis of complex protein sample.

As mentioned above, both ESI MS and MALDI MS have certain advantages in protein analysis. In this work MALDI MS was selected as the analysis tool for several reasons. One reason is that organic solvent is usually added to the aqueous sample solution to run the ESI MS. However, the sample preparation method that is used for this work required the organic solvent to be added manually before ESI MS. Another reason is that MALDI MS has higher tolerance to salts and buffers, which commonly exist in our protein sample. Therefore, MALDI MS is a simple and suitable way to do the protein analysis in this work. 
In summary, both ESI and MALDI MS have been introduced in this section and MS is undoubtedly a powerful tool to analyze biological molecules. However, the limited complexity of the sample composition imposes a real limiting factor, and thus, an appropriate sample preparation method is still required, especially for low abundance proteins. As a critical step prior to protein detection, various types of sample preparation methods are illustrated in next section.

\subsubsection{Protein Sample Preparation}

Sample preparation is an important step in most analytical techniques. In order to successfully perform MS protein analysis, a series of sample preparation procedures are needed to purify proteins from other cellular components or impurities. The first step is to disrupt the membrane of extracted cells; the second step is to fractionate the cellular components into different fractions by ultracentrifugation. In each fraction, target proteins and other proteins/impurities exist together. The third step is to separate and enrich the targeted proteins. The focus of my research is the third step, and so different separation and enrichment methods are illustrated in this section.

One commonly used protein separation method is the two dimensional gel electrophoresis. Proteins can be separated in two dimensions by their isoelectric point (pI) and molecular weight. In first dimension, the proteins move along the gel and accumulate at their isoelectic point upon the voltage application. In second dimension, after denaturing the proteins by sodium dodecyl sulfate (SDS), the negatively charged protein coated SDS allows migration and separation of proteins based on their molecular weight. The resultant proteins can be removed from gel by staining, and then 
analyzed by MS to identify the proteins. This method has the advantage of resolving a large number of proteins. Therefore, it is especially good for separating proteins in a complex sample. Although this method has been widely used, the drawbacks of this method are limitations of sensitivity and overlapping of protein bands.

Liquid chromatography (LC) is also a popular method to separate proteins in a mixture. The LC is carried out either in a column or a plane. First a sample mixture is dissolved in a liquid called the mobile phase, and then the mobile phase carries it through the stationary phase (a column/plane packed with various particles). The separation happens when the molecules in the sample mixture travel through the stationary phase at different speeds. After passing through the column, the mobile phase passes through a detector, and so the protein sample can be identified and separated by measuring different retention time. Nowadays, one type of LC, high performance liquid chromatography (HPLC) has been widely used. A high pressure is required in HPLC to move the mobile phase through the densely packed column. HPLC provides better separation on a shorter length column in comparison with other LC technique. The separated proteins can then be analyzed by MS in either offline or online way. In a recent review, Urban described the currently available methods and techniques commonly used in HPLC in tandem with MS for protein analysis.[5] Comparing with other separation methods, one drawback of the LC technique is that large amount of solvent needed.

Up until this point, two separation methods have been illustrated and both of them required a large amount of protein sample. However, researchers normally only 
have limited amount of sample, and thus it is important to minimize the required sample volume. One rapidly developing technique that can handle extremely small sample volumes (less than pico liters) is lab on a chip (LOC). It is a miniaturized device that combines several functions on a single chip. Recent advances in chip based protein separation provide faster and more convenient methods than conventional separation methods. One example is the two dimensional electrophoresis in a chip, which has the similar principle as the two dimensional gel electrophoresis. Each chip consists of one isoelectric focusing (IEF) channel for the first dimension separation and 29 parallel polyacrylamide gel electrophoresis (PAGE) channels for the second dimension separation. Detection is achieved using a laser induced fluorescence imaging system.[6] LOC technique allows fast analysis, better process control and low costs. However, as a novel technique, it is not yet fully developed.

An alternative to LOC for the sample separation in a minimized volume is capillary electrophoresis (CE). CE is attractive in analytical chemistry as it offers high separation efficiency (very sharp peaks), and the ability to handle small-volume samples due to the low sample consumption in the capillary. Figure 1.1 shows a conventional CE system. Capillaries are usually made by fused silica with inner diameters (i.d.) of 25 to $75 \mu \mathrm{m}$. The lengths of these capillaries vary typically from 10 to $100 \mathrm{~cm}$. The inlet and outlet reservoirs contain the electrodes to connect the capillary ends with a high voltage power supply. The analyte is loaded into the capillary by replacing one of the reservoirs with an analyte solution, and then pressure is applied to push a plug of the analyte solution into the capillary. After replacing the buffers at the inlet and outlet, 
voltage is applied and the separation is performed. Detection is achieved by positioning a UV-visible absorbance detector as shown in Figure 1.1.

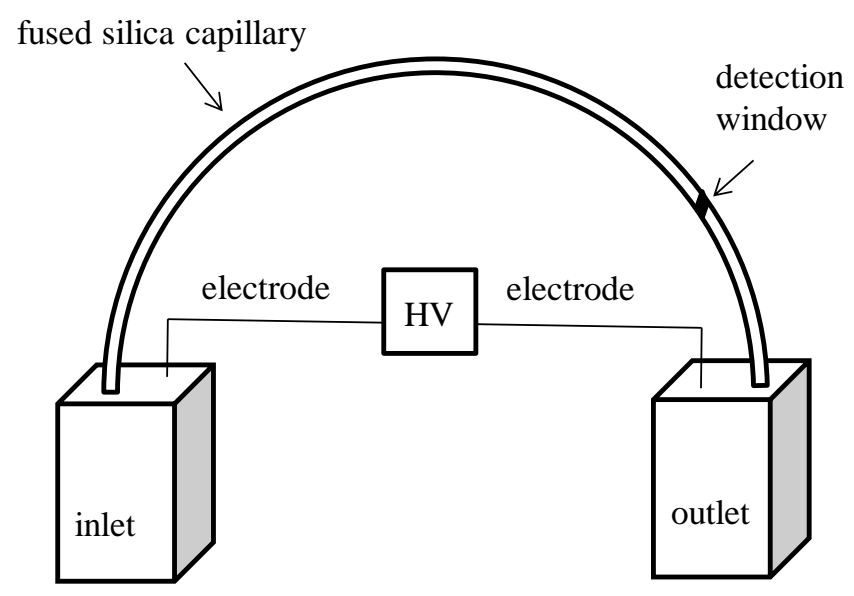

Figure 1.1 Schematic of capillary electrophoresis instrument.

The electrophoretic separation is based on the differential velocities of analytes in an applied electric field. In general, small, highly charged analytes have fast electrophoretic effective mobility. After separation, a pressure can be applied to push the capillary content onto a MS target plate for further MS analysis.

Compared with other separation tools, CE has several advantages: fast and efficient separation, small sample consumption, low cost of capillary, and simplicity of the instrumentation. $[7,8]$ Therefore, $\mathrm{CE}$ is chosen as the sample preparation method in this work. To get a better understanding of the CE system, details about the CE principles, the electro-osmotic flow (EOF), and various coating for capillary are discussed in Appendix 1. Moreover CE is not limited as a separation tool only, but extends as a sample preparation tool for protein enrichment and purification at small 
sample volumes.[9] In next section, various types of CE applications in sample preparation are demonstrated.

\subsection{Sample Preparation by CE}

One challenge involving protein analysis is that the protein expression in biological system spans over a wide range in concentration, and thus enrichment of analytes prior to separation and detection becomes a critical sample preparation step for low abundance proteins. For separations taking place in capillary- or microchannelformats, online enrichment techniques based on electrophoresis are available, and they are reviewed in references.[10-13] In this section, the developments of sample enrichment by CE, particularly the protein enrichment in a discontinuous buffer system are demonstrated in detail.

\subsubsection{In-Capillary Sample Enrichment}

In general, the enrichment mechanism is based on an abrupt reduction of analytes' electrophoretic mobilities as they migrate across a buffer zone boundary inside the capillary. Such stacking behaviour can be induced by a change in local electric field due to differences in ionic conductivity. Alternatively, a $\mathrm{pH}$ change in buffer zones can be used to alter the mobilities of ionizable analytes. Different versions of in-capillary enrichment by $\mathrm{pH}$ changes are reviewed below.

Lunte and co-workers reported $\mathrm{pH}$-mediated sample stacking of small $\mathrm{MW}$ cations[14] and anions,[15] such as catecholamines and vanillic acid, in a high ionic 
strength background. This stacking was based on a neutralization of the sample zone $\mathrm{pH}$, using a plug of strong acid (for cationic analytes) or base (for anionic analytes), in order to reduce the local conductivity. Analytes were therefore stacked as they exited the sample zone. Additional analytes enriched by this technique include cationic pharmaceutics[16] and glutathione in liver microdialysates.[17]

Britz-McKibbin and colleagues developed a dynamic $\mathrm{pH}$ junction for the enrichment of weakly ionic analytes, including nucleotides, catecholamines, and weakly acidic compounds.[18-21] Therein, a sample plug prepared in a $\mathrm{pH}$ either higher or lower than the background electrolyte (BGE) was injected to create a $\mathrm{pH}$ junction. The analyte migrated towards the junction where it experienced a $\mathrm{pH}$-induced mobility reduction and became stacked. The term dynamic referred to the short-lived nature of the $\mathrm{pH}$ junction, which quickly dissipated after stacking to facilitate the separation of enriched analytes. Applications of this technique have since included peptides[22, 23] and proteins.[24]

In a similar manner to the dynamic $\mathrm{pH}$ junction, Cao et al. reported the use of a moving reaction boundary (MBR) for the enrichment of zwitterionic analytes.[25] The operating process is analogous to the dynamic $\mathrm{pH}$ junction technique, where the sample is prepared in a $\mathrm{pH}$ different from the running buffer, and the analytes become stacked prior to dissipation of the $\mathrm{pH}$ junction and subsequent CZE separation. However, the reports by $\mathrm{Cao}$ and colleagues also focused on the theoretical development to understand the stacking mechanisms of this MRB, using amino acids as the model analytes.[26-28] 
Recognizing that macromolecules such as proteins migrate slowly inside the capillary, a prolonged $\mathrm{pH}$ junction is advantageous for stacking larger volumes of protein samples. Pospíchal and co-workers reported a micropreparative protein focusing apparatus, in which an acid and a base were placed at the two ends of an electric field, and the migration of $\mathrm{H}^{+}$and $\mathrm{OH}^{-}$inside a column resulted in a sustained neutralization reaction boundary (NRB).[29] Such a NRB was also studied by Cao et al. as a moving reaction boundary, as mentioned above.[27] The velocity and direction of the NRB movement is determined by the relative flux of $\mathrm{H}^{+}$to that of $\mathrm{OH}^{-}$, which in turn depends on parameters including the ion mobility, ion concentration and local electric field. In Pospíchal's system, non-buffering electrolytes were used, and $\mathrm{H}^{+}$and $\mathrm{OH}^{-}$were generated by electrolysis. This allowed variable control of $\mathrm{H}^{+}$and $\mathrm{OH}^{-}$fluxes and thus the NRB movement during a run. When proteins with relatively neutral pI were present, they acquired net charges in either the acid or the base, and migrated towards the NRB. The focusing of test proteins, myoglobin and insulin, was demonstrated in wide-bore columns with enrichment up to 30 folds.[29]

In summary, the enrichment of small MW cations and anions, weakly ionized analytes, and zwitterionic analytes have successfully achieved by stacking them in the $\mathrm{pH}$ junction which is formed inside the capillary. Our group was also interested in the application of $\mathrm{pH}$-mediated enrichment proteins, but focused on the use of commercial $\mathrm{CE}$ instruments. In the next section, a discontinuous buffer system that has been developed by our group, as well as the applications of this system for protein enrichment, is introduced. 


\subsubsection{Discontinuous Buffer System for Protein Enrichment}

Instead of electrolytic $\mathrm{pH}$ control, two buffers were used to generate the required prolonged $\mathrm{pH}$ junction. This is what we called discontinuous buffer system. One typical discontinuous buffer system that was developed by our group is demonstrated here. It consisted of a $\mathrm{pH} 4.75$ ammonium acetate buffer $(10 \mathrm{mM}$ acetic acid, $\mathrm{pH}$ was adjusted to 4.75 by ammonium hydroxide) and a $\mathrm{pH} 9.25$ ammonium acetate buffer buffer (10 $\mathrm{mM}$ ammonium hydroxide, $\mathrm{pH}$ was adjusted to 9.25 by acetic acid). The $\mathrm{pH}$ values of the discontinuous buffers were chosen to generate equal concentrations of $\left[\mathrm{H}^{+}\right]$and $\left[\mathrm{OH}^{-}\right]$, while acid and base were selected to provide strong buffer capacity at $\mathrm{pH} 4.75$ and 9.25 respectively $\left(\mathrm{pH} \approx \mathrm{pK}_{\mathrm{a}}\right)$, and weak buffer capacity near $\mathrm{pH} 7$. This setup allowed the creation of a sharp, step-shaped, $\mathrm{pH}$ junction inside a silica capillary upon voltage application, which was confirmed experimentally using UV-absorbing $\mathrm{pH}$ indicators.[30]

Figure1.2 is a schematic of the experimental setup. With the acid placed at the anodic reservoir, and the base positioned at the cathodic reservoir, a $\mathrm{pH}$ junction was generated upon voltage application and enrichment factors up to 2000 were recorded.[31] 


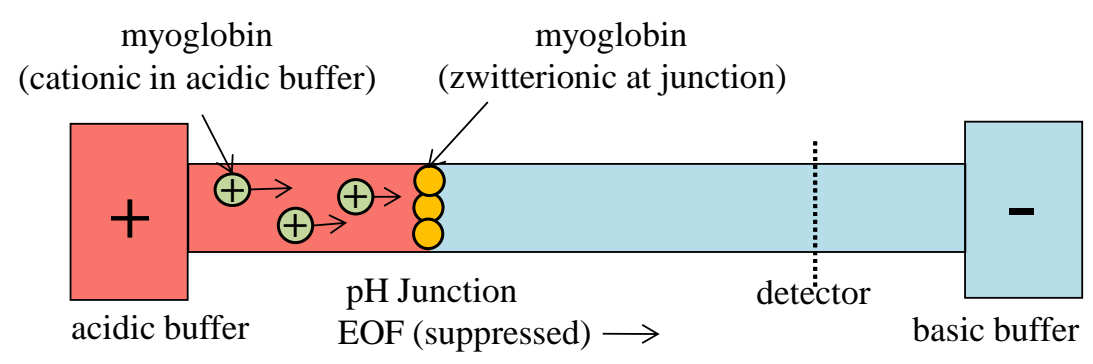

Figure 1.2 Schematic representation of protein preconcentration at the $\mathrm{pH}$ junction.

Following this work, our group extended the use of $\mathrm{pH}$ junction to enrich model proteins, such as myoglobin (pI 7.2), amyloglucosidase (pI 3.6) and cytochrome c (pI 10.6),[31] along with peptides from the tryptic digestion of myoglobin.[32] Importantly, further than the enrichment, the $\mathrm{pH}$ junction also served as a means of protein immobilization and facilitated in-capillary modifications of the enriched proteins, including proteolysis,[33] and purification to remove unwanted background ionic salt and buffer ions.[34, 35]

To prevent the electro-osmotic flow (EOF) from flushing out the proteins and the $\mathrm{pH}$ junction prior to completion of enrichment, the silica capillaries were pretreated with a zwitterionic phospholipid, DLPC. This phospholipid forms a semi-permanent coating on the capillary inner walls and significantly reduces the EOF to the order of $10^{-5} \mathrm{~cm}^{2} \mathrm{~V}^{-1} \mathrm{~s}^{-1}$.[36] An additional benefit of this DLPC coating was the minimization of protein adsorption on capillary wall.[36] Due to the non-zero EOF, the apparent neutralization reaction boundary (NRB) migration in this case was a sum of the intrinsic NRB mobility and the suppresssed EOF. Mesityl oxide was used to experimentally determine the EOF, while the enriched myoglobin peak was used to locate the NRB. 
With the $\mathrm{pH} 4.75 / 9.25$ discontinuous buffers, we previously observed that the enriched protein peak either overlapped or migrated closely with the EOF marker.[31] In other words, the apparent movement of NRB was mostly driven by the EOF, and the NRB mobility was relatively insignificant. This in turn suggested that a near-matching flux of $\mathrm{H}^{+}$and $\mathrm{OH}^{-}$existed in the chosen discontinuous buffers. In addition to the $\mathrm{pH}$ 4.75 ammonium acetate buffer and $\mathrm{pH} 9.25$ ammonium acetate buffer, discontinuous buffer systems based on other buffers and/or other $\mathrm{pH}$ values were also explored; e.g., $\mathrm{pH} 3.75$ ammonium formate with $\mathrm{pH} 9.25$ ammonium formate,[30] and $\mathrm{pH} 4.25$ ammonium acetate with $\mathrm{pH} 9.75$ ammonium acetate buffers.[32, 33, 35] While successful enrichment was observed in all cases, it is apparent that the composition of the discontinuous buffers is a critical factor in determining the ion migration behaviour during enrichment, and thus a systematic study is important to better understand the effect of buffer choices on NRB movement and the mechanism of this enrichment technique.

To study the migration of ions in our discontinuous buffers during enrichment, we have relied on the direct approach of monitoring the movements of UV-absorbing ions with the online $\mathrm{CE}$ detector. This included measuring the electro-osmotic flow (EOF) with mesityl oxide, displaying the $\mathrm{pH}$ profile with $\mathrm{pH}$ indicators, [30, 31] and monitoring the migration of UV-absorbing molecules such as proteins or background salt and buffering ions to be removed.[34, 35] However, the migration of the discontinuous buffer ions themselves (acetate and ammonium), being weakly or nonUV absorbing, could not be monitored in this way. A conductivity detector coupled to a CE instrument would be useful to monitor these optically inactive ions, $[37,38]$ but 
unfortunately it was not available to us. An indirect approach to investigate ion migration behaviours in $\mathrm{CE}$ is computer modelling based on the theories describing electrophoretic processes.

\subsection{Computer Simulation}

Computer simulation programs are available and have already been used in many CE applications, from zone electrophoresis to isoelectric focusing, and have recently been reviewed by Thormann et al.[39, 40] Examples of recent dynamic simulation models are GENTRANS,[41-43] Simul 5,[44] and SPRESSO.[45, 46] In this section, the focus is on the principles and the application of these simulation models.

The computer models are based on partial differential equations in time and space (often in 1-D) that encompass electromigration including analyte charge and mobility, diffusion, and bulk flow to track the movement of each species in solution. These equations also incorporate the principles of electroneutrality, conservation of mass and charge, and dissociation-association equilibria of weak electrolytes and ampholytes.

Both GENTRANS and Simul 5 have been applied to model systems consisting of $\mathrm{pH}$ junctions. Breadmore et al. experimentally demonstrated the formation and extinction of a $\mathrm{pH}$ junction for stacking analytes prior to separation, and were then able to gain further insight and clearly explain the theory of their observations using GENTRANS. This high resolution, transient simulation program incorporates up to 150 components, including strong and weak electrolytes, ampholytes, peptides and proteins. 
However, it is only available in the laboratories of the program developers at the Universities of Bern and Tasmania.[40, 43]

Simul 5, on the other hand, is a free software offered by Professor Bohuslav Gaš for public online download. It features a graphic user interface for ease of use, and runs on any current Windows computer. Simul 5 can simulate any number of multivalent components with good speed, and it can model the real-time progress of ion movements in a simulated capillary. The first application of Simul 5 on a $\mathrm{pH}$ junction technique was published by Kim et al. to investigate the focusing mechanism of weakly acidic analytes at a dynamic $\mathrm{pH}$ boundary.[21]

Computer simulations were correlated with the experimental data to confirm that a migrating hydroxide eigenzone was responsible for the observed enrichment. Additionally, simulations were used to optimize the enrichment with sample $\mathrm{pH}$ and injection length. Britz-McKibbin continued to apply computer simulations to examine the enrichment, separation, and identification of metabolites using a combination of dynamic $\mathrm{pH}$-junction and transient cationic isotachophoresis (tCITP).[47] Ševčík and co-workers have also employed Simul 5 to explain the mechanism of stacking of weakly acidic analytes at a neutralization reaction boundary, where the $\mathrm{pH}$ junction, the isotachophoretic influences of the buffer regions, and the addition of an organic solvent were explored to explain the stacking mechanism.[48]

In the above examples, the analytes were small, weakly ionic molecules injected as a small sample plug at a short-lived $\mathrm{pH}$ junction. In contrast, our work focused on significantly larger, and hence slower, protein analytes that required a prolonged $\mathrm{pH}$ 
junction their enrichment. Our group started to use Simul 5 to model our discontinuous buffer system. In particular, it was applied to stimulate the migration behaviour of TRIS and phosphate during their removal, and to reveal the effect of phosphate on the migration of acetate and ammonium ions.[34] As expected the simulation results resembled the experimental results. Also, noteworthy was the observation of a slow moving NRB from the simulated results, as described by Cao et al.[27] However, this observation was not validated experimentally. It is of interest to explore how computer simulation could provide insight on the prolonged $\mathrm{pH}$ junction formation, maintenance, and manipulation. In this work, computer simulations play important roles in predicting the ions migration and explaining the NRB movement.

\subsection{Overview}

In this chapter, protein analysis, sample preparation techniques, and computer simulation have been introduced. The developments of sample enrichment by $\mathrm{CE}$, particularly the protein enrichment in a discontinuous buffer system have been demonstrated in detail. However, prior to this work, our group only focuses on the protein enrichment and has not investigated on the migration behaviour of various ions in this system. Therefore, in following chapters, the focus is getting a better understanding of migration behavior of discontinuous buffers in $\mathrm{CE}$ during protein enrichment. In chapter 2, the apparatus and reagents are listed, and the details of the experimental setup, especially the simulation setup are illustrated. In chapter 3 , a systematic investigation on the migration behaviour of the buffering ions and protein analyte ions is presented with experimental data and corresponding simulation results. 
Also, the discovery of the $\mathrm{pH}$ junction controlled by buffer composition allows us to remove unwanted background molecule from the enriched protein sample. Chapter 4 is the conclusion and future work. 


\subsection{References}

1. Anderson, N. L.; Anderson, N. G., The human plasma proteome: history, character, and diagnostic prospects. Mol Cell Proteomics 2002, 1 (11), 845-67.

2. Corthals, G. L.; Wasinger, V. C.; Hochstrasser, D. F.; Sanchez, J. C., The dynamic range of protein expression: A challenge for proteomic research. Electrophoresis 2000, 21 (6), 1104-1115.

3. Fenn, J. B., Mass spectrometric implications of high-pressure ion sources. International Journal of Mass Spectrometry 2000, 200 (1-3), 459-478.

4. Karas, M.; Hillenkamp, F., Laser Desorption Ionization of Proteins with Molecular Masses Exceeding 10000 Daltons. Analytical Chemistry 1988, 60 (20), 2299-2301.

5. Urban, J.; Vanek, J.; Stys, D., Current State of HPLC-MS Data Processing and Analysis in Proteomics and Metabolomics. Current Proteomics 2012, 9 (2), 8093.

6. Mouradian, S., Lab-on-a-chip: applications in proteomics. Current Opinion in Chemical Biology 2002, 6 (1), 51-56.

7. Camilleri, P., Capillary electrophoresis : theory and practice. 2nd ed.; CRC Press: Boca Raton, Fla., 1998; p 552 p.

8. Huck, C. W.; Bonn, G. K., Analysis of proteins by capillary electrophoresis. Methods Mol Biol 2008, 384, 507-40.

9. Nesbitt, C. A.; Zhang, H.; Yeung, K. K., Recent applications of capillary electrophoresis-mass spectrometry (CE-MS): CE performing functions beyond separation. Analytica Chimica Acta 2008, 627 (1), 3-24. 
10. Breadmore, M. C.; Dawod, M.; Quirino, J. P., Recent advances in enhancing the sensitivity of electrophoresis and electrochromatography in capillaries and microchips (2008-2010). Electrophoresis 2011, 32 (1), 127-148.

11. Kartsova, L. A.; Bessonova, E. A., Preconcentration techniques in capillary electrophoresis. J. Anal. Chem. 2009, 64 (4), 326-337.

12. Malá, Z.; Šlampová, A.; Gebauer, P.; Boček, P., Contemporary sample stacking in CE. Electrophoresis 2009, 30 (1), 215-229.

13. Nesbitt, C. A.; Zhang, H. X.; Yeung, K. K. C., Recent applications of capillary electrophoresis-mass spectrometry (CE-MS): CE performing functions beyond separation. Anal. Chim. Acta 2008, 627 (1), 3-24.

14. Zhao, Y. P.; Lunte, C. E., $\mathrm{pH}$ mediated field amplification on-column preconcentration of anions in physiological samples for capillary electrophoresis. Anal. Chem. 1999, 71 (18), 3985-3991.

15. Park, S.; Lunte, C. E., On-column sample concentration of high-ionic-strength samples in capillary electrophoresis. J. Microcolumn Sep. 1998, 10 (6), 511-517.

16. Gillogly, J. A.; Lunte, C. E., pH-mediated acid stacking with reverse pressure for the analysis of cationic pharmaceuticals in capillary electrophoresis. Electrophoresis 2005, 26 (3), 633-639.

17. Hoque, M. E.; Amett, S. D.; Lunte, C. E., On-column preconcentration of glutathione and glutathione disulfide using $\mathrm{pH}$-mediated base stacking for the analysis of microdialysis samples by capillary electrophoresis. J. Chromatogr. B 2005, 827 (1), 51-57.

18. Britz-McKibbin, P.; Bebault, G. M.; Chen, D. D. Y., Velocity-difference induced focusing of nucleotides in capillary electrophoresis with a dynamic $\mathrm{pH}$ junction. Anal. Chem. 2000, 72 (8), 1729-1735. 
19. Britz-McKibbin, P.; Chen, D. D. Y., Selective focusing of catecholamines and weakly acidic compounds by capillary electrophoresis using a dynamic $\mathrm{pH}$ junction. Anal. Chem. 2000, 72 (6), 1242-1252.

20. Ptolemy, A. S.; Britz-McKibbin, P., New advances in on-line sample preconcentration by capillary electrophoresis using dynamic $\mathrm{pH}$ junction. Analyst 2008, 133 (12), 1643-1648.

21. Kim, J. B.; Britz-McKibbin, P.; Hirokawa, T.; Terabe, S., Mechanistic study on analyte focusing by dynamic $\mathrm{pH}$ junction in capillary electrophoresis using computer simulation. Anal. Chem. 2003, 75 (16), 3986-3993.

22. Monton, M. R. N.; Nakanishi, K. I. M.; Kim, J.-B.; Terabe, S., Dynamic pH junction technique for on-line preconcentration of peptides in capillary electrophoresis. J. Chromatogr. A 2005, 1079, 266-273.

23. Imami, K.; Monton, M. R. N.; Ishihama, Y.; Terabe, S., Simple on-line sample preconcentration technique for peptides based on dynamic $\mathrm{pH}$ junction in capillary electrophoresis-mass spectrometry. J. Chromatogr. A 2007, 1148 (2), 250-255.

24. Bessonova, E. A.; Kartsova, L. A.; Shmukov, A. U., Electrophoretic determination of albumin in urine using on-line concentration techniques. $J$. Chromatogr. A 2007, 1150 (1-2), 332-338.

25. Cao, C.-X.; He, Y.-Z.; Li, M.; Qian, Y.-T.; Gao, M.-F.; Ge, L.-H.; Zhou, S.-L.; Yang, L.; Qu, Q.-S., Stacking Ionizable Analytes in a Sample Matrix with High Salt by a Transient Moving Chemical Reaction Boundary Method in Capillary Zone Electrophoresis. Anal. Chem. 2002, 74 (16), 4167-4174.

26. Cao, C.; Zhang, W.; Fan, L.; Shao, J.; Li, S., Comparative study on sample stacking by moving reaction boundary formed with weak acid and weak or strong alkali in capillary electrophoresis I. Theory. Talanta 2011, 84, 651-658. 
27. Cao, C. X.; Fan, L. Y.; Zhang, W., Review on the theory of moving reaction boundary, electromigration reaction methods and applications in isoelectric focusing and sample pre-concentration. Analyst 2008, 133 (9), 1139-1157.

28. Zhu, W.; Zhang, W.; Fan, L.-Y.; Shao, J.; Li, S.; Chen, J.-L.; Cao, C.-X., Study on mechanism of stacking of zwitterion in highly saline biologic sample by transient moving reaction boundary created by formic buffer and conjugate base in capillary electrophoresis. Talanta 2009, 78 (3), 1194-1200.

29. Budilova, J.; Pazourek, J.; Krasensky, P.; Pospichal, J., Continuous mode of operation for large volume dosing in analytical carrier ampholyte-free isoelectric focusing of proteins applied to off-line detection of fractions. J. Sep. Sci. 2006, 29 (11), 1613-1621.

30. Jurcic, K.; Nesbitt, C. A.; Yeung, K. K. C., Characterization of discontinuous buffer junctions using $\mathrm{pH}$ indicators in capillary electrophoresis for protein preconcentration. J. Chromatogr. A 2006, 1134 (1-2), 317-325.

31. Nesbitt, C. A.; Lo, J. T. M.; Yeung, K. K. C., Over 1000-fold protein preconcentration for microliter-volume samples at a $\mathrm{pH}$ junction using capillary electrophoresis. J. Chromatogr. A 2005, 1073 (1-2), 175-180.

32. Nesbitt, C. A.; Jurcic, K.; Yeung, K. K. C., Nanoliter-volume protein enrichment, tryptic digestion, and partial separation based on isoelectric points by CE for MALDI mass spectral analysis. Electrophoresis 2008, 29 (2), 466-474.

33. Nesbitt, C. A.; Yeung, K. K. C., In-capillary enrichment, proteolysis and separation using capillary electrophoresis with discontinuous buffers: application on proteins with moderately acidic and basic isoelectric points. Analyst 2009, 134 (1), 65-71.

34. Booker, C. J.; Sun, S.; Woolsey, S.; Mejia, J. S.; Yeung, K. K. C., Removal of sample background buffering ions and myoglobin enrichment via a $\mathrm{pH}$ junction 
created by discontinuous buffers in capillary electrophoresis. J. Chromatogr. A 2011, $1218(33), 5705-5711$.

35. Booker, C. J.; Yeung, K. K. C., In-Capillary Protein Enrichment and Removal of Nonbuffering Salts Using Capillary Electrophoresis with Discontinuous Buffers. Anal. Chem. 2008, 80 (22), 8598-8604.

36. Cunliffe, J. M.; Baryla, N. E.; Lucy, C. A., Phospholipid bilayer coatings for the separation of proteins in capillary electrophoresis. Anal. Chem. 2002, 74 (4), 776-783.

37. Guijt, R. M.; Evenhuis, C. J.; Macka, M.; Haddad, P. R., Conductivity detection for conventional and miniaturised capillary electrophoresis systems. Electrophoresis 2004, 25 (23-24), 4032-4057.

38. Kubáň, P.; Hauser, P. C., Ten years of axial capacitively coupled contactless conductivity detection for CZE - a review. Electrophoresis 2009, 30 (1), 176188.

39. Thormann, W.; Breadmore, M. C.; Caslavska, J.; Mosher, R. A., Dynamic computer simulations of electrophoresis: A versatile research and teaching tool. Electrophoresis 2010, 31 (5), 726-754.

40. Thormann, W.; Caslavska, J.; Breadmore, M. C.; Mosher, R. A., Dynamic computer simulations of electrophoresis: Three decades of active research. Electrophoresis 2009, 30, S16-S26.

41. Thormann, W.; Zhang, C. X.; Caslavska, J.; Gebauer, P.; Mosher, R. A., Modeling of the impact of ionic strength on the electroosmotic flow in capillary electrophoresis with uniform and discontinuous buffer systems. Anal. Chem. 1998, 70 (3), 549-562.

42. Mao, Q. L.; Pawliszyn, J.; Thormann, W., Dynamics of capillary isoelectric focusing in the absence of fluid flow: High resolution computer simulation and 
experimental validation with whole column optical imaging. Anal. Chem. 2000, $72(21), 5493-5502$.

43. Breadmore, M. C.; Mosher, R. A.; Thormann, W., High-resolution computer simulations of stacking of weak bases using a transient $\mathrm{pH}$ boundary in capillary electrophoresis. 1. Concept and impact of sample ionic strength. Anal. Chem. 2006, 78 (2), 538-546.

44. Hruška, V.; Jaroš, M.; Gaš, B., Simul 5 - Free dynamic simulator of electrophoresis. Electrophoresis 2006, 27 (5-6), 984-991.

45. Chou, Y.; Yang, R. J., Numerical solutions for isoelectric focusing and isotachophoresis problems. J. Chromatogr. A 2010,1217 (3), 394-404.

46. Bercovici, M.; Lele, S. K.; Santiago, J. G., Open source simulation tool for electrophoretic stacking, focusing, and separation. J. Chromatogr. A 2009, 1216 (6), 1008-1018.

47. Lee, R.; Ptolemy, A. S.; Niewczas, L.; Britz-McKibbin, P., Integrative metabolomics for characterizing unknown low-abundance metabolites by capillary electrophoresis-mass spectrometry with computer simulations. Anal. Chem. 2007, 79 (2), 403-415.

48. Vitkova, K.; Petr, J.; Maier, V.; Znaleziona, J.; Ševčík, J., Study of electromigration effects on a $\mathrm{pH}$ boundary during the on-line electrokinetic preconcentration by capillary electrophoresis. Electrophoresis 2010, 31 (16), 2771-2777. 
Chapter 2: Experimental 


\subsection{Apparatus}

An Agilent ${ }^{3 \mathrm{D}}$ Capillary Electrophoresis (Palo Alto, CA, USA) instrument with a direct UV-visible absorbance detector was used for all CE experiments. Data was collected by the Agilent ${ }^{3 \mathrm{D}} \mathrm{CE}$ ChemStation software. Fused silica capillaries of $50 \mu \mathrm{m}$ i.d. and $364 \mu \mathrm{m}$ o.d. were purchased from Polymicro Technologies (Phoenix, AZ, USA). The capillaries were cut to a total length of $48.5 \mathrm{~cm}$, with a length-to-detector of $40.0 \mathrm{~cm}$ and they were thermostated to $25^{\circ} \mathrm{C}$ during experiments.

A Bruker Reflex IV MALDI time-of-flight mass spectrometer (Billerica, MA, USA) equipped with a $337 \mathrm{~nm}$ nitrogen laser was used for mass spectral analyses.

\subsection{Reagents}

Deionized water $(18.2 \mathrm{M} \Omega \mathrm{cm})$ from a Millipore water purification system (Bedford, MA, USA) was used to prepare all solutions. A $0.1 \mathrm{mM}$ 1,2-dilauroyl-snglycero-3-phosphocholine (DLPC; Avanti Polar Lipids, Alabaster, AL, USA) solution was prepared in a $20 \mathrm{mM}$ tris(hydroxymethyl)aminomethane (TRIS; Aldrich, St. Louis, MO, USA) and $20 \mathrm{mM}$ calcium chloride (Caledon Laboratories, Georgetown, ON, Canada), and the $\mathrm{pH}$ of this solution was adjusted to $\mathrm{pH} 7.2$ by hydrochloric acid (EM Science, Gibbstown, NJ, USA). Mesityl oxide (MO; Aldrich) was used as a neutral marker to mark original buffer junction. Acetic acid and ammonium hydroxide (EM Science, Gibbstown, NJ, USA) were used to make the buffer solutions. Myoglobin from horse heart (Sigma, St. Louis, MO, USA) was used as received. Benzoic acid (EM Science, Gibbstown, NJ) and benzylamine (Aldrich, St. Louis, MO) were used as the 
UV-absorbing buffers. Urea (Sigma or EM Science) was used as received, and was added directly to the protein sample solutions.

a-Cyano-4-hydroxy-cinnamic acid (CHCA; Sigma) was purified in ethanol (Fisher Scientific, Nepean, ON, Canada) according to the recrystallization procedure provided by Sigma/Aldrich. HPLC grade acetone (Fisher) and HPLC grade methanol (Caledon) were used in preparing CHCA matrix.

\subsection{EOF Measurement}

There are two convenient ways to measure the electro-osmotic mobility. In both ways mesityl oxide (MO) was introduced as an EOF marker. For high magnitude EOFs $\left(>1.5 \times 10^{-4} \mathrm{~cm}^{2} \mathrm{~V}^{-1} \mathrm{~s}^{-1}\right)$, a band of MO was injected into the capillary which filled with buffer solution. The migration time of MO under a constant voltage was used to calculate the EOF by Equation 2.1.

$$
\begin{aligned}
& \mu_{E O F}=\frac{\mathrm{IL}}{\mathrm{tV}} \\
& \text { (Equation 2.1) } \\
& \mu_{E O F}=\frac{\left[\left(\mathrm{t}_{\mathrm{C}}-\mathrm{t}_{\mathrm{B}}\right)-\left(\mathrm{t}_{\mathrm{B}}-\mathrm{t}_{\mathrm{A}}\right)\right] v \mathrm{~L}}{\mathrm{t}_{\mathrm{volt}} \mathrm{V}} \\
& v=\frac{\mathrm{I}}{\mathrm{t}_{\mathrm{C}}} \\
& \mu_{E O F}: \text { EOF "Mobility" }\left(\mathrm{m}^{2} \mathrm{~V}^{-1} \mathrm{~s}^{-1}\right) \\
& \mathrm{L}: \quad \text { Total capillary length }(\mathrm{m}) \\
& \mathrm{V}: \quad \text { Voltage (V) } \\
& v: \text { Velocity }(\mathrm{m} / \mathrm{s})
\end{aligned}
$$$$
\text { I : } \quad \text { Effective capillary length }(\mathrm{m})
$$$$
\mathrm{t} \text { : } \quad \text { Migration time (s) }
$$$$
\text { E : } \quad \text { Electric field }(\mathrm{V})
$$$$
\mathrm{t}_{\mathrm{volt}} \text { : Voltage application time }(\mathrm{s})
$$ 
For low magnitude EOFs $\left(<1.5 \times 10^{-4} \mathrm{~cm}^{2} \mathrm{~V}^{-1} \mathrm{~s}^{-1}\right)$, the above method is not appropriate, because the EOF is low and very long migration times would result. The sequential injection method introduced by Vigh was used to determine the low magnitude EOFs.[1] As shown in Figure 2.1, two bands of MO were injected into the capillary and separated by buffer (step 1 to 3 in Figure 2.1). A short period of voltage application would cause these two bands move as a result of EOF. Then a third band of MO was injected, and pressure was used to push all three bands past the detector (step 5 in Figure 2.1). Three peaks were observed, and the EOF was determined by Equations 2.2 and 2.3.
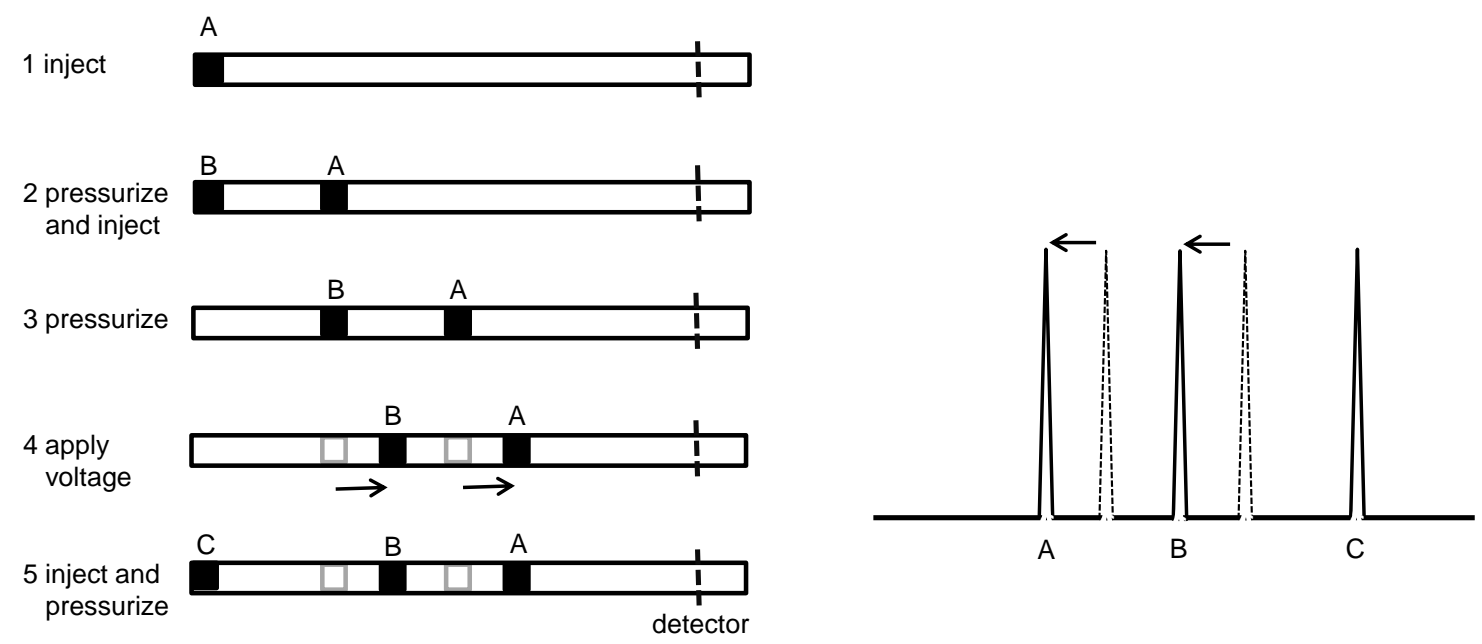

Figure 2.1 EOF measurements by sequential injection. Shadowed bands and peaks show the position of MO if EOF is zero. MO ( $\boldsymbol{\square})$.

\subsection{Protein Enrichment and Urea Removal}

New capillaries were washed by flushing (1 bar) with $0.1 \mathrm{M} \mathrm{NaOH}$ for $10 \mathrm{~min}$, followed by water for $10 \mathrm{~min}$. To minimize protein adsorption, a semi-permanent 
coating of DLPC was used to modify the capillary inner wall by flushing (1 bar) with DLPC solution for $20 \mathrm{~min}$. In between runs, the capillary coating was regenerated by flushing (1 bar) with DLPC solution for $10 \mathrm{~min}$. The capillary was flushed (1 bar) with water for 5 min prior to storage. The DLPC coating was also reported to suppress the electro-osmotic mobility to roughly $10^{-5} \mathrm{~cm}^{2} \mathrm{~V}^{-1} \mathrm{~s}^{-1}$, with the actual values determined by $\mathrm{pH}$ and composition of the background electrolyte.[2]

Our discontinuous buffers consisted of two buffers, an acidic buffer (ammonium acetate in $\mathrm{pH} 4.25$ ), and a basic buffer (ammonium acetate in $\mathrm{pH} 9.75$ ). The acidic buffer was prepared using various concentrations of acetic acid (10 $\mathrm{mM}$ to $50 \mathrm{mM})$, with the $\mathrm{pH}$ adjusted (between 4.25 and 5.25) by adding an appropriate amount of ammonium hydroxide. Comparing with other normal buffer preparation method, the unique point of our strategy is the choice of counter ions to adjust buffer $\mathrm{pH}$ value. Salt ions were not chosen here as the counter ions to form a sodium acetate buffer. The reason is that mobility of $\mathrm{NRB}$ is sensitive to the constitution of the discontinuous buffers. The adding of unnecessary ions disturbs the experimental results and thus should be avoided. Likewise, the ammonium hydroxide at various concentrations (10 $\mathrm{mM}$ to $50 \mathrm{mM}$ ) was adjusted to different $\mathrm{pH}$ values (from 8.75 to 10.25 ) with acetic acid to form the basic buffer. Myoglobin, at a concentration of $10 \mathrm{ng} \mu \mathrm{L}^{-1}$, was prepared in the basic buffer. Unless otherwise stated, the enrichment was conducted as previously reported;[3] that is, the capillary was first filled with the myoglobin sample in basic buffer ( 1 bar). Then a constant voltage $(30 \mathrm{kV})$ was applied with the acidic buffer placed at the inlet (anode) and the basic buffer placed at the outlet (cathode). 
For UV-absorbing buffers system, the $5 \mathrm{mM}$ benzoate $(\mathrm{pH} 4.25)$ replaced acetate as the acidic buffer, while $5 \mathrm{mM}$ ammonium benzoate ( $\mathrm{pH} 9.75$ ) was the basic buffer. First the capillary was filled with half of acidic and half of basic buffer, and then a constant voltage $(30 \mathrm{kV})$ was applied with the acidic buffer at the anode and the basic buffer at the cathode. Likewise, the $5 \mathrm{mM}$ benzylamine ( $\mathrm{pH} 9.75)$ replaced ammonium as the basic buffer, while $5 \mathrm{mM}$ benzylamine acetate $(\mathrm{pH} 4.25)$ was the acidic buffer. For the urea removal experiment, $10 \mathrm{ng} \mu \mathrm{L}^{-1}$ myoglobin was prepared in basic buffer $(\mathrm{pH} 10.25)$ containing $1 \mathrm{M}$ urea. First, the capillary was filled with the urea presented myoglobin sample in basic buffer by flushing ( 1 bar) for 3 min. Then a constant voltage $(30 \mathrm{kV})$ was applied with the $20 \mathrm{mM}$ acidic buffer ( $\mathrm{pH} 5.25)$ placed at the anode and 20 $\mathrm{mM}$ basic buffer $(\mathrm{pH} 10.25)$ placed at the cathode. All the $\mathrm{CE}$ results presented have been verified by triplicate experiments.

\subsection{Simul 5}

Simul 5 obtained online (web.natur.cuni.cz/ gas/) was used in all computer simulation experiments. Our discontinuous buffers system was input into Simul 5 as an isotachophoretic system, with a leading electrolyte (LE, the basic buffer) and terminating electrolyte (TE, the acidic buffer). A screenshot of Simul 5 setup is shown in Figure 2.2. The composition of buffers and analytes can be input in the upper right box. The acidic buffer of the discontinuous buffers was input as the terminating electrolyte (TE). For $20 \mathrm{mM}$ ammonium acetate buffer ( $\mathrm{pH} 4.25$ ), by clicking the add button, acetic acid can be added from the database (default values are provided for the pKa and mobility), and the information about concentration and the electrolyte type can 
be typed in. To adjust $\mathrm{pH}$ to 4.25 , a $4.73 \mathrm{mM}$ ammonium is added by the same way. $\mathrm{pH}$ can be monitored by clicking the $\mathrm{pH}$ (pink line) at the bottom graph of Figure 2.2. The basic buffer (20 mM ammonium acetate buffer, $\mathrm{pH} 9.75)$ was input as the leading electrolyte (LE) in a similar way. Different colour can be chosen for traces to distinguish between the ammonium ions in the TE and that in the LE, likewise for acetate in the TE and acetate in the LE. For simplicity, the TE-LE traces of each of these ions were combined in the figures presented herein.

Myoglobin is not in the Simul 5 database, so manual input of the pKa and mobility is needed. The pKa value of myoglobin was input into Simul 5 by tabulating the number and $\mathrm{pK}_{\mathrm{a}}$ values of the acidic and basic amino acid residues in its sequence: 3.5 (C-terminal), 3.9 (aspartic acid), 4.1 (glutamic acid), 6.0 (histidine), 8.0 (N-terminal), 10.5 (tyrosine and lysine) and 12.5 (arginine). When the overall charge of the protein was positive, the experimentally determined mobility of myoglobin in the acidic buffer was used $\left(1.9 \times 10^{-4} \mathrm{~cm}^{2} \mathrm{~V}^{-1} \mathrm{~s}^{-1}\right)$, and when the overall charge was negative, the mobility of myoglobin determined in the basic buffer $\left(1.5 \times 10^{-4} \mathrm{~cm}^{2} \mathrm{~V}^{-1} \mathrm{~s}^{-1}\right)$ was entered.

The length and other details of capillary can be setup in the run setup window. By clicking the Run Setup button, it shows up as at the right bottom of Figure 2.2. The setup was originally input as the real experimental conditions, but it took 24 hours to simulate a $500 \mathrm{sec}$ run. To speed up the simulation, the capillary length was shorted by 10 times, from $48.5 \mathrm{~cm}$ to $48.5 \mathrm{~mm}$. However, the electric field was maintained as constant; i.e., the voltage was changed from $30 \mathrm{kV}$ in $48.5 \mathrm{~cm}$ to $300 \mathrm{~V}$ in $48.5 \mathrm{~mm}$. 
After adjusting the setup, now it only takes 2 hours to simulate a $500 \mathrm{sec}$ run.

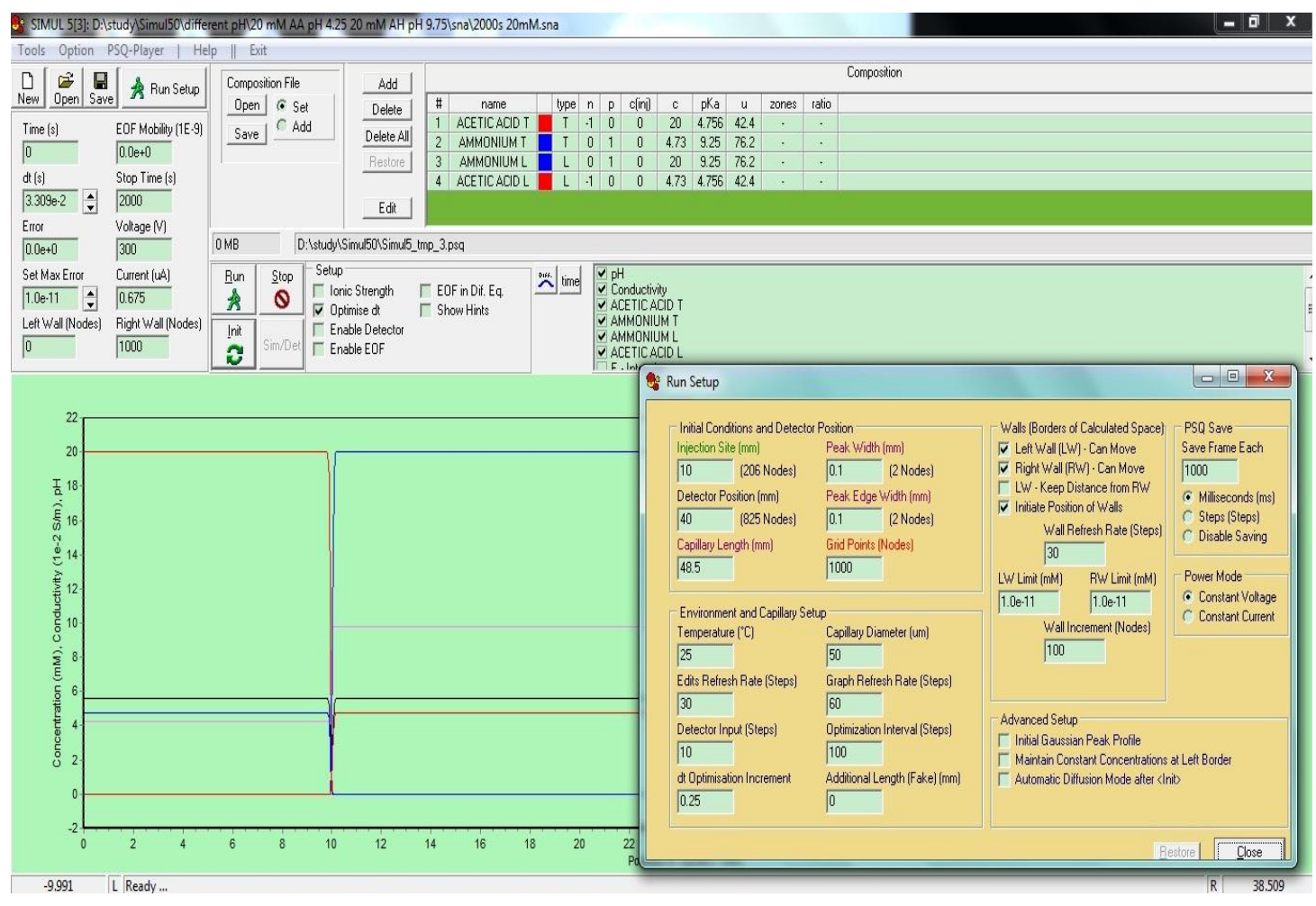

Figure 2.2 A screenshot of Simul 5 setup for simulating a discontinuous buffers system.

In Simul 5, the EOF is handled as a separate, user-defined entry, which does not directly affect the simulation besides moving the entire capillary content forward. Since the EOF was variable in this case due to the different buffer $\mathrm{pH}$ values, a zero EOF was used in all simulation for simplicity. Without EOF pushing the flow toward cathodic direction in simulation, the movement of $\mathrm{NRB}$ can lead the $\mathrm{pH}$ junction moving toward anodic or cathodic direction. To ensure the trend of the $\mathrm{pH}$ junction movement can be accurately observed in Simul 5, an injection site of $10 \mathrm{~mm}$ was chosen for run setup. This is different from the position of initial $\mathrm{pH}$ junction $(0 \mathrm{~mm})$ in real experiments. 


\subsection{MALDI MS}

To facilitate MALDI MS analysis, layers of CHCA matrix were pre-deposited on the target plate, prior to sample deposition from the capillary. The first CHCA layer was $0.35 \mu \mathrm{L}$ of $5 \mathrm{mg} \mathrm{mL}^{-1} \mathrm{CHCA}$ in acetone and methanol (4:1 by volume), followed by the three layers of $0.2 \mu \mathrm{L}$ of saturated CHCA solution in water/methanol (3:2 by volume) and $0.1 \%$ TFA. The multiple layers of CHCA and TFA were required to acidify the sample which can contain basic buffers.

To illustrate how to spot the sample from capillary to MALDI MS plate, a real experimental photo is shown in Figure 2.3. A pressure of 50 mbar was applied to push the capillary content onto a MALDI MS target plate, as previously described.[4] A 20 sec deposition period was used to yield a spot volume of approximately $40 \mathrm{~nL}$. Spotting was done by letting the sample (is pushed out from capillary by pressure) touches the target plate, which was pre-deposited with MALDI matrix. Up to 10 sample spots were collected per CE experiment. 


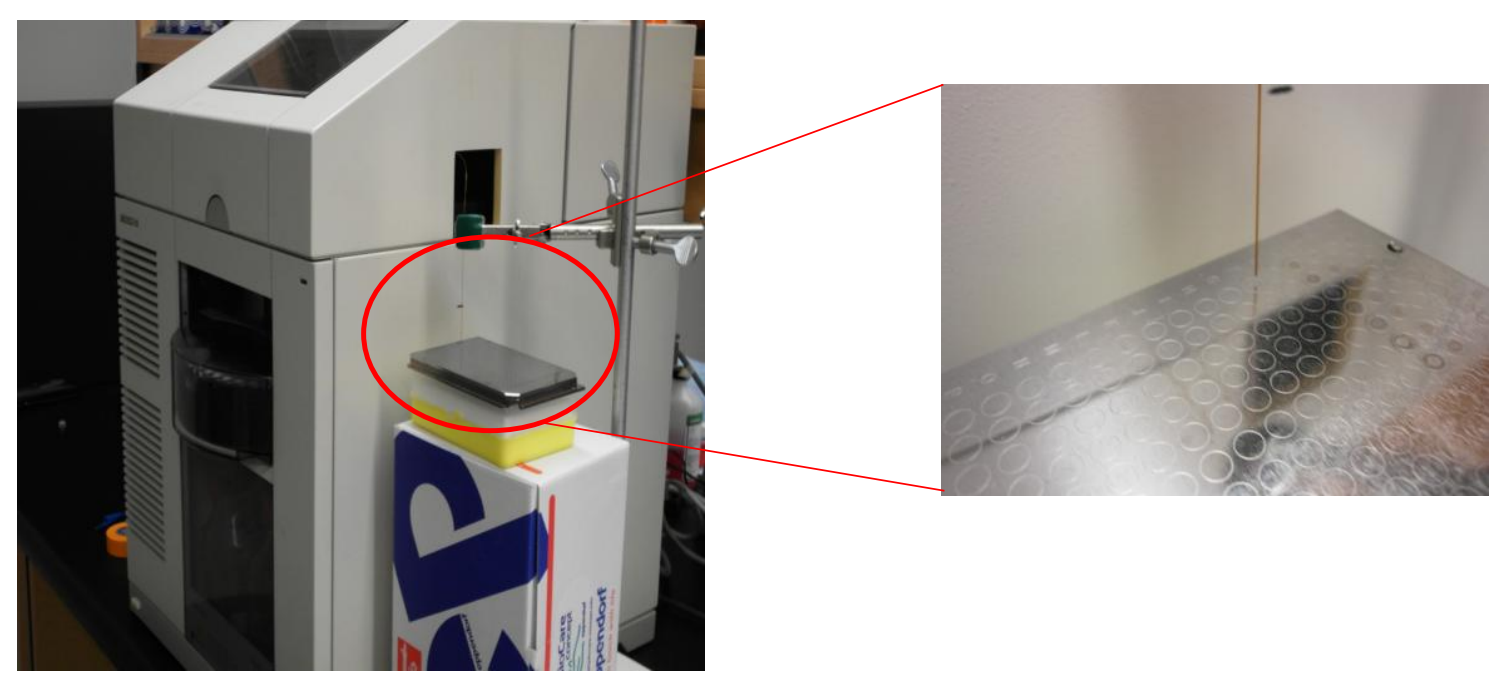

Figure 2.3 An experimental photo of spotting the sample from the CE instrument to a MALDI MS target plate.

All mass spectra of myoglobin were acquired in the positive ion, linear mode. Voltage settings were left at the pre set instrument default settings by Bruker $(20 \mathrm{kV})$. A nitrogen laser was used. Each mass spectrum was a sum of 20 spectra from individual laser shots. Igor Pro 6.2 (WaveMetrics, Lake Oswego, OR, USA) was used to process the data for presentation. 


\subsection{References}

1. Williams, B. A.; Vigh, C., Fast, accurate mobility determination method for capillary electrophoresis. Analytical Chemistry 1996, 68 (7), 1174-1180.

2. Cunliffe, J. M.; Baryla, N. E.; Lucy, C. A., Phospholipid bilayer coatings for the separation of proteins in capillary electrophoresis. Anal. Chem. 2002, 74 (4), 776-783.

3. Nesbitt, C. A.; Lo, J. T. M.; Yeung, K. K. C., Over 1000-fold protein preconcentration for microliter-volume samples at a $\mathrm{pH}$ junction using capillary electrophoresis. J. Chromatogr. A 2005, 1073 (1-2), 175-180.

4. Jurcic, K.; Yeung, K. K., Sphingomyelins as semi-permanent capillary coatings for protein separations in CE and off-line analysis with MALDI-MS. Electrophoresis 2009, 30 (10), 1817-1827. 
Chapter 3: Migration Behaviour of Discontinuous Buffers in Capillary Electrophoresis during Protein Enrichment 
As described in chapter $1, \mathrm{CE}$ is not only an effective separation technique, but can also serve as a sample preparation tool for enrichment and purification at sub-microliter sample volumes. Our approach is based on the use of a discontinuous buffer system consisting of an acid and a base (acetate and ammonium). Proteins with $\mathrm{pI}$ value between the $\mathrm{pH}$ values of these two buffers become stacked at the NRB. However, a systematic study to look at the effect of the migration behaviour of discontinuous buffers in CE during protein enrichment has not been investigated. In this chapter, after validating the accuracy of Simul 5 model on predicting the buffer ions movement, both simulation and experimental methods are used to reveal the ion migration patterns at the buffer junction. Specifically, the effects of $\mathrm{pH}$ and concentration of the discontinuous buffers on the stability and movement of the NRB, and in turn the enrichment of proteins, are investigated.

\subsection{Validation of Simulation on NRB}

Even though Simul 5 was previously applied to model our discontinuous buffers,[1] the focus was on the removal of unwanted background ions, TRIS and phosphate. In this work, our interest is on the discontinuous buffer ions, ammonium and acetate, in particular how they play a role in the migration of the NRB and in turn the enriched myoglobin. Thus, the task of utmost important is to validate the simulation on NRB with experimental data. In this section, to validate the accuracy of simulation, one commonly used discontinuous buffer system was chosen for the comparison of simulation and the real experiment. The differences between simulation and experiments are explained. 
Simul 5 simulation was performed on a discontinuous buffer system with $\left[\mathrm{H}^{+}\right]$in the acid matching the $\left[\mathrm{OH}^{-}\right]$in base; namely $20 \mathrm{mM}$ ammonium acetate (pH 4.25) and $20 \mathrm{mM}$ ammonium acetate $(\mathrm{pH} 9.75)$. A schematic illustrating the capillary content at the starting condition is shown in Figure 3.1. Specifically, $20 \mathrm{mM}$ acetic acid with 4.73 $\mathrm{mM}$ ammonium hydroxide was entered as the anolyte (TE); whereas $20 \mathrm{mM}$ ammonium hydroxide with $4.73 \mathrm{mM}$ acetic acid was entered as the catholyte (LE). Myoglobin was selected as the model protein due to its unique UV absorption at 408 nm which allows easy identification. Details of simulation setup can be found in chapter 2. One major difference between the experimental setup and the simulation setup is the position of the initial $\mathrm{pH}$ junction, whereas $10 \mathrm{~mm}$ for simulation, $0 \mathrm{~mm}$ for experiments. The reason is that a zero EOF is used in simulation for simplicity, and this setup makes sure that the trend of the $\mathrm{pH}$ junction movement is accurately observed in simulation.

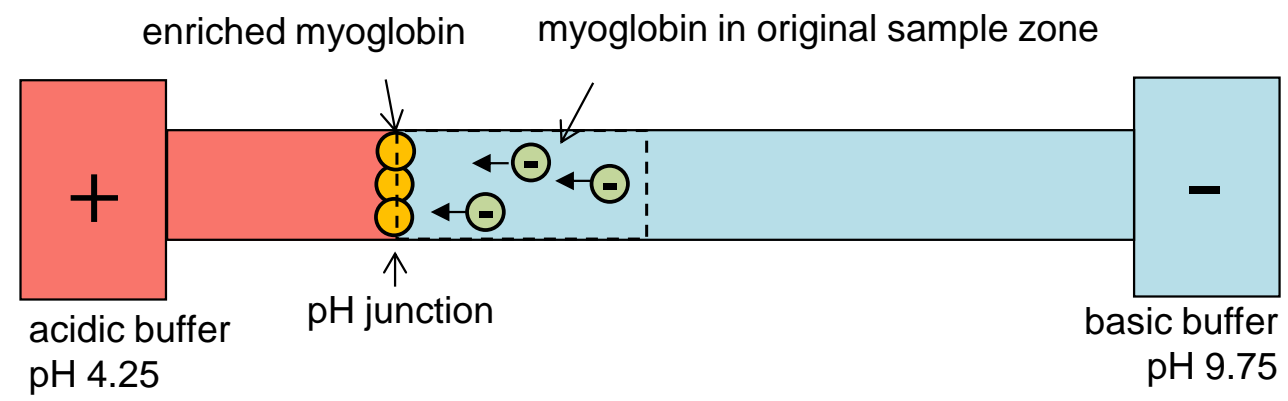

Figure 3.1 A schematic illustrating the capillary content at the starting condition for computer simulation. Yellow circles represent the analyte, myoglobin.

This simulated discontinuous buffer system resulted in the $\mathrm{pH}$ step-junction of $\mathrm{pH} 4.25$ and 9.75 shown in the initial simulation setup $(\mathrm{t}=0$ sec, green trace in 
Figure 3.2 A). A noteworthy observation is the nearly identical initial ionic conductivity between the two sides of the $\mathrm{pH}$ junction (black trace in Figure $3.2 \mathrm{~A}$ ). To minimize simulation time, a small plug, instead of a capillary full, of myoglobin was chosen as the sample zone (pink trace in Figure 3.2 A). The predicted concentration profiles of various ions after 100, and $1000 \mathrm{sec}$ of voltage application are shown in Figure $3.2 \mathrm{~B}$ and $\mathrm{C}$.

Importantly, it predicted the continued presence of a sharp $\mathrm{pH}$ junction and the accumulation of myoglobin as a narrow band which coincided with this $\mathrm{pH}$ junction. The conductivity trace was no longer constant across the $\mathrm{pH}$ junction. A small drop was located on the anodic side next to the $\mathrm{pH}$ junction, which appeared to reflect the decrease in the acetate concentration. Finally, a shift in $\mathrm{pH}$ junction position indicated a cathodic NRB movement. (A video of the simulation process under this condition has been posted on the youtube, and the link is http://www.youtube.com/watch?v=RSeIZ7wOuPA ) 


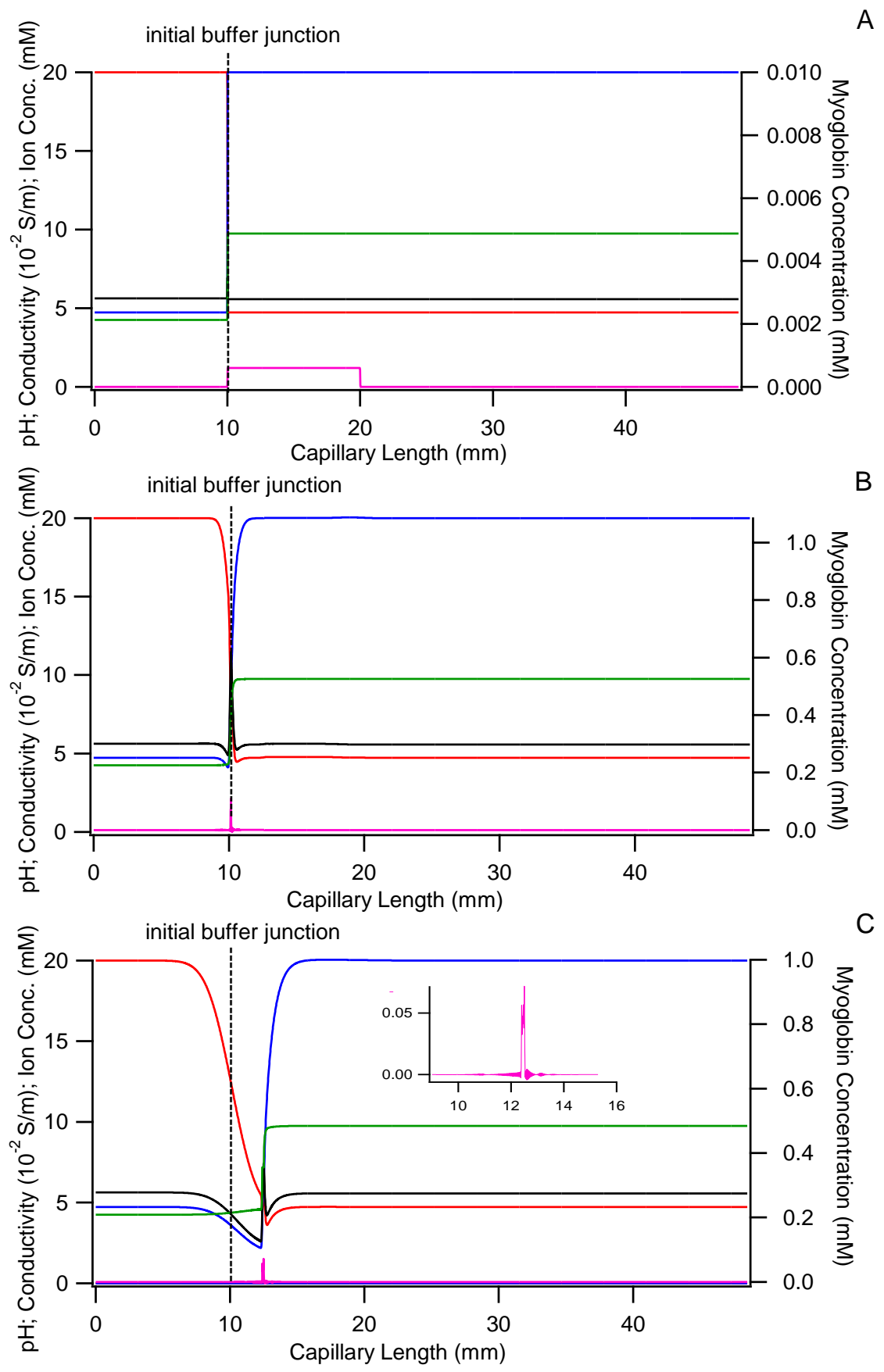

Figure 3.2 Simulated conductivity, $\mathrm{pH}$ and ion concentration profiles at: (A) time $=0$ sec, $(\mathrm{B})$ time $=100 \mathrm{sec}$, and (C) time $=1000 \mathrm{sec}$. Acetate ion conc. $(-)$, conductivity $(-)$, ammonium ion conc. $(-), \mathrm{pH}(-)$, and myoglobin conc. $(-)$. Inset displays a magnified view of the myoglobin peak. 
To validate the simulation results, an enrichment experiment was performed with the same discontinuous buffer composition. In contrast to the starting conditions used in Simul 5, the entire capillary was initially filled with myoglobin prepared in the basic buffer. Hence, the $\mathrm{pH}$ junction initiated between the basic buffer inside the capillary tip and the surrounding acidic buffer in the anodic reservoir.

Another condition that was different between the simulation and experiment was the EOF. In Simul 5, the EOF was treated as zero, and thus the $\mathrm{pH}$ junction movement was solely a result of the moving NRB between the two buffers. In the actual experiment, a suppressed EOF existed in the DLPC coated capillaries. Hence, the pH junction was also mobilized by the EOF, and therefore the apparent migration of the $\mathrm{NRB} / \mathrm{pH}$ junction was a sum of the intrinsic NRB mobility and the EOF. To determine this EOF a plug of MO was injected at the anodic end of the capillary to mark the location of the initial buffer boundary (Figure 3.3).
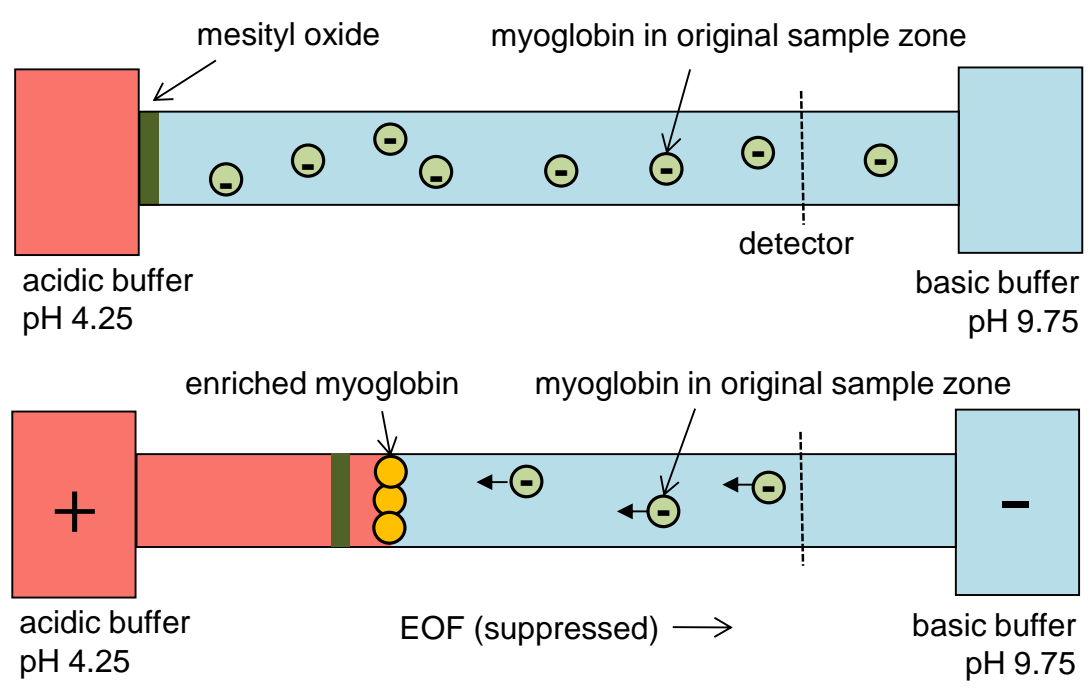

Figure 3.3 A schematic depicting a cathodic NRB during myoglobin enrichment. 
Figure 3.4 displays the absorbance signals recorded at 200 and $254 \mathrm{~nm}$ as the enriched myoglobin and MO passed the detection point. The figure inset is an enlarged view of the myoglobin signal showing the peak shape. In this particular trial, the myoglobin peak preceded the MO peak by approximately 2 min.

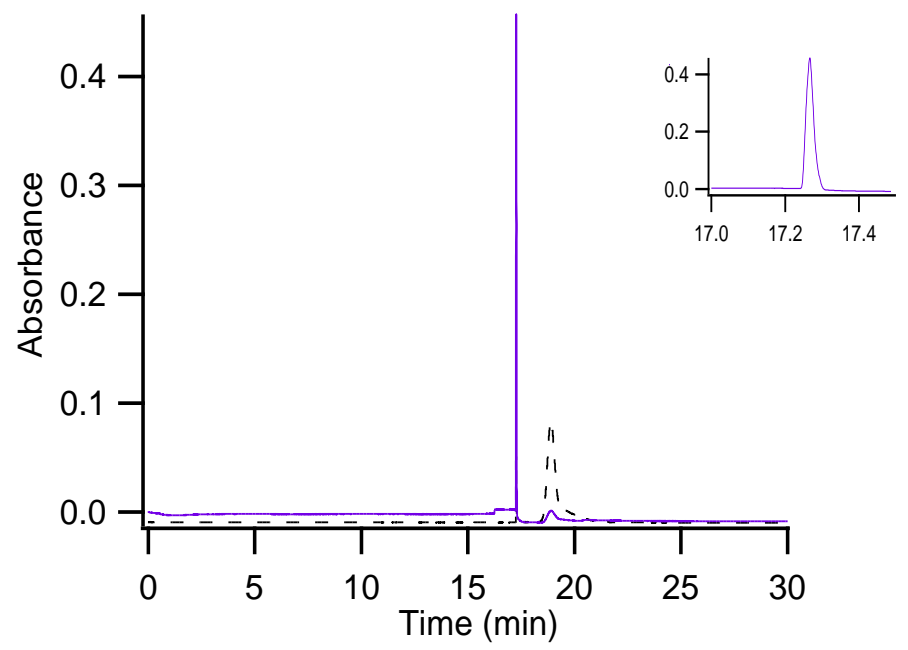

Figure 3.4 UV absorbance signals recorded at 200 (-) and $254 \mathrm{~nm}(---)$ to reveal the presence of myoglobin and MO, respectively, during enrichment with discontinuous buffers $(20 \mathrm{mM})$ of $\mathrm{pH} 4.25$ and 9.75 . Inset displays a magnified view of the myoglobin peak.

However, the migration times of these peaks were found to vary between runs. The mean and standard deviation based on 20 replicates were 21.7 and 4.8 min for myoglobin, and 22.6 and $4.8 \mathrm{~min}$ for MO (Table 3.1). The close similarity in standard deviations suggested that the variability of the migration times was caused predominantly by the EOF. 
Table 3.1 Migration times of myoglobin and MO peaks in 20 runs during enrichment with discontinuous buffers $(20 \mathrm{mM})$ of $\mathrm{pH} 4.25$ and 9.75 .

\begin{tabular}{|c|c|c|c|c|c|}
\hline Run & 1 & 2 & 3 & 4 & 5 \\
\hline $\mathrm{t}_{\mathrm{myo}}(\min )$ & 27.96 & 15.24 & 22.49 & 18.83 & 20.63 \\
\hline$t_{\mathrm{MO}}(\min )$ & 30.05 & 16.86 & 22.59 & 18.31 & 20.98 \\
\hline$\mu_{\mathrm{EOF}}\left(\mathrm{cm}^{2} \mathrm{~V}^{-1} \mathrm{~S}^{-1}\right)$ & $3.59 \mathrm{E}-05$ & $6.39 \mathrm{E}-05$ & $4.77 \mathrm{E}-05$ & 5.89E-05 & $5.13 \mathrm{E}-05$ \\
\hline Run & 6 & 7 & 8 & 9 & 10 \\
\hline $\mathrm{t}_{\mathrm{myo}}(\min )$ & 17.27 & 18.96 & 25.23 & 19.6 & 31.12 \\
\hline $\mathrm{t}_{\mathrm{MO}}(\min )$ & 19.48 & 19.62 & 25.83 & 20.56 & 32.98 \\
\hline$\mu_{\mathrm{EOF}}\left(\mathrm{cm}^{2} \mathrm{~V}^{-1} \mathrm{~S}^{-1}\right)$ & $5.53 \mathrm{E}-05$ & $5.49 \mathrm{E}-05$ & 4.17E-05 & $5.24 \mathrm{E}-05$ & $3.26 \mathrm{E}-05$ \\
\hline Run & 11 & 12 & 13 & 14 & 15 \\
\hline $\mathrm{t}_{\mathrm{myo}}(\min )$ & 20.4 & 22.35 & 18.47 & 21.82 & 23.01 \\
\hline $\mathrm{t}_{\mathrm{MO}}(\min )$ & 21.52 & 21.89 & 19.08 & 22.89 & 25.28 \\
\hline$\mu_{\mathrm{EOF}}\left(\mathrm{cm}^{2} \mathrm{~V}^{-1} \mathrm{~S}^{-1}\right)$ & $5.01 \mathrm{E}-05$ & 4.92E-05 & $5.64 \mathrm{E}-05$ & 4.71E-05 & 4.26E-05 \\
\hline Run & 16 & 17 & 18 & 19 & 20 \\
\hline $\mathrm{t}_{\mathrm{myo}}(\min )$ & 16.09 & 26.91 & 20.24 & 31.66 & 15 \\
\hline $\mathrm{t}_{\mathrm{MO}}(\min )$ & 17.12 & 28.85 & 20.8 & 30.12 & 16.41 \\
\hline$\mu_{\mathrm{EOF}}\left(\mathrm{cm}^{2} \mathrm{~V}^{-1} \mathrm{~S}^{-1}\right)$ & $6.3 \mathrm{E}-05$ & $3.74 \mathrm{E}-05$ & 5.18E-05 & $3.58 \mathrm{E}-05$ & $6.57 \mathrm{E}-05$ \\
\hline \multicolumn{4}{|c|}{ Average for $\mathrm{t}_{\mathrm{myo}}(\mathrm{min})$} & 21.66 & \\
\hline \multicolumn{4}{|c|}{ Standard deviation for $\mathrm{t}_{\mathrm{myo}}$} & 4.82 & \\
\hline \multicolumn{4}{|c|}{ Average for $t_{\mathrm{MO}}(\min )$} & 22.56 & \\
\hline & \multicolumn{3}{|c|}{ Standard deviation for $t_{M O}$} & 4.80 & \\
\hline & \multicolumn{3}{|c|}{ Average for $\mu_{\mathrm{EOF}}\left(\mathrm{cm}^{2} \mathrm{~V}^{-1} \mathrm{~S}^{-1}\right)$} & 4.97E-05 & \\
\hline & \multicolumn{3}{|c|}{ Standard deviation for $\mu_{\mathrm{EOF}}$} & $9.70 \mathrm{E}-06$ & \\
\hline
\end{tabular}


Presumably one would determine the electro-osmotic mobility based on the migration time of the MO. However, this was not feasible in this case due to the EOF in a DLPC modified capillary was previously determined to vary by $\mathrm{pH}$.[2] Thus in the discontinuous buffer system, EOF does not keep a constant value through the capillary, but has one value in acidic buffer and another value in basic buffer.

For $20 \mathrm{mM}$ pH 9.75 ammonium acetate buffer, EOF can be measured by Equation 2.1. As shown in Figure 3.5 A, the time of MO peak is $8.35 \mathrm{~min}$, so the EOF is $1.3 \times 10^{-4} \mathrm{~cm}^{2} \mathrm{~V}^{-1} \mathrm{~s}^{-1}$. For $20 \mathrm{mM}$ pH 4.25 ammonium acetate buffer, the sequential injection method was used to determine the EOF. Three MO peak time are 15.46, 17.58, and $19.71 \mathrm{~min}$, and the EOF is $2.5 \times 10^{-7} \mathrm{~cm}^{2} \mathrm{~V}^{-1} \mathrm{~s}^{-1}$ (Figure $3.5 \mathrm{~B}$ ). In other words, a faster EOF occurred at the beginning of the run when the capillary was mostly filled with the $\mathrm{pH} 9.75$ buffer, and a slower EOF occurred at the end of the run when the capillary was mostly filled with $\mathrm{pH} 4.25$ buffer. 

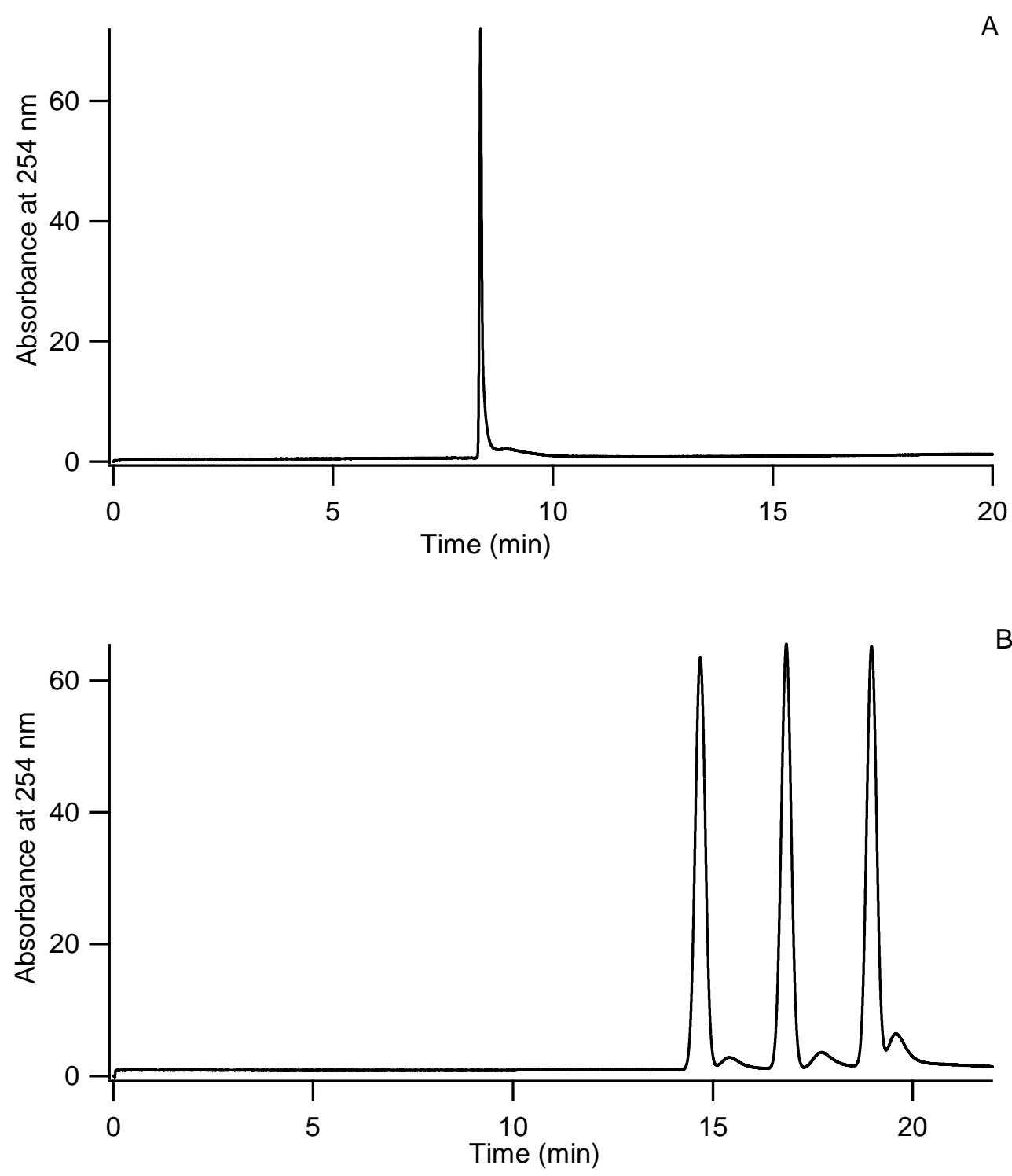

Figure 3.5 (A) UV absorbance signal recorded at $254 \mathrm{~nm}$ to measure EOF in $20 \mathrm{mM}$ pH 9.75 ammonium acetate buffer; (B) UV absorbance signal recorded at $254 \mathrm{~nm}$ to measure EOF in $20 \mathrm{mM} \mathrm{pH} 4.25$ ammonium acetate buffer. 
As the run proceeded, the EOF gradually slowing itself was due to the increase of the acidic buffer in the capillary. As a result, the exact NRB mobility could not be determined simply by subtracting the EOF. Instead, the difference in migration times $\left(t_{\mathrm{MO}^{-}} \mathrm{t}_{\mathrm{myo}}\right)$ was determined for each of the 20 trials. An average of 0.9 min was obtained, with a standard deviation of $1.0 \mathrm{~min}$. (data not shown) Such results at least allowed us to conclude a cathodic, near-zero, NRB movement, which in turn validated the simulated small cathodic NRB movement observed in Figure 3.2 C.

As a conclusion, a discontinuous buffer system, $20 \mathrm{mM}$ ammonium acetate buffer $(\mathrm{pH} 4.25)$ and $20 \mathrm{mM}$ ammonium acetate buffer ( $\mathrm{pH} 9.75)$, was chosen for simulation and experimental setup. Both the simulation and experimental result showed a cathodic NRB movement in this discontinuous buffer system, and thus the accuracy of simulation was validated.

\subsection{Ion Migration Behaviour Determined Using UV-Absorbing lons}

Up until this point, we focused primarily on the $\mathrm{pH}$ profile of the discontinuous buffers in the simulated results obtained from Simul 5. In this section, the purpose of this work is to visualize the migration of buffer ions, we will examine the migration of acetate and ammonium ions in the simulation results during protein enrichment, and compare them to experimental data obtained using UV-absorbing buffers ions, $5 \mathrm{mM}$ benzoate ( $\mathrm{pH} 4.25$ ) and $5 \mathrm{mM}$ benzylamine ( $\mathrm{pH} 9.75)$ to reveal the migration of acetate and ammonium ions respectively. 
The experimental setup shows in Figure 3.6. First the capillary was filled with basic buffer, and then the acidic buffer was injected to push the $\mathrm{pH}$ junction into the middle of the capillary. After $600 \mathrm{sec}$ of voltage application, 30 mbar pressure was applied to push the $\mathrm{pH}$ junction past the detector. The value of $5 \mathrm{mM}$ was chosen for UV-absorbing buffers since this concentration was high enough to get the absorbing signal by UV detector. And $600 \mathrm{sec}$ was chosen since it was long enough to examine the migration behaviour.

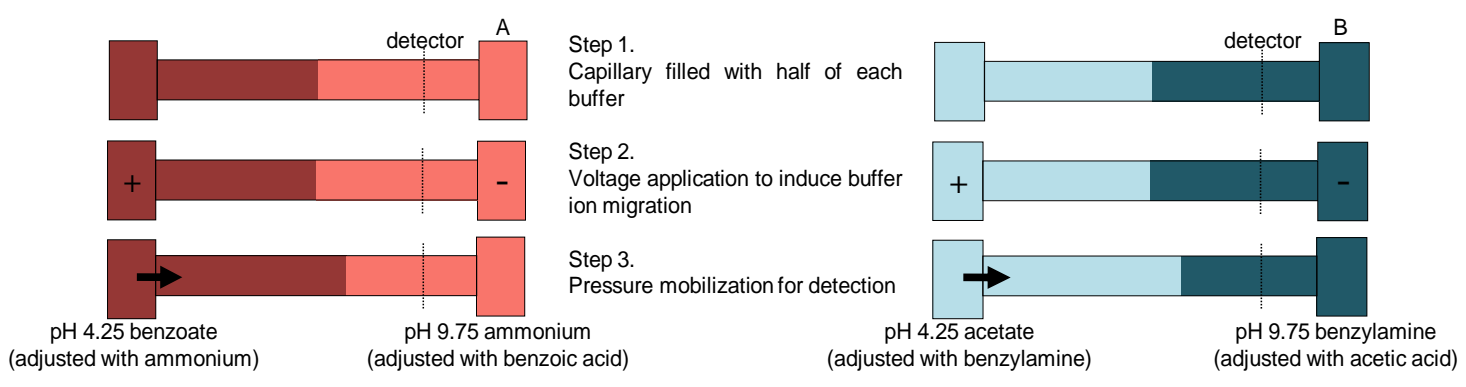

Figure 3.6 (A) Experimental setup to determine the migration of benzoate ions in discontinuous buffers during voltage application. (B) Experimental setup to determine the migration of benzylamine ions in discontinuous buffers during voltage application.

The simulation setup of UV-absorbing ions benzoate/benzylamine is illustrated below. To reveal the migration of acetate ion by benzoate ion, the TE consisting $5 \mathrm{mM}$ benzoic acid and $2.58 \mathrm{mM}$ ammonium represent the $\mathrm{pH} 4.25,5 \mathrm{mM}$ ammonium benzoate buffer as anolyte. The LE consisting $5 \mathrm{mM}$ ammonium and $1.14 \mathrm{mM}$ benzoic acid represent the $\mathrm{pH} 9.75,5 \mathrm{mM}$ ammonium benzoate buffer as catholyte. To reveal the migration of ammonium ion by benzylamine ion, the TE consisting $5 \mathrm{mM}$ acetic acid and $1.14 \mathrm{mM}$ benzylamine represent the $\mathrm{pH} 4.25,5 \mathrm{mM}$ benzylamine acetate buffer as anolyte. The LE consisting $5 \mathrm{mM}$ benzylamine and $1.32 \mathrm{mM}$ acetic acid 
represent the $\mathrm{pH} 9.75,5 \mathrm{mM}$ benzylamine acetate buffer as catholyte. The initial injection site was $20 \mathrm{~mm}$, which differed from previous setup (10 mm) for simulation process. This change of setup helps to observe the ion concentration evenly on both sides of $\mathrm{pH}$ junction.
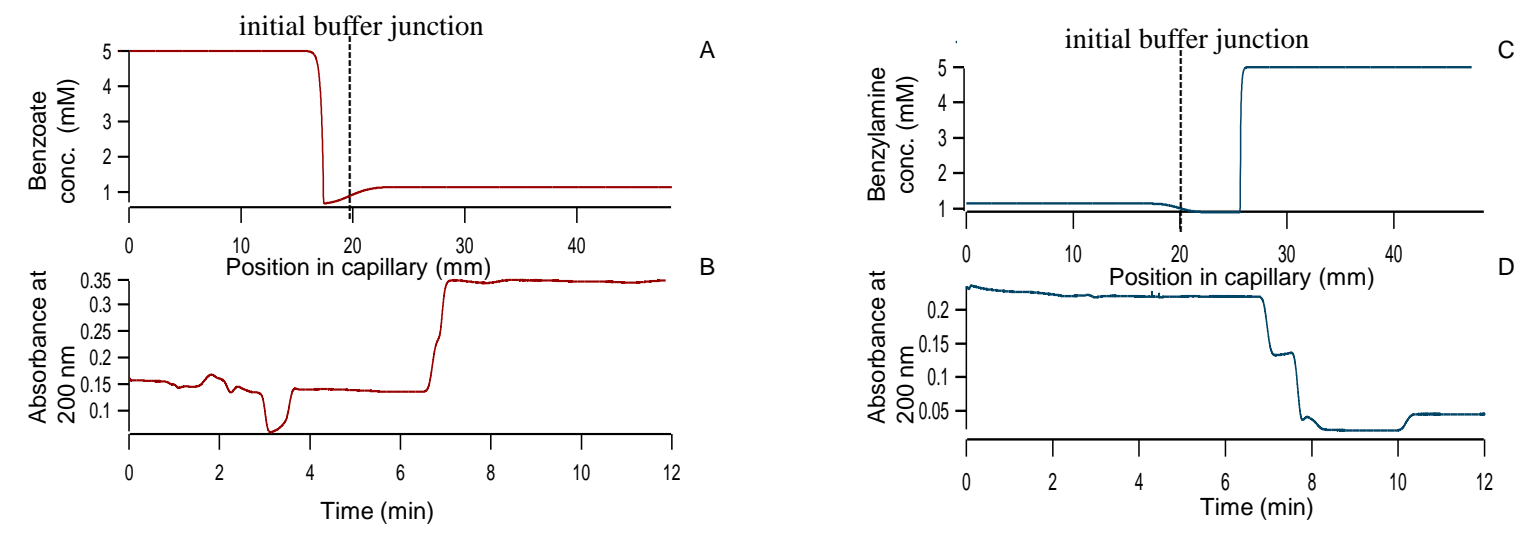

Figure 3.7 (A) Simul 5 results predicting the location of benzoate at $600 \mathrm{sec}$. Initial buffer junction at $20 \mathrm{~mm}$; (B) Experimental results obtained after 10 min of voltage application under the setup illustrated in Figure 3.6 A. (C) Simul 5 results predicted the location of benzylamine at $600 \mathrm{sec}$. Initial buffer junction at $20 \mathrm{~mm}$; (D) Experimental results obtained after $600 \mathrm{sec}$ of voltage application under the setup illustrated in Figure 3.6 B.

The simulation and experimental results are shown in Figure 3.7. For the migration of acidic buffer, the simulation result showed it moved in the anodic direction (Figure $3.7 \mathrm{~A}$ ), and the experimental result (Figure $3.7 \mathrm{~B}$ ) resembled the simulation result. Comparing the ammonium benzoate buffer $(\mathrm{pH} 4.25)$ with the ammonium acetate buffer $(\mathrm{pH} 4.25)$ that we used in the protein enrichment process, the benzoate ion migrated to the opposite direction compared to acetate ion. The reason is the $\mathrm{pKa}$ 
value and the mobility difference between benzoate and acetate. For the migration of basic buffer, both the simulation and experimental results demonstrated a cathodic direction movement of benzylamine (Figure $3.7 \mathrm{C}$ and $\mathrm{D}$ ). Also, the migration of benzylamine was at the same trend as ammonium.

In conclusion, the experimental results of benzoate/benzylamine overall resembled the simulation results, this confirms the accuracy of Simul 5 in predict the ion migration behavior. This again proves Simul 5 is an excellent tool to predict the ions migration behaviour, the next step is to utilize simulation to get a better understanding about the effects of buffer ions on the NRB movement.

\subsection{Discontinuous Buffer pH}

Our research on discontinuous buffer systems was initially conducted with $\mathrm{pH}$ 4.75 and $\mathrm{pH} 9.25$ ammonium acetate buffers,[3] and more recently with $\mathrm{pH} 4.25$ and $\mathrm{pH}$ 9.75 ammonium acetate buffers. $[2,4,5]$ The $\mathrm{pH}$ values of these buffers were selected to generate equal concentrations of $\left[\mathrm{H}^{+}\right]$and $\left[\mathrm{OH}^{-}\right]$, and thus, a near-zero NRB movement was expected. Additional buffers examined previously included phosphate, TRIS, formate and citrate. Successful myoglobin enrichment was only observed for two additional buffer pairs, $\mathrm{pH} 3.75$ ammonium formate with $\mathrm{pH} 9.25$ ammonium formate, and pH 4.75 TRIS acetate with pH 8.0 TRIS acetate.[6] However, the NRB movements in these buffers were not determined at that time. Thus, in this section, a systematic study on the effect of buffer $\mathrm{pH}$ on the NRB movement is presented. $20 \mathrm{mM}$ ammonium acetate buffer with various $\mathrm{pH}$ combinations were chosen to build discontinuous buffer systems. Both simulation and experimental results are presented. 
The $\mathrm{pH}$ combination of $4.75 / 9.75$ was chosen as an example to illustrate the simulation and experimental setup. Figure 3.8 is a demonstration of the simulation setup for this $\mathrm{pH}$ combination. The initial $\mathrm{pH}$ junction was setup at $10 \mathrm{~mm}$ because of the same reason mentioned in chapter 2. To form $20 \mathrm{mM}$ ammonium acetate buffer (pH 4.75), $20 \mathrm{mM}$ acetic acid with $4.73 \mathrm{mM}$ ammonium hydroxide was input as the anolyte (LE), whereas $20 \mathrm{mM}$ ammonium hydroxide and $4.73 \mathrm{mM}$ acetic acid was entered as the catholyte (TE) to form $20 \mathrm{mM}$ ammonium acetate buffer ( $\mathrm{pH}$ 9.75). To simplify the system, the myoglobin plug was not put into the simulation process and it would not affect the mobility of NRB.

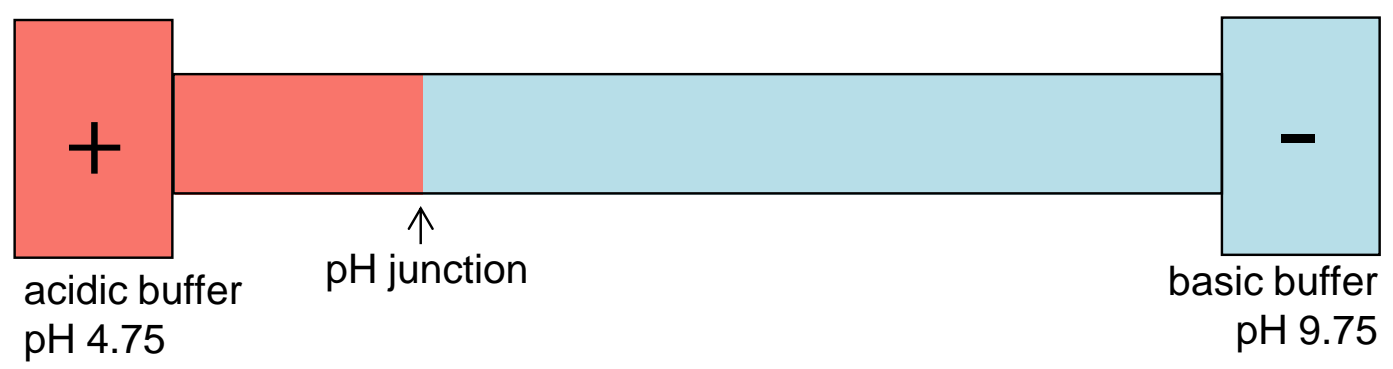

Figure 3.8 A schematic illustrating the capillary content at the starting condition of the computer simulation.

As shown in Figure 3.9 A, a pH step-junction of $\mathrm{pH} 4.75$ and 9.75 was formed in the initial simulation setup. An interesting observation is that the initial ionic conductivity in the acidic buffer is higher than basic buffer. Figure 3.9 B and C shows the simulation results at 100 and $1000 \mathrm{sec}$. The conductivity kept higer in the acidic buffer than in the basic buffer. A noteworthy observation is that the NRB moved 
towards anodic direction, which is the opposite direction comparing with NRB movement under the $\mathrm{pH}$ combination of 4.25/9.75.

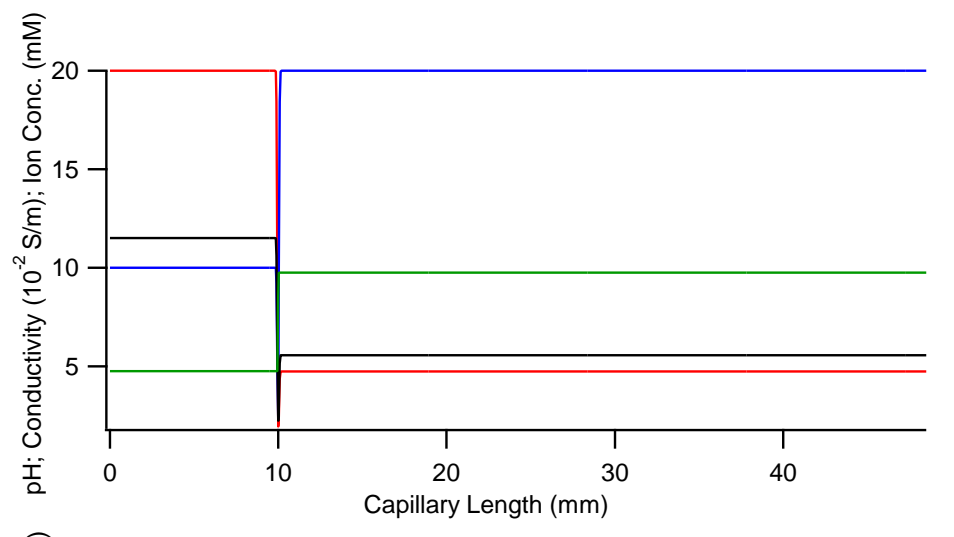

A

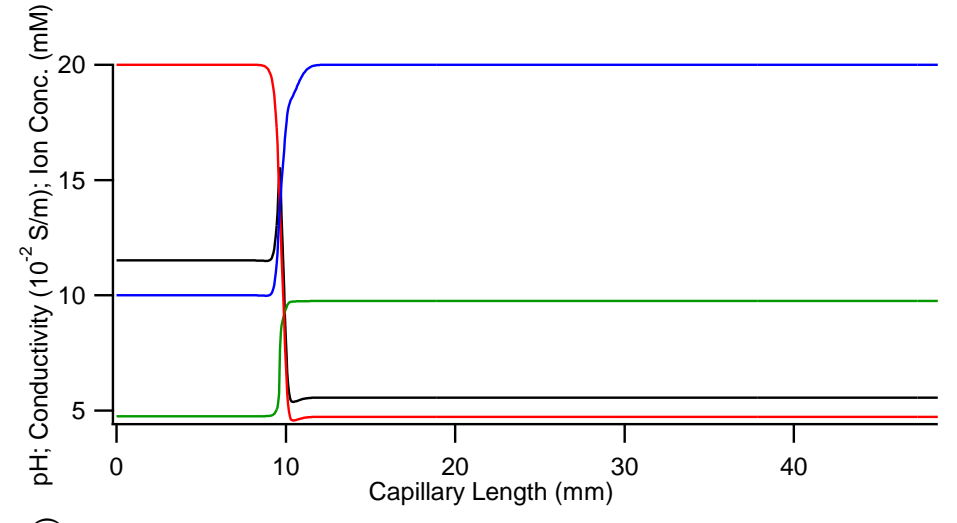

B

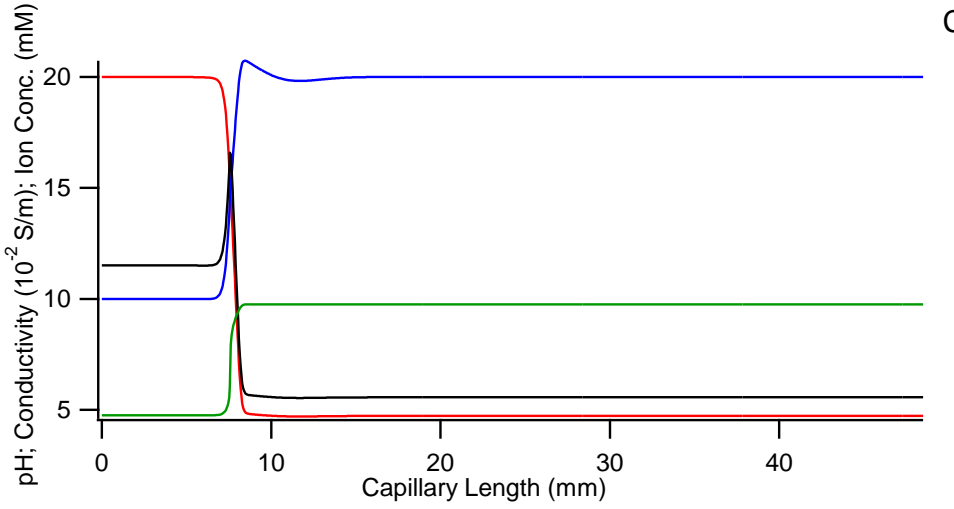

Figure 3.9 Simulated conductivity, $\mathrm{pH}$ and ion concentration profiles at: $(\mathrm{A})$ time $=0$ sec, (B) time $=100 \mathrm{sec}$, and (C) time $=1000 \mathrm{sec}$. Acetate ion conc. $(-)$, conductivity (一), ammonium ion conc. (-), and $\mathrm{pH}(-)$. 
To validate the simulation results, a protein enrichment experiment was performed with the same discontinuous buffer composition. The experimental conditions were set as those in Figure 3.3, with the only variable being the $\mathrm{pH}$ of the two buffers (from $4.25 / 9.75$ to $4.75 / 9.75$ ). Figure 3.10 is the experimental result, where the purple line stands for the peak of enriched protein at $200 \mathrm{~nm}$ and the dash line stands for the peak of MO at $254 \mathrm{~nm}$. This determined an anodic NRB movement, which validated the simulated anodic NRB movement in Figure 3.9. Significantly, the reversed direction of NRB movement under 4.25/9.75 and 4.75/9.75 confirmed the importance of understanding the migration behaviour of discontinuous buffers during protein enrichment. So our next step is to test the movement of NRB under various $\mathrm{pH}$ combinations.

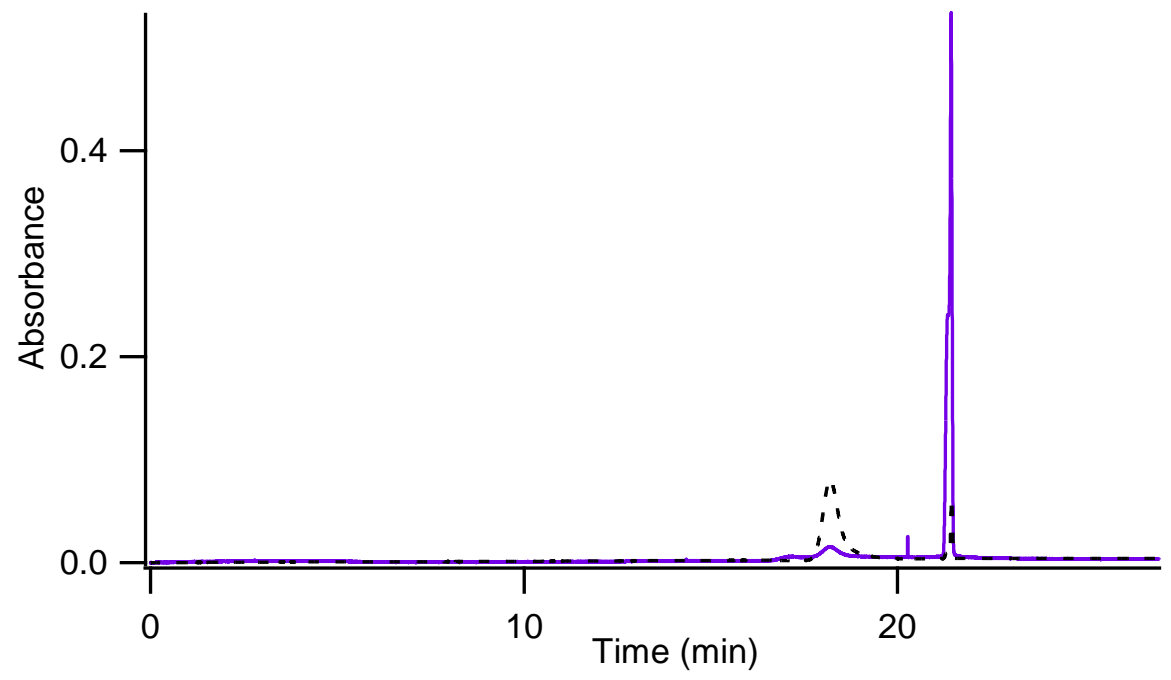

Figure 3.10 UV absorbance signals recorded at 200 (-) and $254 \mathrm{~nm}(---)$ to reveal the presence of myoglobin and MO, respectively, during enrichment with discontinuous buffers of $\mathrm{pH} 4.75$ and 9.75 . 
Table 3.2 lists the various $\mathrm{pH}$ combinations used for our simulations and experiments (the concentrations of the two buffers were kept at $20 \mathrm{mM}$ ). The $\mathrm{pH}$ values were chosen to provide a wide range of $\left[\mathrm{H}^{+}\right] /\left[\mathrm{OH}^{-}\right]$ratios, and thus large differences in the relative ion flux between $\mathrm{H}^{+}$and $\mathrm{OH}^{-}$, in order to induce significantly different $\mathrm{NRB}$ movements.

Table 3.2 $\left[\mathrm{H}^{+}\right] /\left[\mathrm{OH}^{-}\right]$ratios of various discontinuous buffer combinations.

\begin{tabular}{ccccc}
\hline Acid buffer pH & Basic buffer $\mathrm{pH}$ & {$\left[\mathrm{H}^{+}\right]$} & {$\left[\mathrm{OH}^{-}\right]$} & {$\left[\mathrm{H}^{+}\right] /\left[\mathrm{OH}^{-}\right]$} \\
\hline 4.25 & 8.75 & $5.6 \mathrm{E}-05$ & $5.6 \mathrm{E}-06$ & 10 \\
4.25 & 9.25 & $5.6 \mathrm{E}-05$ & $1.8 \mathrm{E}-05$ & 3.1 \\
4.25 & 9.75 & $5.6 \mathrm{E}-05$ & $5.6 \mathrm{E}-05$ & 1 \\
4.25 & 10.25 & $5.6 \mathrm{E}-05$ & $1.8 \mathrm{E}-04$ & 0.31 \\
4.75 & 9.75 & $1.8 \mathrm{E}-05$ & $5.6 \mathrm{E}-05$ & 0.31 \\
5.25 & 9.75 & $5.6 \mathrm{E}-06$ & $5.6 \mathrm{E}-05$ & 0.1 \\
5.25 & 10.25 & $5.6 \mathrm{E}-06$ & $1.8 \mathrm{E}-04$ & 0.031 \\
\hline
\end{tabular}

In all simulation results obtained from the various discontinuous buffer combinations, $\mathrm{pH}$ trace profiles are picked and shows in Figure 3.11 A. To illustrate the differences in NRB velocities, the positions of $\mathrm{pH}$ traces at $\mathrm{t}=1000 \mathrm{sec}$ were chosen, with the initial position $(\mathrm{t}=0 \mathrm{sec})$ marked by a dashed line. The $\mathrm{pH}$ traces on the right 
side of the dashed line indicate forward cathodic NRB movements; whereas $\mathrm{pH}$ traces on the left side indicate reverse anodic NRB movements.

To obtain the corresponding experimental data, myoglobin enrichment was conducted with the same list of discontinuous buffers in Table 3.2. In each experimental result, a myoglobin peak along with an MO peak was observed. As discussed, the NRB velocity and the varying electro-osmotic mobility (marked by MO peak) together determined the migration time of the myoglobin peak. To focus on changes in the NRB velocity, the myoglobin signals were shifted in time (the $\mathrm{x}$-axis direction) to align the MO peaks to 0 min (Figure $3.11 \mathrm{~B}$ ). As a result, myoglobin peaks observed before the MO peaks indicate cathodic NRB movements, while myoglobin peaks detected after MO indicate anodic NRB movements. 

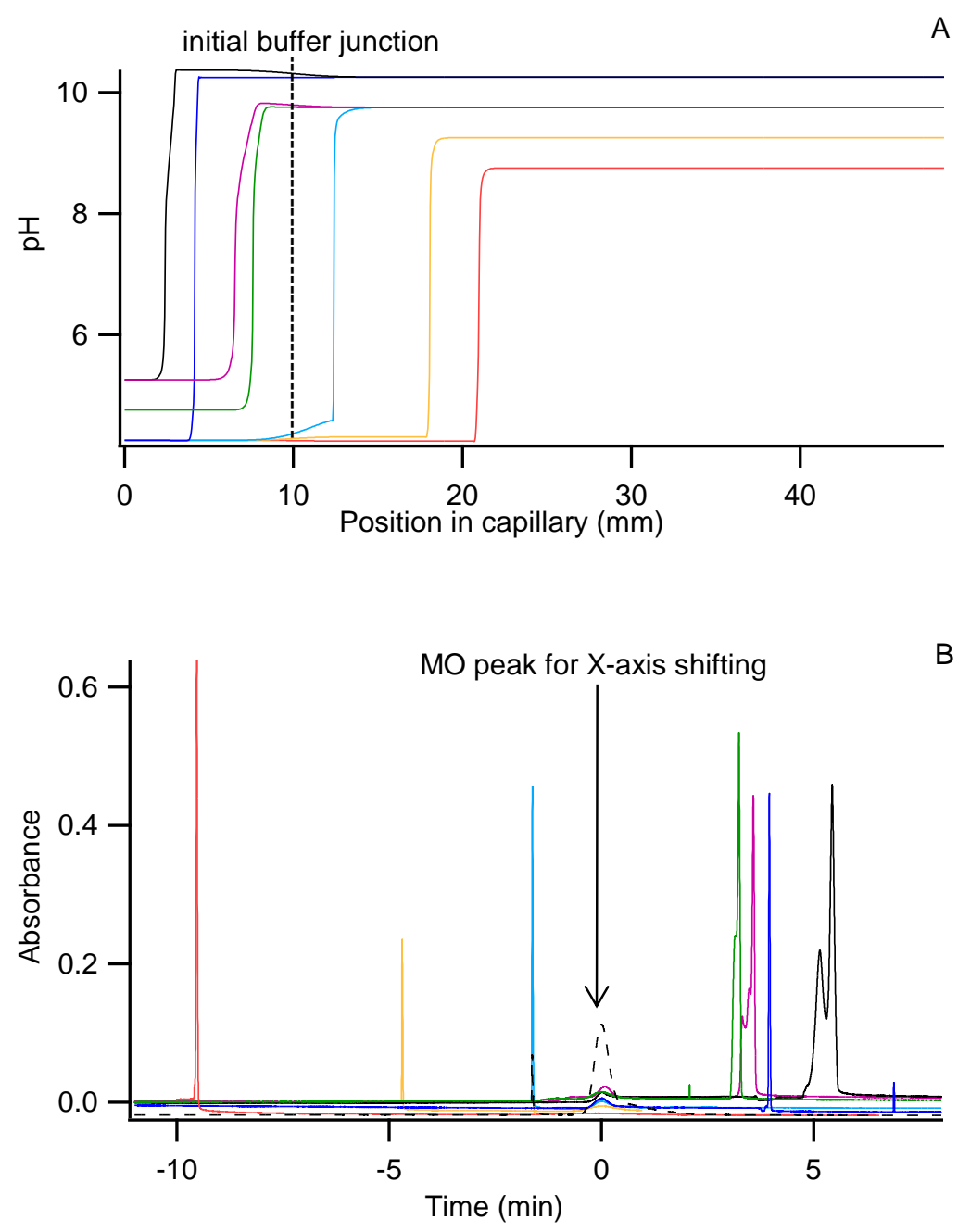

Figure 3.11 (A) Simulated locations of $\mathrm{pH}$ junctions at $1000 \mathrm{sec}$ with discontinuous buffers of various $\mathrm{pH}$ combinations. (B) Experimental results of the enriched myoglobin peaks obtained with discontinuous buffers of various $\mathrm{pH}$ combinations. The traces were aligned to position the MO peaks at $0 \mathrm{~min}$. The $\mathrm{pH}$ values of acidic/basic buffer were: 5.25/10.25 (-), 4.25/10.25 (-), 5.25/9.75 (-), 4.75/9.75 (-), 4.25/9.75 (-), 4.25/9.25 (-), 4.25/8.75 (-), and MO (---).

The most important observation from comparing the simulated and experimental results was the identical order, from most anodic to most cathodic NRB movements. 
This again confirmed that Simul 5 was an excellent tool in predicting the ion migration behaviours during protein enrichment with our discontinuous buffers. Generally, the NRB moved in the cathodic direction when $\left[\mathrm{H}^{+}\right] /\left[\mathrm{OH}^{-}\right]$was larger than 1 , and moved in the anodic direction when $\left[\mathrm{H}^{+}\right] /\left[\mathrm{OH}^{-}\right]$was smaller than 1. Larger NRB movements were observed when the difference between $\left[\mathrm{H}^{+}\right]$and $\left[\mathrm{OH}^{-}\right]$was greater.

The only exception was the $\mathrm{pH} 4.25 / 10.25$ buffer pair, where the NRB velocity was faster than predicted according to the order in $\left[\mathrm{H}^{+}\right] /\left[\mathrm{OH}^{-}\right]$ratio. Likewise, for the buffer pair of $\mathrm{pH} 4.25 / 9.75$, where $\left[\mathrm{H}^{+}\right]$was equal to $\left[\mathrm{OH}^{-}\right]$, a small cathodic $\mathrm{NRB}$ displacement was predicted and observed. Under these two observations where $\mathrm{pH}$ alone could not explain the behaviour, one could attribute the results to the other two parameters that determine $\mathrm{H}^{+}$and $\mathrm{OH}^{-}$flux, namely the local ionic conductivity and mobility of $\mathrm{H}^{+}$and $\mathrm{OH}^{-}$. For example, the conductivity for $\mathrm{pH} 4.25 / 9.75$ buffer pair, according to Figure $3.2 \mathrm{C}$, was lower on the anodic side of NRB than that on the cathodic side, and thus leads to a cathodic NRB movement.

Another factor likely contributed to the observed NRB movements is the mobility of the $\mathrm{H}^{+}\left(350 \mathrm{~m}^{2} \mathrm{~V}^{-1} \mathrm{~s}^{-1}\right)$ is higher than that of $\mathrm{OH}^{-}\left(198 \mathrm{~m}^{2} \mathrm{~V}^{-1} \mathrm{~s}^{-1}\right)$.[7] Figure 3.12 is a demonstration of the movement of $\mathrm{H}^{+}$and $\mathrm{OH}^{-}$inside the capillary with $20 \mathrm{mM}$ discontinuous buffers of $\mathrm{pH}$ composition 4.25/9.75. Upon voltage application, the $\mathrm{H}^{+}$from acidic buffer moved toward $\mathrm{pH}$ junction and encountered the $\mathrm{OH}^{-}$from basic buffer, so a water boundary formed. However, this boundary was not stay at the same position and actually moved toward cathodic direction. This was because the mobility of the $\mathrm{H}^{+}$was higher than that of $\mathrm{OH}^{-}$, which pushed the $\mathrm{pH}$ junction moved 
towards the $\mathrm{OH}^{-}$direction. Thus the different mobility of $\mathrm{H}^{+}$and $\mathrm{OH}^{-}$can be caused the change of the NRB moving direction.

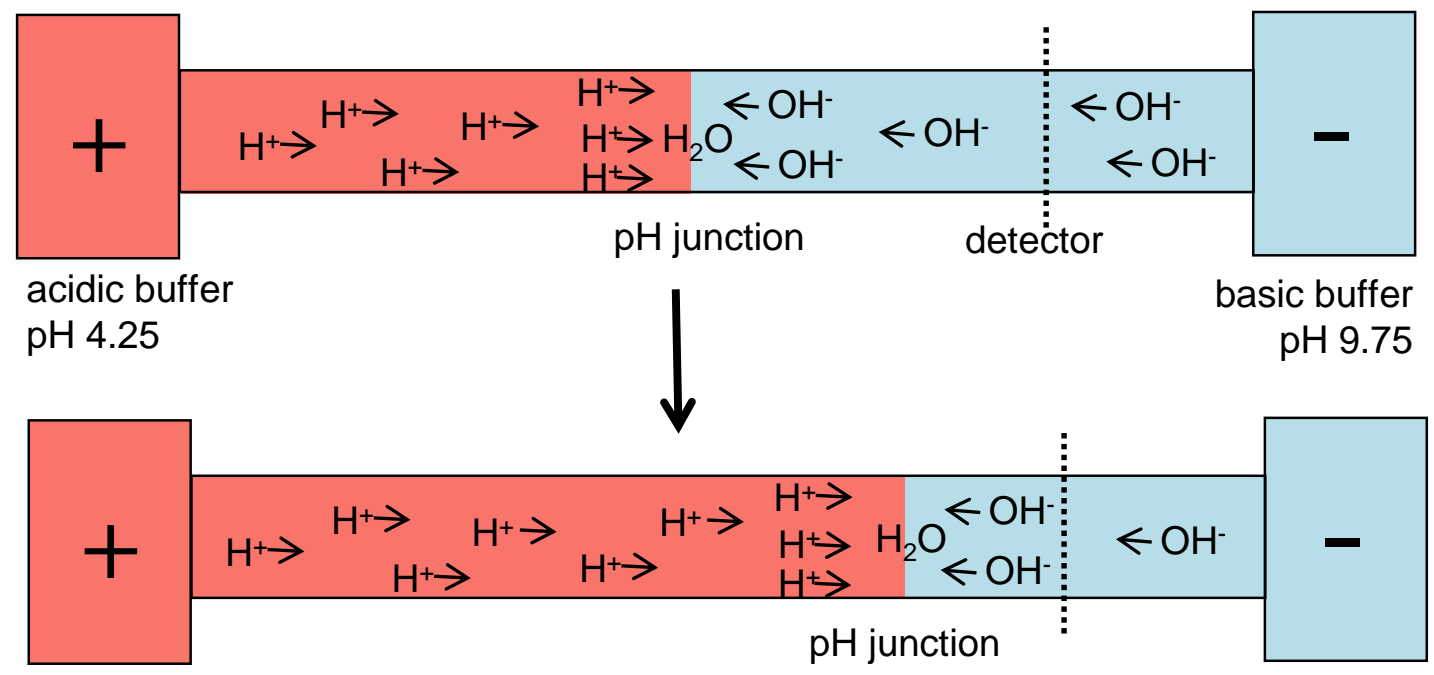

Figure 3.12 A demonstration of the movement of $\mathrm{H}^{+}$and $\mathrm{OH}^{-}$inside the capillary with discontinuous buffers of $\mathrm{pH} 4.25$ and 9.75 .

Other than the NRB movement, another noteworthy observation in Figure $3.11 \mathrm{~B}$ was the different peak shapes of the enriched myoglobin. Sharp, single peaks resulted in four discontinuous buffer combinations, and broad split peaks were observed in three buffer pairs, namely $\mathrm{pH} 4.75 / 9.75,5.25 / 9.75$, and 5.25/10.25. Importantly, Simul 5 also predicted more gradual $\mathrm{pH}$ transitions, at the basic side of the junction, for these three buffer pairs (Figure 3.11 A). Furthermore, the broadening of the $\mathrm{pH}$ junction (green line) coincided with a large drop in conductivity (black line) in all three cases (Figure 3.13 E, F, and G). Hence, we speculated that the proteins were stacked first by the conductivity rise as they approached the junction from the basic buffer, and subsequently focused a second time when they reached the centre of the $\mathrm{pH}$ 
junction, resulting in the observed peak splitting.
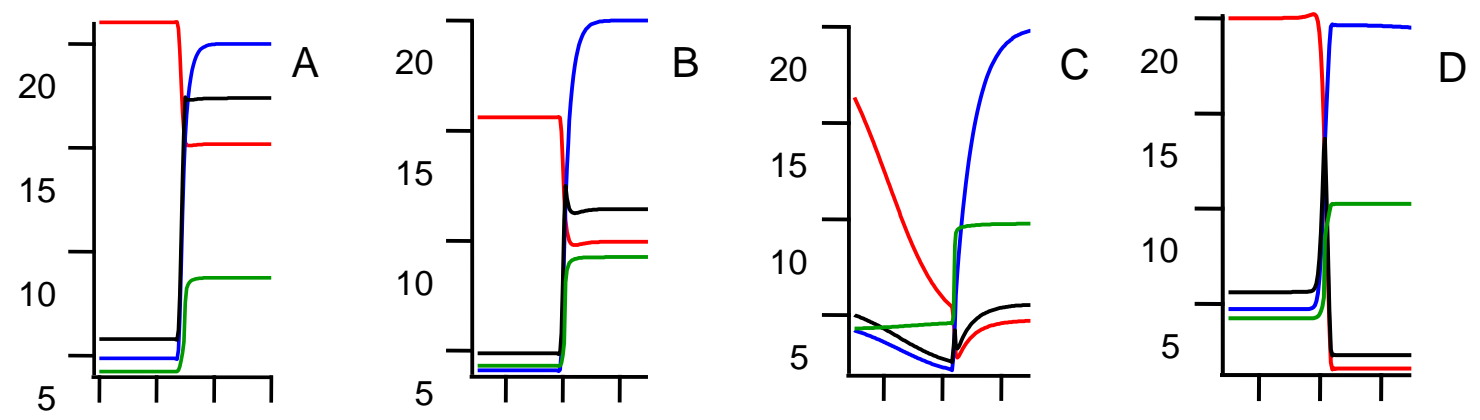

18202224

161820

101214 246
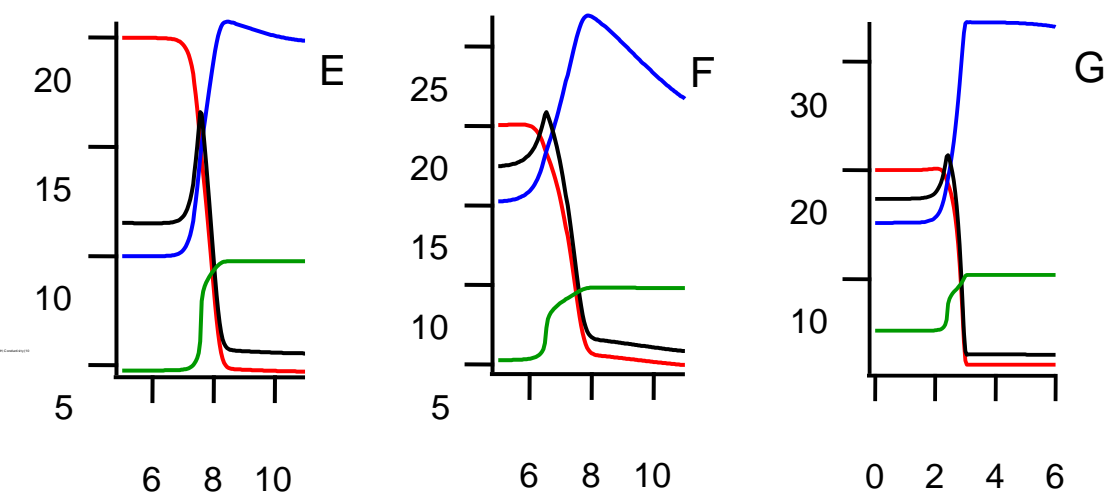

$\begin{array}{lll}6 & 8 & 10\end{array}$

$$
\begin{aligned}
& \begin{array}{lllllll}
6 & 8 & 10 & 0 & 2 & 4 & 6
\end{array} \\
& \text { Capillary Length (mm) }
\end{aligned}
$$

Figure 3.13 Simulation results of discontinuous buffers under various $\mathrm{pH}$ combinations at $\mathrm{t}=1000 \mathrm{sec}$. The $\mathrm{pH}$ values of acidic/basic buffer were: (A) 4.25/8.75, (B) 4.25/9.25, (C) 4.25/9.75, (D) 4.25/10.25, (E) 4.75/9.75, (F) 5.25/9.75, and (G) 5.25/10.25. Panels (A-D) correspond to single myoglobin peaks observed in Figure 3.11 B. Panels (E-G) correspond to split myoglobin peaks observed in Figure 3.11 B. Acetate conc. (-), conductivity (-), ammonium conc. (-), and $\mathrm{pH}(-)$. Computer simulation conditions were same as in Figure 3.11 A. 
In this section, various $\mathrm{pH}$ combinations of discontinuous buffer system have been chosen to study the effect of buffer $\mathrm{pH}$ on the NRB movement. From both the simulation and experimental results, the NRB moved in the cathodic direction when $\left[\mathrm{H}^{+}\right] /\left[\mathrm{OH}^{-}\right]$was larger than 1 , and moved in the anodic direction when $\left[\mathrm{H}^{+}\right] /\left[\mathrm{OH}^{-}\right]$was smaller than 1. The split peak observed in Figure 3.11 illustrated the importance of background buffer ions and the effects they can have on the $\mathrm{pH}$ junction formation. Therefore, additional investigation into the role of the discontinuous buffer ions continues in the next section.

\subsection{Discontinuous Buffer Concentration}

Previous enrichment experiments in our laboratory with discontinuous buffers were typically performed at equal concentrations of acidic and basic buffer, 10 or 20 $\mathrm{mM}$. In this section, the formation of a $\mathrm{pH}$ junction and the movement of a NRB are examined with discontinuous buffers ( $\mathrm{pH} 4.25 / 9.75)$, under various concentrations of acidic/basic buffer: 10/10, 10/50, 50/10, and 50/50 mM.

Simul 5 model were conducted with these four buffer pairs. Figure 3.14 shows the $\mathrm{pH}$ junction locations and profiles after $1000 \mathrm{sec}$ of voltage application. It predicted significant cathodic NRB movements at buffer concentrations (acidic/basic buffer) of 10/10 and 10/50 mM (Figure $3.14 \mathrm{~A}$ and $\mathrm{B}$ ), and near-zero NRB movements at 50/50 and 50/10 mM (Figure 3.14 C and D). 

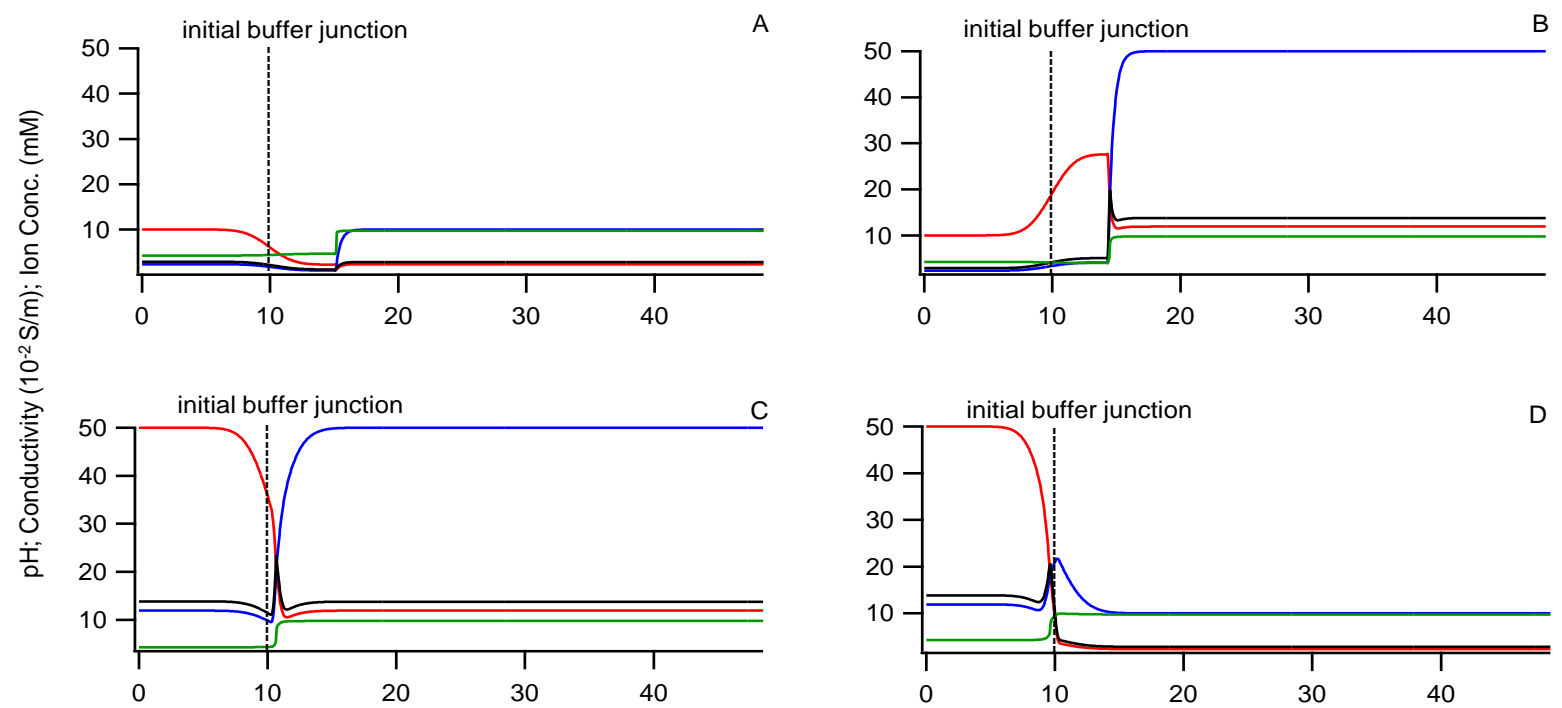

Capillary Length $(\mathrm{mm})$

Figure 3.14 Simulation results of discontinuous buffers under various concentrations (acetate/ammonium, $\mathrm{mM} / \mathrm{mM}$ ) at $\mathrm{t}=1000 \mathrm{sec}$ : (A) 10/10, (B) 10/50, (C) 50/50, and (D) 50/10. Acetate conc. (-), conductivity (-), ammonium conc. (-), and $\mathrm{pH}(-)$. Initial buffer junction at $10 \mathrm{~mm}$, the computer simulation setup same as in Figure 3.1.

Myoglobin enrichment experiments were performed using the same four buffer pairs. An injection of a MO plug was used again to mark the initial position of the buffer interface for EOF determination. Triplicate experiments were conducted. In each case, a myoglobin peak and a MO peak were obtained (Figure 3.15). The NRB moved towards cathodic direction at buffer concentrations (acidic/basic buffer) of 10/10 and 10/50 mM (Figure 3.15 A and B). Near-zero NRB movements observed at 50/50 mM (Figure $3.15 \mathrm{C}$ ), and NRB moved towards anodic direction at 50/10 mM (Figure 3.15 D). 


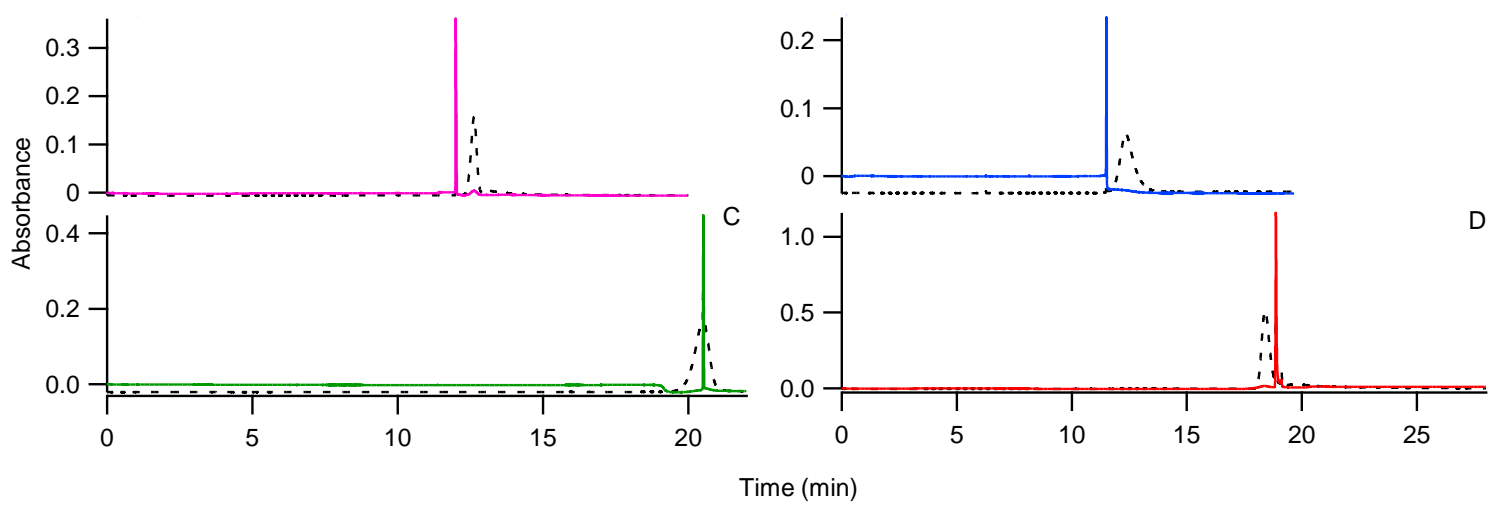

Figure 3.15 Experimental results of myoglobin enrichment under various concentrations (acetate/ammonium, $\mathrm{mM} / \mathrm{mM}$ ) at $\mathrm{t}=1000 \mathrm{sec}$ : (A) 10/10, (B) 10/50, (C) 50/50, and (D) 50/10. The $\mathrm{pH}$ of all discontinuous buffers were held at $\mathrm{pH} 4.25$ and pH 9.75, myoglobin (-), $\mathrm{MO}(---)$.

As in section 3.1, significant run-to-run variability in migration times due to EOF fluctuation was also observed here. To best illustrate the differences in NRB movements obtained from the four buffer pairs, while accounting for run-to-run variability, the migration time differences between $\mathrm{MO}$ and myoglobin $\left(\mathrm{t}_{\mathrm{MO}}-\mathrm{t}_{\mathrm{myo}}\right)$ from triplicates are shown in Figure 3.16. Positive values of $t_{\mathrm{MO}}-t_{\mathrm{myo}}$ indicate cathodic NRB movements, while negative values refer to NRB movements in the anodic direction. 


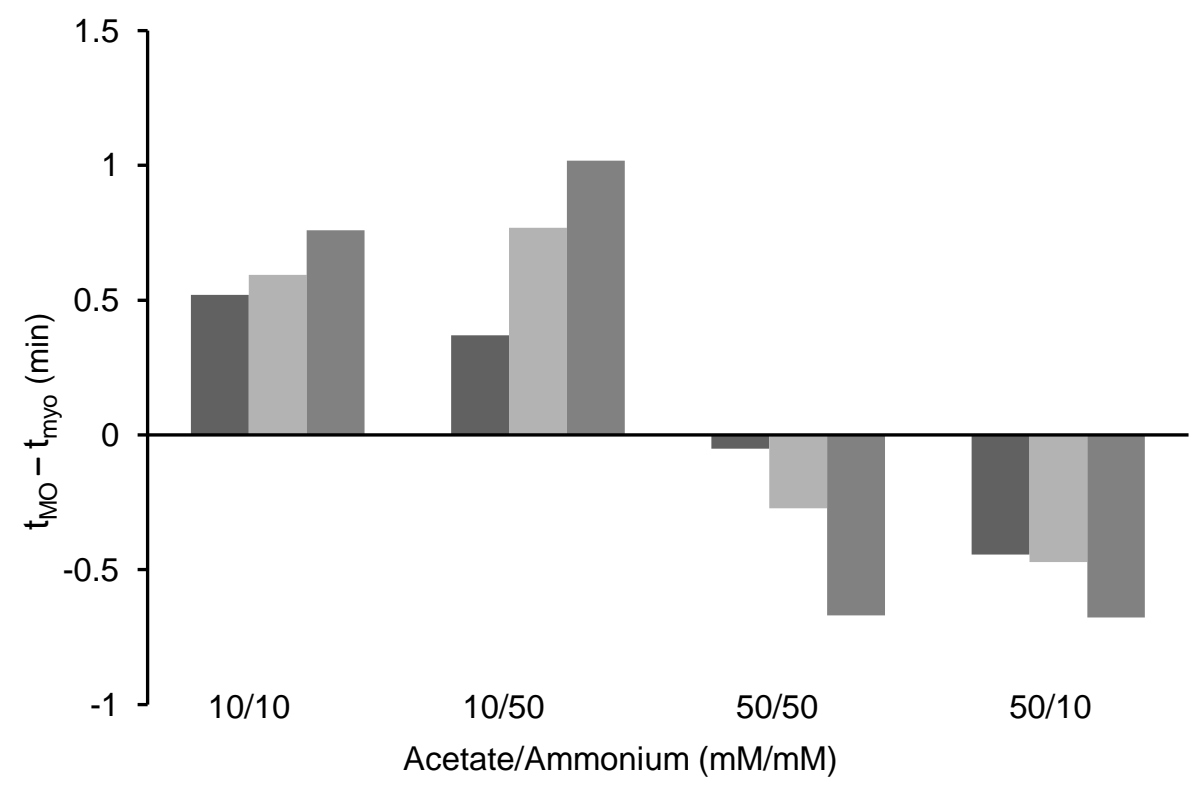

Figure 3.16 The migration time differences between $M O\left(t_{M O}\right)$ and myoglobin $\left(t_{m y o}\right)$ from triplicates (each bar represents one experiment) obtained at various discontinuous buffer concentrations.

Taking run-to-run variation into account, the experimental data generally supported the simulation results. That is, Simul 5 correctly predicted similarly significant cathodic NRB movements with buffer concentrations of 10/10 and 10/50 $\mathrm{mM}$, and relatively slower NRB movements with the concentrations of 50/10 and 50/50 $\mathrm{mM}$. While the direction of NRB movement at $50 / 50 \mathrm{mM}$ was opposite to the simulated direction, such a NRB could be regarded as near-zero where the direction became less significant.

Interestingly, based on the four buffer concentrations studied, it appeared that the NRB movement was mainly determined by the concentration of the acetate, and less affected by the concentration of the ammonium. After reviewing the full Simul 5 data, 
the conductivity profile near the $\mathrm{pH}$ junction appeared to explain the NRB movements observed in Figure 3.14. In the buffer pairs of $10 / 10$ and $10 / 50 \mathrm{mM}$, the conductivity on the anodic (acid) side of the $\mathrm{pH}$ junction was lower, and thus promoted higher $\mathrm{H}^{+}$flux and cathodic NRB movements. In the $50 / 50 \mathrm{mM}$ buffer pair, the conductivity profile was symmetrical across the $\mathrm{pH}$ junction, and a negligible NRB movement was obtained. Finally, for the 50/10 mM buffer pair, a higher conductivity was obtained on the anodic side, which resulted in an anodic, albeit very small, NRB movement.

In summary, by comparing the changes in NRB movements influenced by buffer $\mathrm{pH}$ (Figure 3.11) and buffer concentrations (Figure 3.14 and Figure 3.15), one can generalize that the buffer $\mathrm{pH}$ is a more effective parameter in manipulating and control the NRB compared to buffer concentration.

\subsection{Protein Enrichment and Purification from Urea}

\subsubsection{Urea Removal by Discontinuous Buffers System}

The above experimental and simulation results provide the information for one to understand and control the NRB movement in discontinuous buffers. In this section, it is illustrated how a fast moving NRB can actively mobilize the enriched proteins away from the original sample zone, which can be beneficial for purifying samples containing unwanted background molecules that bear a neutral net charge.

For illustration, urea will be used as a model neutral background molecule. It is a common protein denaturant that unfolds proteins by disrupting the non covalent interactions, $[8,9]$ and can be used to elute affinity-captured proteins.[10] However, the 
presence of urea can suppress the mass spectral signals of proteins, likely due to a decrease of evaporation efficiency.[11] Solid phase capture of proteins and peptides is the most common approach of urea removal.[12-14] Herein, a non sorptive-based, submicroliter volume purification is proposed by performing protein enrichment with discontinuous buffers that generate a moving NRB. Such NRB movement is expected to carry the enriched protein molecules far away from the unwanted neutral background present in the initial sample zone.

The sample consisted of $10 \mathrm{ng} \mu \mathrm{L}^{-1}$ myoglobin and $1 \mathrm{M}$ urea, prepared in the basic buffer. It was injected to fill the capillary at the beginning of the run, to provide an injection volume of $c a .1 \mu \mathrm{L}$ (Figure $3.17 \mathrm{~A}$ ). In this setup, an anodic NRB movement was required to move the enriched myoglobin away from the sample zone. Based on the results in Figure 3.11, the largest anodic NRB movement was recorded with acidic buffer at $\mathrm{pH} 5.25$ and basic buffer at $\mathrm{pH} 10.25$, and thus they were selected for this experiment (concentration at $20 \mathrm{mM}$ ). 

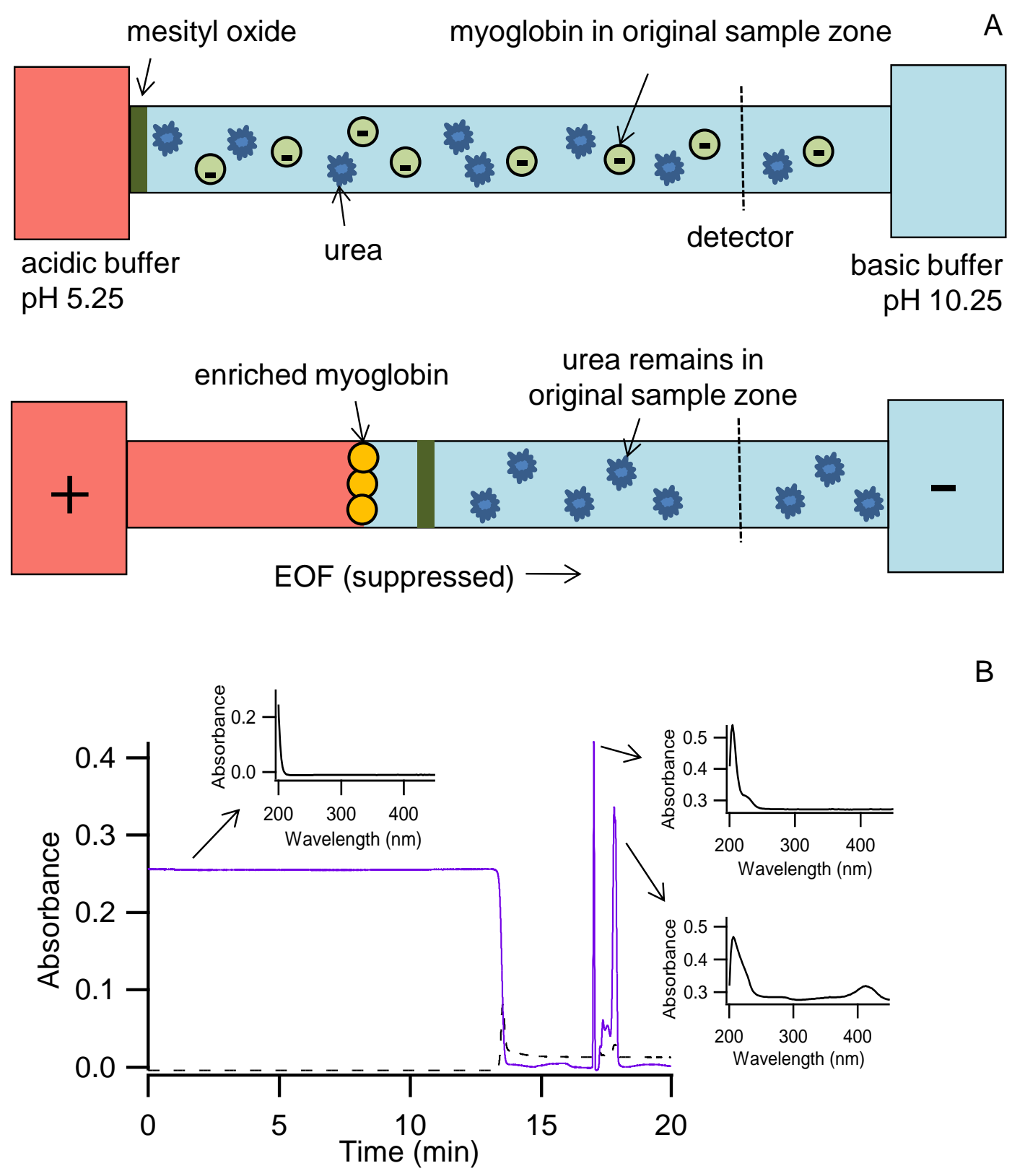

Figure 3.17 (A) Schematics illustrating the experimental setup and proposed ion migration behaviours during myoglobin enrichment and simultaneous urea removal. (B) UV absorbance signals at $200(-)$ and $254 \mathrm{~nm}(---)$ during the experiment. Insets display the UV absorption spectra of the indicated regions. 
Figure 3.17 B displays the UV absorption signal recorded during the enrichment and purification. Urea, at high concentration, absorbs significantly at $200 \mathrm{~nm}$, and was detected as a long rectangular plug between 0-13 min as the capillary content was mobilized by the residual EOF. Subsequently, two peaks were recorded, at approximately 17 and 18 min. To help determine their identity, UV absorption spectra were collected and are shown as insets in Figure $3.17 \mathrm{~B}$. The characteristic heme absorption at $408 \mathrm{~nm}$ indicated the second peak at $18 \mathrm{~min}$. as myoglobin. Hence, a 5 min separation between the myoglobin peak and the urea zone resulted, which was estimated to be roughly $250 \mathrm{~nL}$ in volume. This large separation was highly advantageous later when performing fraction collection for offline MALDI MS analysis. However, by comparing the first peak $(17 \mathrm{~min})$ to the spectra of urea (0-13 $\mathrm{min})$ and myoglobin $(18 \mathrm{~min})$, it seems like that the first peak at $17 \mathrm{~min}$ does not belong to urea or myoglobin. Thus next section is to identify of this unknown peak.

\subsubsection{Identification of the Unknown Peak}

To determine the origin of the first peak at 17 min. Blank experiments were conducted without the presence of myoglobin. The experimental setup is shown in Figure 3.18. The same discontinuous buffer system was used $(20 \mathrm{mM}$ acidic buffer at $\mathrm{pH} 5.25$ and $20 \mathrm{mM}$ basic buffer at $\mathrm{pH}$ 10.25). First the capillary filled with urea presented basic buffer, then inject a small band of neutral marker, MO, to label initial $\mathrm{pH}$ junction. The second step was upon the voltage application, the urea moved away from NRB. 
Step 1.

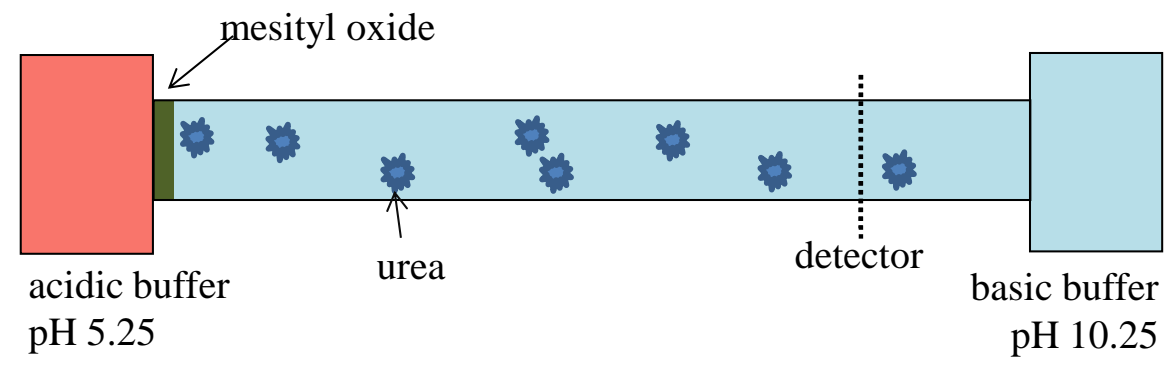

Step 2.

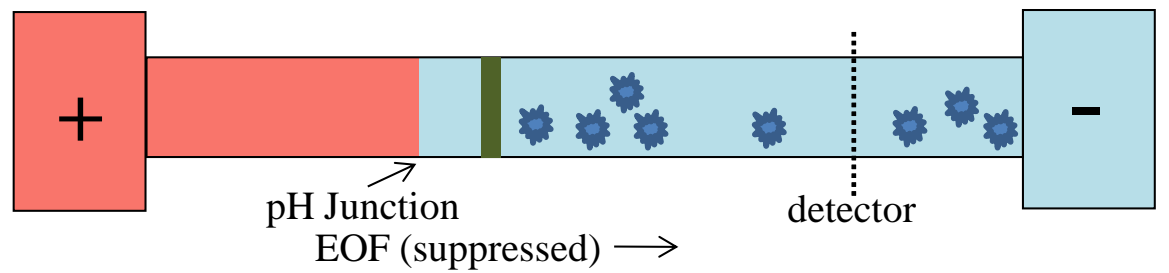

Figure 3.18 Experimental setup to determine the movement of $1 \mathrm{M}$ urea using discontinuous buffers: $20 \mathrm{mM}$ acidic buffer ( $\mathrm{pH} 5.25)$ and $20 \mathrm{mM}$ basic buffer $(\mathrm{pH} 10.25)$.

The experimental results of urea sample in discontinuous buffers at $200 \mathrm{~nm}$ and $214 \mathrm{~nm}$ is shown in Figure 3.19. After a large urea plug shown up, a sharp unknown peak was observed (around $20 \mathrm{~min}$ ) at $200 \mathrm{~nm}$. Interestingly at $214 \mathrm{~nm}$ wavelength, the unknown peak still existed while the urea plug disappeared. Therefore, this unknown peak came from the urea sample, but it was not the urea. 


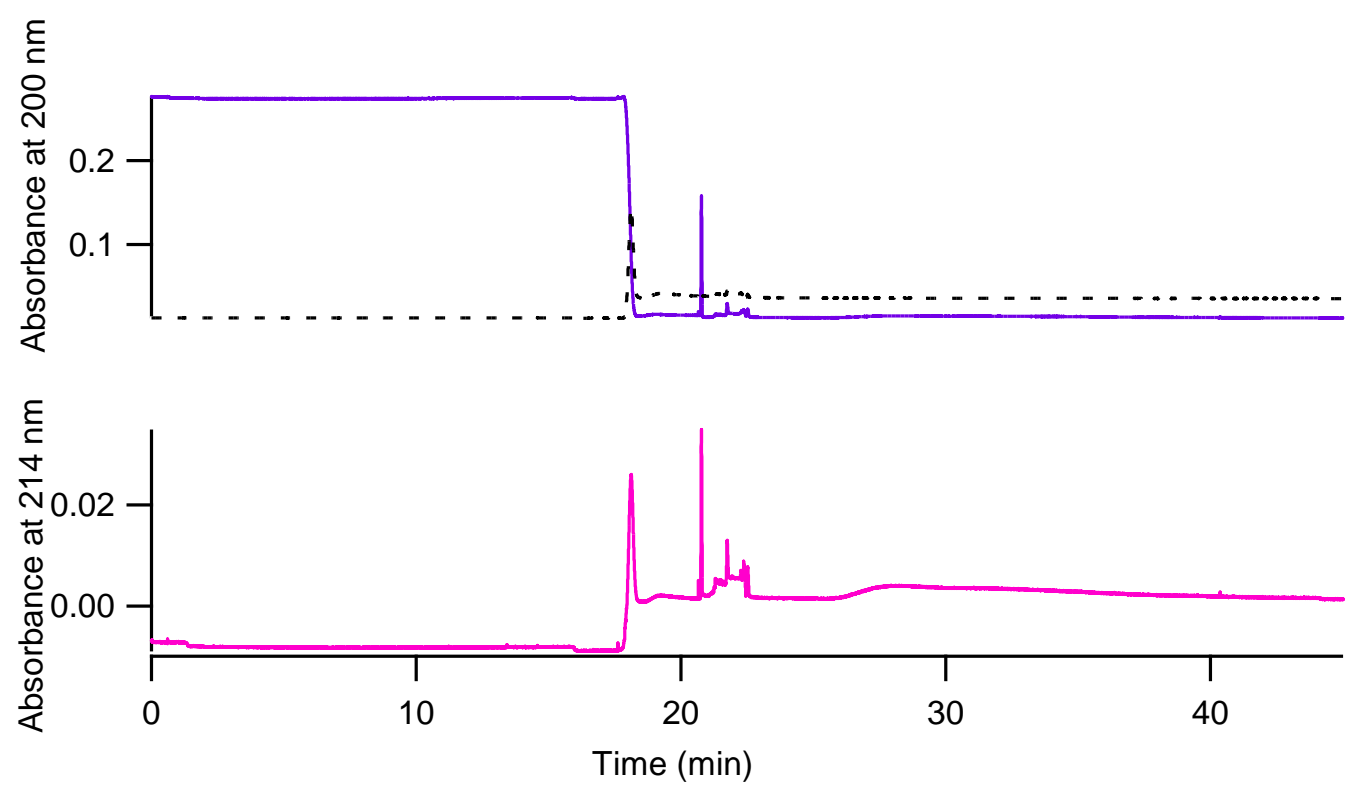

Figure 3.19 Experimental results of urea sample in discontinuous buffers at $200 \mathrm{~nm}$ and $214 \mathrm{~nm}$ during $30 \mathrm{kV}$ voltage application, MO (---) marked the initial buffer junction.

In addition to above blank experiment, four different lots of urea, BCBD7141V, 057K01321, 109K00821 (Sigma) and 41058130 (EM Science), have been used to confirm the blank experimental results. Similar peaks as the one at 20 min in Figure 3.19 were observed in three cases, with varying peak heights and widths. This indicated that the signal likely originated from impurities or degradation products in the reagents.

\subsubsection{MALDI MS Analysis}

After successful removal of urea from enriched protein by $\mathrm{CE}$, to illustrate the benefit of our protein enrichment and purification technique, offline MALDI MS analysis was conducted. Following protein enrichment, one end of the capillary was repositioned to outside of the CE instrument (shown in Figure 2.3 in chapter 2). 
Pressure was applied to push the capillary content out of the capillary as fractions of ca. $40 \mathrm{~nL}$ droplets. These droplets were spotted onto the MALDI MS target predeposited with CHCA.

The mass spectrum obtained from the fraction that contained most of the myoglobin is shown as the black trace in Figure 3.20. For comparison, an untreated sample consisting of $100 \mathrm{ng} \mu \mathrm{L}^{-1}$ myoglobin and $1 \mathrm{M}$ urea was spotted from a capillary in the same way for MS analysis (shown as the red trace in Figure 3.20). Despite the higher concentration, the untreated sample resulted in lower MS signal intensities. This illustrated that the enrichment and purification of myoglobin was successful by our technique. It also facilitated the subsequent offline MALDI MS analysis, and substantial improvement in the quality of the mass spectrum was evident.

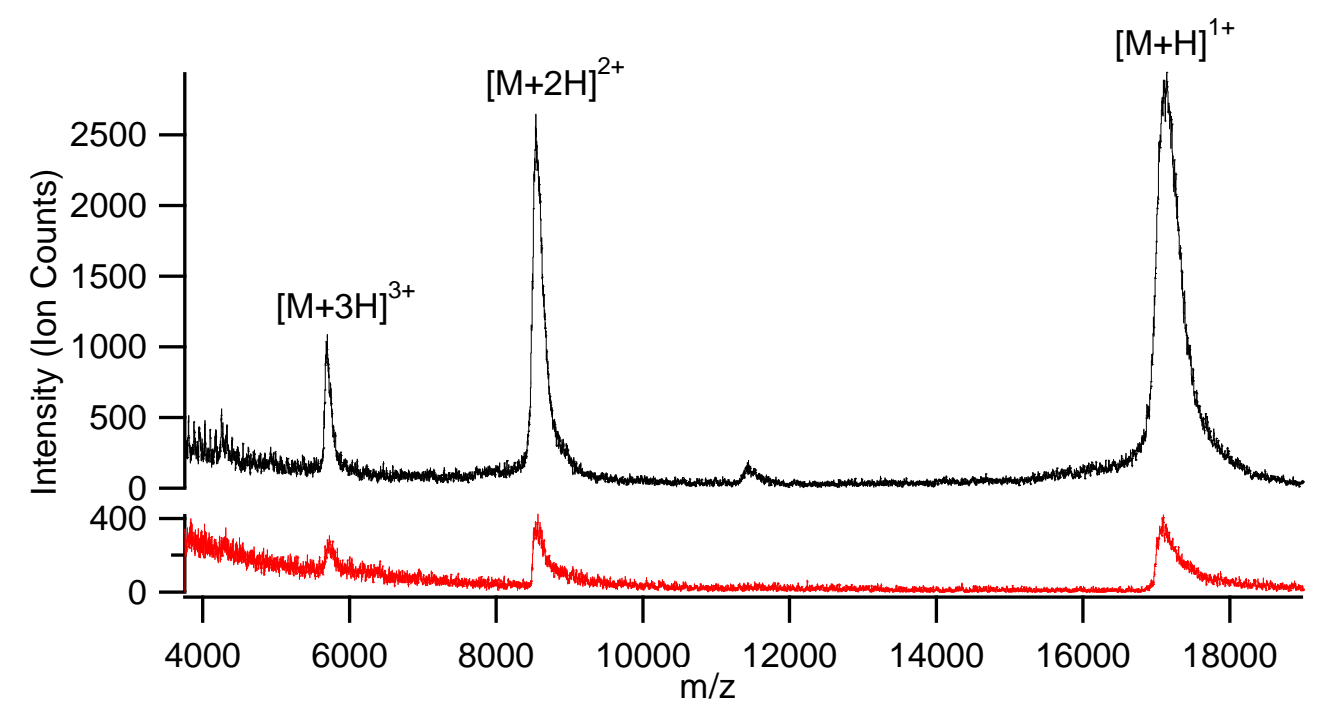

Figure 3.20 MALDI mass spectra of myoglobin: from an untreated $100 \mathrm{ng} \mu \mathrm{L}^{-1}$ sample in $1 \mathrm{M}$ urea (-), and from a $10 \mathrm{ng} \mu \mathrm{L}^{-1}$ sample in $1 \mathrm{M}$ urea after enrichment and urea removal (-). 
In summary, after understanding the mechanism of the NRB formation and the electrophoretic migration of various ions during the protein enrichment by simulation and experiments, we can manipulate NRB behaviours by controlling the discontinuous buffer composition. The removal of urea as an unwanted background molecule from the enriched protein sample was successful achieved using the discontinuous buffer system consisting of $20 \mathrm{mM}$ ammonium acetate buffer (pH 5.25) and $20 \mathrm{mM}$ ammonium acetate buffer ( $\mathrm{pH} 10.25)$. 


\subsection{References}

1. Booker, C. J.; Sun, S.; Woolsey, S.; Mejia, J. S.; Yeung, K. K. C., Removal of sample background buffering ions and myoglobin enrichment via a $\mathrm{pH}$ junction created by discontinuous buffers in capillary electrophoresis. J. Chromatogr. A 2011, 1218 (33), 5705-5711.

2. Booker, C. J.; Yeung, K. K. C., In-Capillary Protein Enrichment and Removal of Nonbuffering Salts Using Capillary Electrophoresis with Discontinuous Buffers. Anal. Chem. 2008, 80 (22), 8598-8604.

3. Nesbitt, C. A.; Lo, J. T. M.; Yeung, K. K. C., Over 1000-fold protein preconcentration for microliter-volume samples at a $\mathrm{pH}$ junction using capillary electrophoresis. J. Chromatogr. A 2005, 1073 (1-2), 175-180.

4. Nesbitt, C. A.; Yeung, K. K. C., In-capillary enrichment, proteolysis and separation using capillary electrophoresis with discontinuous buffers: application on proteins with moderately acidic and basic isoelectric points. Analyst 2009, 134 (1), 65-71.

5. Nesbitt, C. A.; Jurcic, K.; Yeung, K. K. C., Nanoliter-volume protein enrichment, tryptic digestion, and partial separation based on isoelectric points by CE for MALDI mass spectral analysis. Electrophoresis 2008, 29 (2), 466474.

6. Jurcic, K.; Nesbitt, C. A.; Yeung, K. K. C., Characterization of discontinuous buffer junctions using $\mathrm{pH}$ indicators in capillary electrophoresis for protein preconcentration. J. Chromatogr. A 2006, 1134 (1-2), 317-325.

7. Vanýsek, P., Ionic conductivity and diffusion at infinite dilution. In $C R C$ Handbook of Chemistry and Physics [Online] 92 ed.; Haynes, W. H., Ed. CRC Press Online: 2011-2012. 
8. Kauzmann, W., Some factors in the interpretation of protein denaturation. Adv. Protein Chem. 1959, 14, 1-63.

9. Pace, C. N., Determination and analysis of urea and guanidine hydrochloride denaturation curves. Methods Enzymol. 1986, 131, 266-280.

10. Kaiser, D. A.; Goldschmidtclermont, P. J.; Levine, B. A.; Pollard, T. D., Characterization of Renatured Profilin Purified by Urea Elution from Poly-LProline Agarose Columns. Cell Motil. Cytoskeleton 1989, 14 (2), 251-262.

11. Antignac, J. P.; de Wasch, K.; Monteau, F.; De Brabander, H.; Andre, F.; Le Bizec, B., The ion suppression phenomenon in liquid chromatography-mass spectrometry and its consequences in the field of residue. Anal. Chim. Acta 2005, 529 (1-2), 129-136.

12. Huh, Y. S.; Yang, K.; Hong, Y. K.; Jun, Y. S.; Hong, W. H.; Kim, D. H., Removal of urea from urea-rich protein samples using metal ions in a microfluidic device. Process Biochem. 2007, 42 (4), 649-654.

13. Sudhir, P. R.; Wu, H. F.; Zhou, Z. C., Identification of peptides using gold nanoparticle-assisted single-drop microextraction coupled with AP-MALDI mass spectrometry. Anal. Chem. 2005, 77 (22), 7380-7385.

14. Xu, Y.; Bruening, M. L.; Watson, J. T., Non-specific, on-probe cleanup methods for MALDI-MS samples. Mass Spectrom. Rev. 2003, 22 (6), 429-440. 
Chapter 4: Conclusions and Future Work 


\subsection{Conclusions}

Capillary electrophoresis, with the use of suitable discontinuous buffers, can serve as an effective tool for sample preparation for proteins in small sample volumes. A selection of discontinuous buffers, and their $\mathrm{pH}$ conditions, had previously been studied and demonstrated to work effectively.[1-3] However, a systematic study to look at the effect of buffer composition on the migration of ions within the discontinuous buffers has not been reported. In this work, the use of Simul 5 together with experimental validation for such an investigation was reported. The results concluded that the $\mathrm{pH}$ junction formed from discontinuous buffers in $\mathrm{CE}$ behaves as a NRB, with its mobility mostly determined by the $\mathrm{pH}$ of the buffers, and to a lesser extent, by the buffer concentrations. Simul 5 correctly predicted the direction and velocity of the $\mathrm{NRB}$, and therefore is invaluable in understanding the migration of various ions in the discontinuous buffers.

These findings allowed us to effectively manipulate the behaviour and properties of the NRB, and in turn facilitated the simultaneous myoglobin enrichment and the removal of urea in the sample background. An enhancement in MS signals was illustrated by an offline MALDI mass spectral analysis.

\subsection{Future Work}

While the NRB movement has been characterized as a function of $\mathrm{pH}$ and concentration of discontinuous buffers in this work, we successfully developed a method to remove a neutral molecule, urea, from a protein sample. Furthermore many 
sample background molecules can be removed by this method as well. It is not limited to neutral molecules, but can also work for weak acid/base. As a future work, one weak acid example is shown below.

Dithiothreitol (DTT) is frequently used to reduce the disulfide bonds of proteins and it is necessary to remove the excess DTT from the protein sample solution for further analysis.[4] In order to perform this clean up, the discontinuous buffer system which contains $20 \mathrm{mM}$ ammonium acetate buffer $(\mathrm{pH} 5.25)$ and $20 \mathrm{mM}$ ammonium acetate buffer ( $\mathrm{pH} 10.25$ ) can be used. DTT is negative charged in the base buffer, and as similarity to urea it will become neutral at the initial buffer junction while protein stacks at the NRB. Thus the goal of protein purification can be reached.

Up until this point, we only focus on the application of $\mathrm{pH}$ combination of $5.25 / 10.25$, which causes the NRB to move towards anodic direction. In section 3.3 , it demonstrated NRB can move towards the opposite direction (cathodic) under the $\mathrm{pH}$ combination of $4.25 / 8.75$. In this case, the initial buffer junction can also be moved away from NRB. Thus it is possible to develop a method to remove background ions by the $\mathrm{pH}$ combination of $4.25 / 8.75$, which is suitable for proteins that are sensitive to the higher $\mathrm{pH}$ of basic buffer.

In section 3.1, we mentioned about the shift of peaks between runs and illustrated that it was caused predominantly by EOF. It is important to find a coating that is able to stabilize EOF between different runs. So our second direction of future work is to find a "perfect" coating to overcome the EOF issue. 
In addition to the development and improvement of experimental parts, the application of computer simulation is another important part that needed further research. As one of the most powerful tools, Simul 5 has been chosen to simulate our discontinuous buffer system to help us understand the ion migration behaviour inside the capillary in this work.[5] Simul 5 provides many template constituent for users to choose from, or users can create a new constituent if it does not exist in the program already. In addition it is convenient to adjust $\mathrm{pH}$ and concentration of the composition. Based on these advantages, the application of the computer simulation program can be extended to other discontinuous buffer systems that we have developed. Thus, a better understanding on the effect of buffer choices will be achieved. 


\subsection{References}

1. Nesbitt, C. A.; Jurcic, K.; Yeung, K. K., Nanoliter-volume protein enrichment, tryptic digestion, and partial separation based on isoelectric points by $\mathrm{CE}$ for MALDI mass spectral analysis. Electrophoresis 2008, 29 (2), 466-474.

2. Booker, C. J.; Yeung, K. K., In-capillary protein enrichment and removal of nonbuffering salts using capillary electrophoresis with discontinuous buffers. Analytical Chemistry 2008, 80 (22), 8598-8604.

3. Nesbitt, C. A.; Lo, J. T.; Yeung, K. K., Over 1000-fold protein preconcentration for microliter-volume samples at a $\mathrm{pH}$ junction using capillary electrophoresis. Journal of chromatography.A 2005, 1073 (1-2), 175-180.

4. Xiao, M.; Getz, E. B.; Chakrabarty, T.; Cooke, R.; Selvin, P. R., Effect of DTT vs TCEP reductants on protection and labeling of myosin. Biophysical Journal 1998, 74 (2), A179-A179.

5. Booker, C. J.; Sun, S.; Woolsey, S.; Mejia, J. S.; Yeung, K. K., Removal of sample background buffering ions and myoglobin enrichment via a $\mathrm{pH}$ junction created by discontinuous buffers in capillary electrophoresis. Journal of chromatography.A 2011, 1218 (33), 5705-5711. 


\section{Appendix 1: Capillary Electrophoresis}


As a rapidly developing separation technique, capillary electrophoresis (CE) is attractive in analytical chemistry as it offers high separation efficiency, and the ability to handle small-volume samples due to the low sample consumption in the capillary. $[1,2]$ The electrophoretic separation is based on the differential velocities of analytes $(v)$ in an applied electric field which in turn, is defined by the electrophoretic effective mobility of analytes $\left(\mu_{e}\right)$ (the ratio of charge/size) and the field strength $(E)$ (applied voltage/capillary length), as shown in Equation A.1 and A.2. In general, small, highly charged analytes have fast electrophoretic effective mobility.

$$
\begin{array}{ll}
v=\mu_{e} E & \text { (Equation A.1) } \\
\mu_{e}=\frac{q}{6 \pi \eta r} & \text { (Equation A.2) }
\end{array}
$$

$v:$ The velocity $\left(\mathrm{m} \mathrm{s}^{-1}\right)$ of ion

$\mu_{e}:$ The electrophoretic effective mobility $\left(\mathrm{m}^{2} \mathrm{~V}^{-1} \mathrm{~s}^{-1}\right)$ of analytes

$E$ : The electric field strength $\left(\mathrm{V} \mathrm{m}^{-1}\right)$

$q:$ The ion charge (C)

$\eta$ : The solution viscosity (pa s)

$r$ : The ion radius $(\mathrm{m})$

\section{Electro-Osmotic Flow}

Addition to the migration of analytes, another important movement during voltage application in $\mathrm{CE}$ is the net flow of the bulk solution inside the capillary due to electro-osmotic. Electro-osmotic flow (EOF) is generated by the surface charge on the inner capillary wall. The silanol groups $(-\mathrm{SiOH})$ on the inner wall of the capillary can be easily ionized from $-\mathrm{SiOH}$ to $-\mathrm{SiO}^{-}$, resulting in a net negatively charged surface. When the capillary is filled with a solution, positive ions from the solution accumulate around 
the negatively charged surface due to electrostatic interactions. Upon voltage application, these positive ions move towards the cathode carrying the bulk solution in the same direction, generating EOF (Figure A.1).
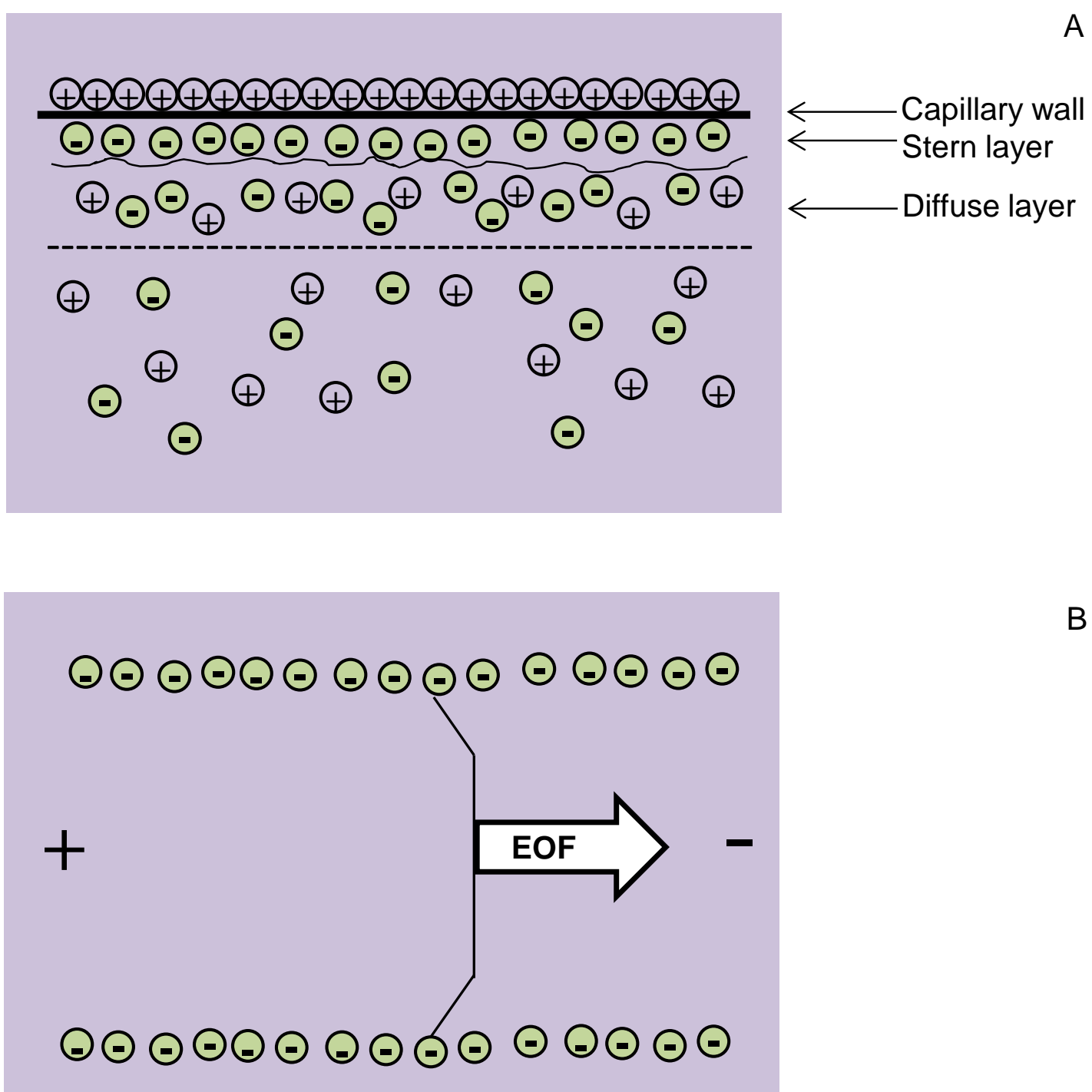

B

Figure A.1 (A) Schematic representation of the double layer at the capillary wall. (B) Bulk flow towards the cathode upon the application of voltage.

As a fundamental constituent of CE operation, EOF can be expressed in terms of electro-osmotic mobility $\left(\mu_{E O F}\right)$ by Equation A.3. It shows that the magnitude of EOF is 
dependent on the zeta potential $(\delta)$ which in turn, affects by $\mathrm{pH}$ and ionic strength of solution.[3, 4] At high $\mathrm{pH}$, the silanol groups are mostly deprotonated, which causes more positive ions gathering near the wall and induces a fast EOF. At low $\mathrm{pH}$, silanol groups become protonated and results in a slow EOF. Apart from $\mathrm{pH}$, another important factor that affects EOF is the ionic strength. A high ionic strength compresses the space between negatively charged inner wall and positive ions and thus decreases EOF. Conversely, a low ionic strength leads to an increase of EOF.

$$
\mu_{E O F}=\varepsilon \delta / \eta \quad \text { (Equation A.3) }
$$

$\mu_{E O F}:$ The electro-osmotic mobility $\left(\mathrm{m}^{2} \mathrm{~V}^{-1} \mathrm{~s}^{-1}\right)$

$\varepsilon:$ The dielectric constant

$\delta:$ The zeta potential $(\mathrm{V})$

$\eta:$ The solution viscosity (pa s)

\section{Capillary Coating}

One challenge for protein analysis by $\mathrm{CE}$ is the negatively charged inner capillary wall causes the adsorption of proteins on the capillary wall. To prevent the protein adsorption and control EOF, many capillary coatings have been developed. They can be categorized as dynamic[5], permanent,[6] and semi-permanent coating.[7] For dynamic coating, the coating reagent is present in the running buffer as an additive, and coating reversible adsorbs on the wall. Hence the coating reagent must be kept in the running buffer all the time. To form a permanent coating, a modifier is used to deactivate or neutralizes the anionic charge of silanols on the inner walls. It only requires flush once and does not present in the running buffer. However, it is difficult to design a permanent coating for all possible EOF and the coating procedures are 
normally complex. Semi-permanent coating is more stable than dynamic coating and only require flushed through the capillary before each experiment run. Lucy's group introduced a phospholipid bilayer coating, 1,2-dilauroyl-sn-phosphatidylcholine (DLPC), which has became one of the commonly used zwitterionic semi-permanent coatings. This coating has the advantages of easy preparation, strongly adsorbing onto the capillary wall, and effective prevention of analytes adsorption especially for cationic species.[8] As an ideal coating material, DLPC has been utilized in our lab for the protein/peptide enrichment in a discontinuous buffers system by CE to avoid adsorption of proteins and adjust EOF.[9-11] In this work, it was chosen as the capillary coating due to the same reason. 


\section{References}

1. Camilleri, P., Capillary electrophoresis : theory and practice. 2nd ed.; CRC Press: Boca Raton, Fla., 1998; p 552 p.

2. Huck, C. W.; Bonn, G. K., Analysis of proteins by capillary electrophoresis. Methods Mol Biol 2008, 384, 507-40.

3. Wang, W.; Zhao, L.; Jiang, L. P.; Zhang, J. R.; Zhu, J. J.; Chen, H. Y., EOF measurement by detection of a sampling zone with end-channel amperometry in microchip CE. Electrophoresis 2006, 27 (24), 5132-7.

4. Sebastiano, R.; Mendieta, M. E.; Antonioli, P.; Bossi, A.; Righetti, P. G.; Citterio, A., Organic and inorganic di-cations for capillary silica coating and EOF modulation in CE: Example of application in PEG analysis. Electrophoresis 2006, 27 (8), 1495-501.

5. Righetti, P. G.; Gelfi, C.; Verzola, B.; Castelletti, L., The state of the art of dynamic coatings. Electrophoresis 2001, 22 (4), 603-611.

6. Liu, J. K.; Lee, M. L., Permanent surface modification of polymeric capillary electrophoresis microchips for protein and peptide analysis. Electrophoresis 2006, 27 (18), 3533-3546.

7. Stutz, H., Protein attachment onto silica surfaces - a survey of molecular fundamentals, resulting effects and novel preventive strategies in CE. Electrophoresis 2009, 30 (12), 2032-2061.

8. Lucy, C. A.; MacDonald, A. M.; Gulcev, M. D., Non-covalent capillary coatings for protein separations in capillary electrophoresis. Journal of Chromatography A 2008, 1184 (1-2), 81-105. 
9. Nesbitt, C. A.; Lo, J. T.; Yeung, K. K., Over 1000-fold protein preconcentration for microliter-volume samples at a $\mathrm{pH}$ junction using capillary electrophoresis. Journal of chromatography.A 2005, 1073 (1-2), 175180.

10. Zhang, H.; Zhang, C.; Lajoie, G. A.; Yeung, K. K., Selective sampling of phosphopeptides for detection by MALDI mass spectrometry. Analytical Chemistry 2005, 77 (18), 6078-6084.

11. Jurcic, K.; Nesbitt, C. A.; Yeung, K. K., Characterization of discontinuous buffer junctions using $\mathrm{pH}$ indicators in capillary electrophoresis for protein preconcentration. Journal of chromatography.A 2006, 1134 (1-2), 317-325. 


\section{Curriculum Vitae}

of Ting Li

\section{EDUCATION}

Master of Science Candidate, University of Western Ontario Sept. 2010- Aug. 2012

- Analytical Chemistry in Department of Chemistry

Master of Science, Shanghai University

Sept. 2007- Jun. 2010

- Analytical Chemistry

Bachelor of Engineering, Jiangnan University

Sept. 2003- Jul. 2007

- Chemical Engineering

\section{HONOURS AND AWARDS}

Western Graduate Research Scholarship

Jan. 2012

Kwang-Hua Education Foundation Scholar Award

Nov. 2009

The University's Innovation Fund for graduate students

Sept. 2008 - Sept. 2009

Wake Scholar Award

Jun. 2006

The Dean Scholar Award

Jun. 2005 


\section{LABORATORY WORK EXPERIENCE}

Graduate Research Assistant, University of Western Ontario Sept. 2010- Aug. 2012

- Perform protein enrichment and purification by $\mathrm{CE}$

Graduate Teaching Assistant, University of Western Ontario Sept. 2010- Aug. 2012

- Lab TA for 1100 and 1200 (Discovering chemistry I)

- Lab TA for $2272 \mathrm{f}$ (Introductory analytical chemistry II)

Graduate Research Assistant, Shanghai University

Sept. 2007- Jun. 2010

- Rapid electrochemical detection of DNA damage by nano-biosensors

Fourth Year Research Project, Jiangnan University

Dec. 2006- Jul. 2007

- Synthesis of phosphoric acid glycerol stearate

\section{PUBLICATIONS AND PRESENTATIONS}

6 Ting Li, Christina J. Booker, and Ken K.-C. Yeung, Migration behaviour of discontinuous buffers in capillary electrophoresis during protein enrichment. Analyst, 2012, DOI: 10.1039/c2an35548e.

5 Ting Li, Christina J. Booker, and Ken K.-C. Yeung, Removal of unwanted neutral molecules in the protein sample by manipulation of the $\mathrm{pH}$ junction during protein enrichment. Poster. $60^{\text {th }}$ Conference on Mass Spectrometry and Allied Topics, Vancouver, BC, May 2012.

4 Ting Li, Christina J. Booker, and Ken K.-C. Yeung, Understanding the migration behaviour of discontinuous buffers in CE for protein enrichment. Poster. $94^{\text {st }}$ Canadian Chemistry Conference and Exhibition, Montreal, QC, June 2011. 
3 Ting Li, Qi Fan, Tao Liu, Xiaoli Zhu, Jing Zhao, and Genxi Li. Detection of breast cancer cells specially and accurately by an electrochemical method. Biosensors and Bioelectronics, 2010, 25: 2685-2689.

2 Jing Zhao, Xiaoli Zhu, Ting Li, and Genxi Li. Self-assembled multilayer of gold nanoparticles for amplified electrochemical detection of cytochrome c. Analyst, 2008, 133: $1242-1245$.

1 Junyi Huang, Ting Li, Zhenyu Chen, Xinjian Liu, and Shanli Liu. Rapid electrochemical detection of DNA damage and repair with epigallocatechin gallate, chlorogenic acid and ascorbic acid. Electrochemistry Communications, 2008, 10: 11981200. 